Cochrane Database of Systematic Reviews

\title{
Single-dose intravenous diclofenac for acute postoperative pain in adults (Review)
}

McNicol ED, Ferguson MC, Schumann R

McNicol ED, Ferguson MC, Schumann R.

Single-dose intravenous diclofenac for acute postoperative pain in adults.

Cochrane Database of Systematic Reviews 2018, Issue 8. Art. No.: CD012498.

DOI: 10.1002/14651858.CD012498.pub2.

www.cochranelibrary.com

Single-dose intravenous diclofenac for acute postoperative pain in adults (Review) 
TABLE OF CONTENTS

PLAIN LANGUAGE SUMMARY

SUMMARY OF FINDINGS

BACKGROUND

OBJECTIVES

METHODS

RESULTS

Figure 1.

Figure 2.

Figure 3.

DISCUSSION

AUTHORS' CONCLUSIONS

ACKNOWLEDGEMENTS

REFERENCES

CHARACTERISTICS OF STUDIES

DATA AND ANALYSES

Analysis 1.1. Comparison 1: Diclofenac versus placebo, Outcome 1: Number of participants with at least $50 \%$ pain relief at 4 hours

Analysis 1.2. Comparison 1: Diclofenac versus placebo, Outcome 2: Number of participants with at least $50 \%$ pain relief at 6 hours

Analysis 1.3. Comparison 1: Diclofenac versus placebo, Outcome 3: Number of participants using rescue medication over 4 to 6 hours postinterventions

Analysis 1.4. Comparison 1: Diclofenac versus placebo, Outcome 4: Number of participants withdrawing due to lack of efficacy

Analysis 1.5. Comparison 1: Diclofenac versus placebo, Outcome 5: Number of participants withdrawing due to adverse events

Analysis 1.6. Comparison 1: Diclofenac versus placebo, Outcome 6: Number of participants withdrawing for any cause ........... Analysis 1.7. Comparison 1: Diclofenac versus placebo, Outcome 7: Number of participants reporting any adverse event ....... Analysis 1.8. Comparison 1: Diclofenac versus placebo, Outcome 8: Number of participants experiencing a serious adverse event

Analysis 1.9. Comparison 1: Diclofenac versus placebo, Outcome 9: Number of participants experiencing renal dysfunction .... Analysis 1.10. Comparison 1: Diclofenac versus placebo, Outcome 10: Number of participants experiencing a cardiovascular event

Analysis 1.11. Comparison 1: Diclofenac versus placebo, Outcome 11: Number of participants experiencing bleeding ............ Analysis 1.12. Comparison 1: Diclofenac versus placebo, Outcome 12: Number of participants experiencing thrombophlebitis Analysis 1.13. Comparison 1: Diclofenac versus placebo, Outcome 13: Number of participants reporting nausea Analysis 1.14. Comparison 1: Diclofenac versus placebo, Outcome 14: Number of participants experiencing vomiting ............ Analysis 1.15. Comparison 1: Diclofenac versus placebo, Outcome 15: Number of participants with at least 50\% pain relief at 6 hours: $18.75 \mathrm{mg}$

Analysis 2.1. Comparison 2: Diclofenac versus another NSAID, Outcome 1: Number of participants with at least $50 \%$ pain relief at 6 hours

Analysis 2.2. Comparison 2: Diclofenac versus another NSAID, Outcome 2: Number of participants using rescue medication over 4 to 6 hours postinterventions

Analysis 2.3. Comparison 2: Diclofenac versus another NSAID, Outcome 3: Number of participants withdrawing due to lack of efficacy

Analysis 2.4. Comparison 2: Diclofenac versus another NSAID, Outcome 4: Number of participants withdrawing due to adverse events

Analysis 2.5. Comparison 2: Diclofenac versus another NSAID, Outcome 5: Number of participants withdrawing for any cause Analysis 2.6. Comparison 2: Diclofenac versus another NSAID, Outcome 6: Number of participants reporting any adverse event

Analysis 2.7. Comparison 2: Diclofenac versus another NSAID, Outcome 7: Number of participants experiencing a serious adverse event

Analysis 2.8. Comparison 2: Diclofenac versus another NSAID, Outcome 8: Number of participants experiencing renal dysfunction

Analysis 2.9. Comparison 2: Diclofenac versus another NSAID, Outcome 9: Number of participants experiencing a cardiovascular event 
Analysis 2.10. Comparison 2: Diclofenac versus another NSAID, Outcome 10: Number of participants experiencing bleeding ...

Analysis 2.11. Comparison 2: Diclofenac versus another NSAID, Outcome 11: Number of participants experiencing thrombophlebitis

Analysis 2.12. Comparison 2: Diclofenac versus another NSAID, Outcome 12: Number of participants with at least $50 \%$ pain relief at 6 hours: $18.75 \mathrm{mg}$

Analysis 3.1. Comparison 3: Diclofenac high dose versus low dose, Outcome 1: Number of participants with at least $50 \%$ pain

relief at 6 hours

APPENDICES

WHAT'S NEW

HISTORY

CONTRIBUTIONS OF AUTHORS

DECLARATIONS OF INTEREST

SOURCES OF SUPPORT

DIFFERENCES BETWEEN PROTOCOL AND REVIEW

NOTES

INDEX TERMS 
[Intervention Review]

\section{Single-dose intravenous diclofenac for acute postoperative pain in adults}

Ewan D McNicol1,2,3, McKenzie C Ferguson", Roman Schumann ${ }^{1}$

1Department of Anesthesiology and Perioperative Medicine, Tufts Medical Center, Boston, MA, USA. 2Department of Pharmacy, Tufts Medical Center, Boston, Massachusetts, USA. ${ }^{3}$ Pain Research, Education and Policy (PREP) Program, Department of Public Health and Community Medicine, Tufts University School of Medicine, Boston, Massachusetts, USA. ${ }^{4}$ Pharmacy Practice, Southern Illinois University Edwardsville, Edwardsville, IL, USA

Contact: Ewan D McNicol, ewan.mcnicol@mcphs.edu, ewanmcnicol@comcast.net.

Editorial group: Cochrane Pain, Palliative and Supportive Care Group.

Publication status and date: Stable (no update expected for reasons given in 'What's new'), published in Issue 8, 2020.

Citation: McNicol ED, Ferguson MC, Schumann R. Single-dose intravenous diclofenac for acute postoperative pain in adults. Cochrane Database of Systematic Reviews 2018, Issue 8. Art. No.: CD012498. DOI: 10.1002/14651858.CD012498.pub2.

Copyright @ 2018 The Cochrane Collaboration. Published by John Wiley \& Sons, Ltd.

\section{A B S T R A C T}

\section{Background}

Postoperative administration of non-steroidal anti-inflammatory drugs (NSAIDs) reduces patient opioid requirements and, in turn, reduces the incidence and severity of opioid-induced adverse events (AEs).

\section{Objectives}

To assess the analgesic efficacy and adverse effects of single-dose intravenous diclofenac, compared with placebo or an active comparator, for moderate to severe postoperative pain in adults.

\section{Search methods}

We searched the following databases without language restrictions: the Cochrane Central Register of Controlled Trials (Cochrane Register of Studies Online), MEDLINE, and Embase on 22 May 2018. We checked clinical trials registers and reference lists of retrieved articles for additional studies.

\section{Selection criteria}

We included randomized trials that compared a single postoperative dose of intravenous diclofenac with placebo or another active treatment, for treating acute postoperative pain in adults following any surgery.

\section{Data collection and analysis}

We used standard methodological procedures expected by Cochrane. Two review authors independently considered trials for review inclusion, assessed risk of bias, and extracted data.

Our primary outcome was the number of participants in each arm achieving at least 50\% pain relief over a four- and six-hour period.

Our secondary outcomes were time to, and number of participants using rescue medication; withdrawals due to lack of efficacy, AEs, and for any cause; and number of participants experiencing any AE, serious AEs (SAEs), and NSAID-related AEs. We performed a post hoc analysis of opioid-related AEs, to enable indirect comparisons with other analyses of postoperative analgesics.

For subgroup analysis, we planned to analyze different doses and formulations of parenteral diclofenac separately.

We assessed the overall quality of the evidence for each outcome using GRADE and created two 'Summary of findings' tables. 


\section{Main results}

We included eight studies, involving 1756 participants undergoing various surgeries (dental, mixed minor, abdominal, and orthopedic), with 20 to 175 participants receiving intravenous diclofenac in each study. Mean study population ages ranged from 24.5 years to 54.5 years. Intravenous diclofenac doses varied among and within studies, ranging from $3.75 \mathrm{mg}$ to $75 \mathrm{mg}$. Five studies assessed newer formulations of parenteral diclofenac that could be administered as an undiluted intravenous bolus. Most studies had an unclear risk of bias for several domains and a high risk of bias due to small sample size. The overall quality of evidence for each outcome was generally low for reasons including unclear risk of bias in studies, imprecision, and low event numbers.

\section{Primary outcome}

Three studies (277 participants) produced a number needed to treat for an additional beneficial outcome (NNTB) for at least $50 \%$ of maximum pain relief versus placebo of 2.4 ( $95 \%$ confidence interval ( $\mathrm{Cl}) 1.9$ to 3.1) over four hours (low-quality evidence). Four studies (436 participants) produced an NNTB of 3.8 versus placebo ( $95 \% \mathrm{CI} 2.9$ to 5.9$)$ over six hours (low-quality evidence). No studies provided data for the comparison of intravenous diclofenac with another NSAID over four hours. At six hours there was no difference between intravenous diclofenac and another NSAID (low-quality evidence).

\section{Secondary outcomes}

For secondary efficacy outcomes, intravenous diclofenac was generally superior to placebo and similar to other NSAIDs.

For time to rescue medication, comparison of intravenous diclofenac versus placebo demonstrated a median of 226 minutes for diclofenac versus 80 minutes for placebo ( 5 studies, 542 participants, low-quality evidence). There were insufficient data for pooled analysis for comparisons of diclofenac with another NSAID (very low-quality evidence).

For the number of participants using rescue medication, two studies (235 participants) compared diclofenac with placebo. The number needed to treat to prevent one additional harmful event (NNTp) (here, the need for rescue medication) compared with placebo was 3.0 ( 2.2 to 4.5 , low-quality evidence). The comparison of diclofenac with another NSAID included only one study (98 participants). The NNTp was 4.5 (2.5 to 33 ) for ketorolac versus diclofenac (very low-quality evidence).

The numbers of participants withdrawing were generally low and inconsistently reported (very low-quality evidence). Participant withdrawals were: $6 \%(8 / 140)$ diclofenac versus $5 \%$ (7/128) placebo, and 9\% (8/87) diclofenac versus 7\% (6/82) another NSAID for lack of efficacy; $2 \%$ (4/211) diclofenac versus $0 \%$ (0/198) placebo, and 3\% (4/138) diclofenac versus 2\% (2/129) another NSAID due to AEs; and $11 \%$ (21/191) diclofenac versus $17 \%$ (30/179) placebo, and $18 \%$ (21/118) diclofenac versus $15 \%(17 / 111)$ another NSAID for any cause.

Overall adverse event rates were similar between intravenous diclofenac and placebo (71\% in both groups, 2 studies, 296 participants) and between intravenous diclofenac and another NSAID (55\% and 58\%, respectively, 2 studies, 265 participants) (low-quality evidence for both comparisons). Serious and specific AEs were rare, preventing meta-analysis.

There were sufficient data for a dose-effect analysis for our primary outcome for only one alternative dose, $18.75 \mathrm{mg}$. Analysis of the highest dose employed in each study demonstrated a relative benefit compared with placebo of 1.9 (1.4 to 2.4), whereas for the group receiving $18.75 \mathrm{mg}$, the relative benefit versus placebo was 1.6 (1.2 to 2.1, 2 studies). Compared to another NSAID, the high-dose analysis demonstrated a relative benefit of 0.9 (0.8 to 1.1$)$, for the group receiving $18.75 \mathrm{mg}$, the relative benefit was 0.78 ( 0.65 to 0.93$)$. For direct comparison of high dose versus $18.75 \mathrm{mg}$, the proportion of participants with at least $50 \%$ pain relief was $66 \%$ (90/137) for the high-dose arm versus $57 \%$ (77/135) in the low-dose arm. There were insufficient data for subgroup meta-analysis of different diclofenac formulations.

\section{Authors' conclusions}

The amount and quality of evidence for the use of intravenous diclofenac as a treatment for postoperative pain is low. The available evidence indicates that postoperative intravenous diclofenac administration offers good pain relief for the majority of patients, but further research may impact this estimate. Adverse events appear to occur at a similar rate to other NSAIDs. Insufficient information is available to assess whether intravenous diclofenac has a different rate of bleeding, renal dysfunction, or cardiovascular events versus other NSAIDs. There was insufficient information to evaluate the efficacy and safety of newer versus traditional formulations of intravenous diclofenac. There was a lack of studies in major and cardiovascular surgeries and in elderly populations, which may be at increased risk for adverse events.

\section{PLAIN LANGUAGE SUMMARY}

\section{Single-dose intravenous diclofenac for short-term pain after surgery in adults}

\section{Bottom line}

There is some evidence that intravenous diclofenac is effective for reducing pain after surgery in adults, but it is less clear how safe it is in this setting.

\section{Background}

Single-dose intravenous diclofenac for acute postoperative pain in adults (Review)

Copyright ๑ 2018 The Cochrane Collaboration. Published by John Wiley \& Sons, Ltd. 
Pain is common in the short term after surgery. Non-steroidal anti-inflammatory drugs (NSAIDs, aspirin-like drugs) are often given along with opioids (such as morphine) to treat pain. However, NSAIDs may cause bleeding (e.g. at the site of an incision or wound) and injury to the kidneys and gut. Diclofenac is an NSAID that can be given by injection into a vein (intravenously), which may be useful when patients are not able to take medicines by mouth.

\section{Study characteristics}

In May 2018, we searched for clinical trials where intravenous diclofenac was used to treat pain after surgery in adults. We found eight studies enrolling a total of 1756 people that met our requirements. The studies were similar in their design, although they were carried out in different surgeries (dental, mixed minor surgeries, abdominal, and orthopedic). The dose of intravenous diclofenac used also varied. Intravenous diclofenac was mostly compared to placebo (a sham treatment, such as a bag of saline administered into a vein) or another NSAID.

\section{Key findings}

We were most interested in determining the number of participants with at least half the maximum possible pain relief over four or six hours after treatment. Around twice as many participants had at least half the maximum possible pain relief when they received diclofenac versus those who received placebo. When diclofenac was compared with another NSAID, similar numbers of participants had at least half the maximum possible pain relief. Other assessments, such as how quickly and how many participants needed rescue medication (an extra pain medication available to study participants if the study medication is not treating the participant's pain well enough), and how many participants withdrew from a study, also usually showed that intravenous diclofenac was better than placebo and similar to other NSAIDs.

There was insufficient information in the studies to make a good assessment of side effects and serious side effects, but the rate at which they occurred appeared to be similar among all treatments. Very few participants dropped out of the studies because of side effects. This is usually the case in studies where patients are only in a study for a short period of time.

\section{Quality of the evidence}

We generally rated the quality of the evidence for each assessment as low due to issues with the design of many of the studies, and low overall numbers of people enrolled. Low-quality evidence means that further research may have an important impact on our findings. 
SUMMARY OF FINDINGS

Summary of findings 1 . Intravenous diclofenac compared to placebo for acute postoperative pain in adults

Intravenous diclofenac ( $37.5 \mathrm{mg}$ to $75 \mathrm{mg}$ ) compared to placebo for acute postoperative pain in adults

Patient or population: Adults (mean study ages 25 to 55 years) with acute postoperative pain after dental, mixed minor, abdominal, or orthopedic surgeries

Settings: Hospital or community

Intervention: Intravenous diclofenac (37.5 $\mathrm{mg}$ to $75 \mathrm{mg}$ )

Comparison: Placebo

\begin{tabular}{|c|c|c|c|c|c|c|}
\hline \multirow[t]{2}{*}{ Outcomes } & \multicolumn{2}{|c|}{ Probable outcome with } & \multirow{2}{*}{$\begin{array}{l}\text { Relative effect and NNTB } \\
\text { or NNTH }(95 \% \mathrm{CI})\end{array}$} & \multirow{2}{*}{$\begin{array}{l}\text { No. of partici- } \\
\text { pants } \\
\text { (studies) }\end{array}$} & \multirow{2}{*}{$\begin{array}{l}\text { Quality of the } \\
\text { evidence } \\
\text { (GRADE) }\end{array}$} & \multirow[t]{2}{*}{ Comments } \\
\hline & Placebo & Diclofenac & & & & \\
\hline $\begin{array}{l}\text { Number of participants with at least } \\
50 \% \text { pain relief at } 4 \text { hours }\end{array}$ & 228 per 1000 & $\begin{array}{l}\mathbf{6 4 3} \text { per } 1000 \\
(458 \text { to } 905)\end{array}$ & $\begin{array}{l}\text { RR } 2.8 \text { ( } 2.0 \text { to } 4.0) \\
\text { NNTB } 2.4 \text { ( } 1.9 \text { to } 3.1 \text { ) }\end{array}$ & $\begin{array}{l}277 \\
\text { (3 studies) }\end{array}$ & $\begin{array}{l}\oplus \oplus \ominus \ominus \\
\text { low } 1,2,3,4\end{array}$ & \\
\hline $\begin{array}{l}\text { Number of participants with at least } \\
50 \% \text { pain relief at } 6 \text { hours }\end{array}$ & 336 per 1000 & $\begin{array}{l}\mathbf{5 9 2} \text { per } 1000 \\
(478 \text { to } 730)\end{array}$ & $\begin{array}{l}\text { RR } 1.8 \text { (1.4 to } 2.2) \\
\text { NNTB } 3.8 \text { ( } 2.9 \text { to } 5.9)\end{array}$ & $\begin{array}{l}436 \\
\text { (4 studies) }\end{array}$ & $\begin{array}{l}\oplus \oplus \oplus \ominus \\
\text { low } 1,2\end{array}$ & \\
\hline $\begin{array}{l}\text { Median (or mean) time to use of rescue } \\
\text { medication }\end{array}$ & $\begin{array}{l}\text { Median: } 80 \\
\text { minutes }\end{array}$ & $\begin{array}{l}\text { Median: } 226 \mathrm{~min}- \\
\text { utes }\end{array}$ & Not applicable & $\begin{array}{l}542 \\
\text { (5 studies) }\end{array}$ & $\begin{array}{l}\oplus \oplus \oplus \ominus \\
\text { low } 1,5\end{array}$ & \\
\hline $\begin{array}{l}\text { Number of participants using rescue } \\
\text { medication over } 4 \text { to } 6 \text { hours postinter- } \\
\text { ventions }\end{array}$ & 810 per 1000 & $\begin{array}{l}\mathbf{4 7 8} \text { per } \mathbf{1 0 0 0} \\
\text { (389 to } 592 \text { ) }\end{array}$ & $\begin{array}{l}\text { RR } 0.59 \text { ( } 0.48 \text { to } 0.73) \\
\text { NNTp } 3.0 \text { ( } 2.2 \text { to } 4.5)\end{array}$ & $\begin{array}{l}235 \\
\text { (2 studies) }\end{array}$ & $\begin{array}{l}\oplus \oplus \ominus \ominus \\
\text { low } 1,3\end{array}$ & \\
\hline $\begin{array}{l}\text { Number of participants experiencing a } \\
\text { serious adverse event }\end{array}$ & 4 per 1000 & $\begin{array}{l}\mathbf{4} \text { per } \mathbf{1 0 0 0} \\
(1 \text { to } 31)\end{array}$ & RR 1.0 (0.15 to 7.02$)$ & $\begin{array}{l}472 \\
\text { (5 studies) }\end{array}$ & $\begin{array}{l}\oplus \oplus \oplus \ominus \\
\text { low } 1,6\end{array}$ & $\begin{array}{l}\text { Studies under- } \\
\text { powered to } \\
\text { detect these } \\
\text { events. }\end{array}$ \\
\hline
\end{tabular}

Cl: confidence interval; NNTB: number needed to treat for an additional beneficial outcome; NNTH: number needed to treat for an additional harmful outcome; NNTp: number needed to treat to prevent one event; RR: risk ratio

GRADE Working Group grades of evidence

High quality: We are very confident that the true effect lies close to that of the estimate of the effect. 
Moderate quality: We are moderately confident in the effect estimate; the true effect is likely to be close to the estimate of effect, but there is a possibility that it is substantially different.

Low quality: Our confidence in the effect estimate is limited; the true effect may be substantially different from the estimate of the effect.

Very low quality: We have very little confidence in the effect estimate; the true effect is likely to be substantially different from the estimate of effect.

1Unclear risk of bias in several domains.

2Unexplained heterogeneity.

3 Total number of participants $<400$

4Large magnitude of effect: $R R>2$.

5 Imprecision: unable to estimate confidence intervals due to reporting of median data.

6 Very low number of events.

\section{Summary of findings 2 . Intravenous diclofenac compared to another NSAID for acute postoperative pain in adults}

Intravenous diclofenac ( $37.5 \mathrm{mg}$ or $75 \mathrm{mg}$ ) compared to another NSAID for acute postoperative pain in adults

Patient or population: Adults (mean study ages 25 to 55 years) with acute postoperative pain after dental, mixed minor, abdominal, or orthopedic surgeries Settings: Hospital or community

Intervention: Intravenous diclofenac (37.5 mg or $75 \mathrm{mg}$ )

Comparison: Another NSAID

\begin{tabular}{|c|c|c|c|c|c|c|}
\hline \multirow[t]{2}{*}{ Outcomes } & \multicolumn{2}{|c|}{ Probable outcome with } & \multirow{2}{*}{$\begin{array}{l}\text { Relative effect and } \\
\text { NNTB or NNTH ( } 95 \% \\
\text { CI) }\end{array}$} & \multirow{2}{*}{$\begin{array}{l}\text { No. of partici- } \\
\text { pants } \\
\text { (studies) }\end{array}$} & \multirow{2}{*}{$\begin{array}{l}\text { Quality of the } \\
\text { evidence } \\
\text { (GRADE) }\end{array}$} & \multirow[t]{2}{*}{ Comments } \\
\hline & Another NSAID & Diclofenac & & & & \\
\hline $\begin{array}{l}\text { Number of participants with at least } 50 \% \text { pain } \\
\text { relief at } 4 \text { hours }\end{array}$ & See comment & See comment & Not estimable & 0 & See comment & $\begin{array}{l}\text { Assessed as } \\
\text { very low quali- } \\
\text { ty due to lack of } \\
\text { data. }\end{array}$ \\
\hline $\begin{array}{l}\text { Median (or mean) time to use of rescue med- } \\
\text { ication }\end{array}$ & $\begin{array}{l}\text { Median: } 255 \\
\text { minutes }\end{array}$ & $\begin{array}{l}\text { Median: } 144 \\
\text { minutes }\end{array}$ & Not estimable & $\begin{array}{l}169 \\
\text { (1 study) }\end{array}$ & $\begin{array}{l}\oplus \odot \odot \odot \\
\text { very low } 1,2,3\end{array}$ & \\
\hline $\begin{array}{l}\text { Number of participants using rescue medica- } \\
\text { tion over } 4 \text { to } 6 \text { hours postinterventions }\end{array}$ & 255 per 1000 & $\begin{array}{l}\mathbf{4 7 0} \text { per } 1000 \\
\text { (266 to } 830)\end{array}$ & $\begin{array}{l}\text { RR } 1.8 \text { (1.0 to } 3.3) \\
\text { NNTH4.5 (2.5 to } 33)\end{array}$ & $\begin{array}{l}98 \\
\text { (1 study) }\end{array}$ & $\begin{array}{l}\oplus \ominus \ominus \ominus \\
\text { very low } 1,2,4\end{array}$ & \\
\hline
\end{tabular}


Number of participants experiencing a serious

adverse event

5 per 1000

5 per 1000

(1 to 32$)$

RR 0.94 (0.13 to 6.6)

423

(4 studies)

$\oplus \oplus \ominus \ominus$

$\oplus \oplus \odot \odot$

Studies under-

powered to

detect these

events.

Cl: confidence interval; NNTB: number needed to treat for an additional beneficial outcome; NNTH: number needed to treat for an additional harmful outcome; NSAID: nonsteroidal anti-inflammatory drug; RR: risk ratio

GRADE Working Group grades of evidence

High quality: We are very confident that the true effect lies close to that of the estimate of the effect.

Moderate quality: We are moderately confident in the effect estimate; the true effect is likely to be close to the estimate of effect, but there is a possibility that it is substantially different.

Low quality: Our confidence in the effect estimate is limited; the true effect may be substantially different from the estimate of the effect.

Very low quality: We have very little confidence in the effect estimate; the true effect is likely to be substantially different from the estimate of effect.

1Unclear risk of bias in several domains.

2 Total number of participants $<400$.

3Imprecision: unable to estimate confidence intervals due to reporting of median data.

${ }^{4}$ Fewer than 400 participants in unpublished studies required to change the NNTB to an unacceptably high level of 10.

5 Very low number of events. 


\section{B A C K G R O U N D}

The methodology and sections of the text in this protocol are derived from a series of reviews published in the Cochrane Library that assess single or combined analgesic agents for postoperative pain, and from suggested wording from the Cochrane Pain, Palliative and Supportive Care Review Group (Derry 2016).

\section{Description of the condition}

Patients frequently experience pain after surgery. Evidence indicates that around $80 \%$ of patients experience postoperative pain and that $75 \%$ of patients report pain of moderate or greater severity (Chou 2016). Many patients receive suboptimal perioperative analgesia, which affects quality of life, functioning, and time to recovery, and places them at risk for developing acute postsurgical complications and persistent postsurgical pain (Apfelbaum 2003; Chou 2016).

As noted, this review is based on a series of reviews published in the Cochrane Library whose aim is to increase awareness of the range of analgesics that are potentially available, and present evidence for relative analgesic efficacy through indirect comparisons with placebo, in very similar trials performed in a standard manner, with very similar outcomes, and over the same duration. Such relative analgesic efficacy does not in itself determine choice of drug for any situation or person, but guides policymaking at the local level. The series covers all analgesics licensed for acute postoperative pain in the UK, and metamizol, which is commonly used in Spain, Portugal, and Latin American countries. The results have been examined in overviews of efficacy and harm (Moore 2015a; Moore 2015b), and related individual reviews include ibuprofen (Derry 2009), paracetamol (acetaminophen) (Toms 2008), ketoprofen and dexketoprofen (Barden 2009), codeine (Derry 2010), and combinations such as ibuprofen plus paracetamol (Derry 2013a), ibuprofen plus codeine (Derry 2013b), and paracetamol plus codeine (Toms 2009).

\section{Description of the intervention}

\section{Acute-pain trials}

Single-dose trials in acute pain are commonly short in duration, rarely lasting longer than 12 hours. The numbers of participants are small, allowing no reliable conclusions to be drawn about safety. To show that the analgesic is working, it is necessary to use placebo (McQuay 2005). There are clear ethical considerations in doing this. These ethical considerations are addressed by using acute-pain situations where the pain is expected to go away, and by providing additional analgesia, commonly called rescue analgesia, if the pain has not diminished after about one hour. This is reasonable, because not all participants given an analgesic will have significant pain relief. Approximately $18 \%$ of participants given placebo will have significant pain relief (Moore 2006), and up to $50 \%$ may have inadequate analgesia with active medicines. Hence, the use of additional or rescue analgesia is important for all participants in the trials.

Clinical trials measuring the efficacy of analgesics in acute pain have been standardized over many years (McQuay 2012). Trials have to be randomized and double-blind. Typically, in the first few hours or days after an operation, patients develop pain that is moderate to severe in intensity, and will then be given the test analgesic or placebo. Pain is measured using standard pain intensity scales immediately before the intervention, and then using pain intensity and pain relief scales over the following four to six hours for shorter-acting drugs, and up to 12 or 24 hours for longer-acting drugs. Pain relief of half the maximum possible pain relief or better (at least 50\% pain relief) is typically regarded as a clinically useful outcome (Moore 2011a). For patients given rescue medication, it is usual for no additional pain measurements to be made, and for all subsequent measures to be recorded as initial pain intensity or baseline (zero) pain relief (baseline observation carried forward, BOCF). This process ensures that analgesia from the rescue medication is not wrongly ascribed to the test intervention. In some trials the last observation is carried forward (LOCF), which gives an inflated response for the test intervention compared to placebo, but the effect has been shown to be negligible over four to six hours (Moore 2005). Patients usually remain in the hospital or clinic for at least the first six hours following the intervention, with measurements supervised, although they may then be allowed home to make their own measurements in trials of longer duration.

Knowing the relative efficacy of different analgesic drugs at various doses can be helpful (Moore 2015b).

\section{Recommendations for non-steroidal anti-inflammatory drug use in postoperative guidelines}

Treatment guidelines for acute pain developed by major professional organizations recommend a multimodal approach to analgesia, which routinely includes administration of both an opioid and one or more non-opioids, the latter of which frequently includes a non-steroidal anti-inflammatory drug (NSAID) (Chou 2016; Macintyre 2010). Postoperative administration of NSAIDs has been shown to reduce patient requirements for opioids and, in turn, to reduce the incidence and severity of opioid-induced adverse events (AEs) (Cepeda 2005). Parenteral analgesics are required postoperatively if patients are unable to tolerate oral medications. Until recently, the only parenteral NSAID available in the USA and many other countries was ketorolac. Parenteral ketorolac has demonstrated efficacy in reducing pain and opioid requirements (Cepeda 2005). However, its acute safety profile includes increased risk of gastrointestinal bleeding and renal events, particularly with use beyond five days and in at-risk populations, thought to be due to in part to its selectivity for the cyclooxygenase-1 (COX-1) enzyme (Feldman 1997; Strom 1996). Parenteral formulations of the commonly used NSAIDs ibuprofen and diclofenac have been developed, expanding the menu of NSAID agents for treating postoperative pain in patients who require intravenous (IV) analgesia (Daniels 2016; McCormack 2008; Scott 2012).

\section{Parenteral diclofenac}

Diclofenac, first introduced in Europe in 1973, has an established role in the treatment of acute and chronic pain (Daniels 2016; Hoy 2016; Todd 1988). It has analgesic, antipyretic, and anti-inflammatory properties. In its oral formulation, it has demonstrated limited efficacy in the treatment of acute postoperative pain (Derry 2015). A parenteral formulation of diclofenac has been available outside of the USA for several decades (Gan 2012). Due to diclofenac's poor solubility, this formulation contains the solubilizing agents benzyl alcohol and propylene glycol. The use of these solubilizers further necessitates that the drug be administered intramuscularly; or if administered 
intravenously, that it be further diluted and buffered (with sodium bicarbonate) before administration via slow infusion over 30 to 120 minutes, in order to prevent venous irritation. These added steps may delay analgesia, potentially limiting this formulation's role in acute postoperative pain management. Recently developed formulations of parenteral diclofenac employ hydroxypropyl- $\beta$-cyclodextrin (HP $\beta C D$ ) as a solubility enhancer. These formulations do not require further dilution or buffering and may be administered as bolus IV (Dyloject) or subcutaneous (Akis, Dicloin) injections (Hoy 2016).

\section{How the intervention might work}

Non-steroidal anti-inflammatory drugs inhibit COX isoenzymes 1 and 2 , thereby reducing the formation of prostaglandins that are responsible for pain and inflammation at a site of injury or disease (FitzGerald 2001). In addition to their peripheral effects, NSAIDs act in the spinal cord and central nervous system to reduce pain even when inflammation is not present. They also act upon inflammatory pathways other than those involving COX. Diclofenac shares these properties, and additionally is thought to increase $\beta$-endorphin levels and inhibit the N-methyl-D-aspartate (NMDA) pathway (Gan 2010).

Inhibition of COX may also play a role in the AE profile of NSAIDs. Non-steroidal anti-inflammatory drugs account for more reports of drug toxicity than any other agents (Hawkey 2002). Risk factors for toxicity include dose, duration of therapy, patient age, and pre-existing renal impairment. At least two forms of COX are expressed in tissues: COX-1 is responsible for the production of prostaglandins that play a predominately protective role in the gastrointestinal tract, vascular system, and kidneys, and for the production of thromboxane A2, which is responsible for platelet aggregation and vasoconstriction (FitzGerald 2004); COX-2 is expressed constitutively only in the central nervous system and kidneys, but in other organs it is induced after trauma (including surgery) and inflammation. Inhibition of the production of protective prostaglandins and thromboxane may lead to gastrointestinal, hematological, cardiovascular, and renal AEs. Postoperative patients are at greater risk of developing NSAIDinduced acute kidney injury as they may be volume depleted, as are the elderly, who rely on prostaglandins to maintain renal function. Non-steroidal anti-inflammatory drugs that selectively inhibit the COX-2 isoenzyme or that have a balanced COX-1/COX-2 profile may reduce the incidence of gastrointestinal bleeding and interfere less with platelet aggregation in comparison to NSAIDs that are selective for COX-1 (such as ketorolac) (FitzGerald 2001; FitzGerald 2004). Conversely, NSAIDs that are selective for COX-2 may increase the risk of a cardiovascular event. Non-steroidal antiinflammatory drugs may also occasionally produce liver damage, particularly with long-term use (APS 2008).

\section{Why it is important to do this review}

The recent reformulation of parenteral diclofenac has led to a renewed interest in the use of this agent in the perioperative setting. The newer formulation may provide a more rapid onset of analgesia than traditional formulations. In theory, diclofenac's balanced COX-1/COX-2 profile may reduce the risk of development of acute postoperative AEs as observed with ketorolac, such as gastrointestinal bleeding. Studies in healthy volunteers have suggested a reduced risk of platelet dysfunction compared with COX-1 selective NSAIDs (Bauer 2010), and pooled analyses of safety data from clinical trials have demonstrated a reduction in the rate of thrombophlebitis versus traditional formulations of parenteral diclofenac, and similar rates of renal dysfunction to placebo (Colucci 2009; Daniels 2016). However, no systematic reviews to date have assessed the efficacy or safety of this agent.

\section{OB JECTIVES}

To assess the analgesic efficacy and adverse effects of singledose intravenous diclofenac, compared with placebo or an active comparator, for moderate to severe postoperative pain in adults.

\section{METHODS}

\section{Criteria for considering studies for this review \\ Types of studies}

We included randomized controlled trials with at least 10 participants randomly allocated to each treatment group and double-blind assessment of participant outcomes. We included multiple-dose studies if appropriate data from the first dose were available, and cross-over studies provided that data from the first phase were presented separately or could be obtained.

We excluded:

- review articles, case reports, and clinical observations;

- studies of experimental pain;

- studies of less than four hours' duration or studies that did not present data over four to six hours postdose;

- studies where pain was not patient-reported.

For postpartum pain, we included studies if the pain investigated was due to episiotomy or Caesarean section irrespective of the presence of uterine cramps; we excluded studies investigating pain due to uterine cramps alone.

We required full journal publication, with the exception of online clinical trial results, summaries of otherwise unpublished clinical trials, and abstracts with sufficient data for analysis.

\section{Types of participants}

We included studies of adults (aged 18 years and above) with established postoperative pain of moderate to severe intensity following day surgery or inpatient surgery. For studies using a visual analogue scale (VAS) (see Glossary: Appendix 1), we considered that pain intensity of greater than $30 \mathrm{~mm}$ equates to pain of at least moderate intensity (Collins 1997).

\section{Types of interventions}

Diclofenac, administered as a single IV dose, for the relief of acute postoperative pain, and compared to placebo or any active comparator.

\section{Types of outcome measures}

\section{Primary outcomes}

- Participants achieving at least 50\% pain relief over a four- to sixhour period.

\section{Secondary outcomes}

- Median (or mean) time to use of rescue medication. 
- Number of participants using rescue medication over a four- to six-hour period.

- Withdrawals due to lack of efficacy, AEs, and for any cause.

- Participants experiencing any AE.

- Participants experiencing any serious AE (SAE). Serious adverse events typically include any untoward medical occurrence or effect that at any dose results in death, is lifethreatening, requires hospitalization or prolongation of existing hospitalization, results in persistent or significant disability or incapacity, is a congenital anomaly or birth defect, is an 'important medical event' that may jeopardize the patient, or may require an intervention to prevent one of the above characteristics or consequences.

- Specific AEs, particularly renal dysfunction, cardiovascular events, bleeding, and thrombophlebitis.

In addition, we performed a post hoc analysis of AEs that might be considered to be related to opioid use, in an attempt to enable indirect comparisons with other analyses of postoperative analgesics. A reduction in opioid requirements with an effective analgesic may, in turn, reduce the incidence of opioid-induced side effects. We assessed the following opioid-related AEs:

- nausea;

- vomiting;

- nausea and vomiting;

- pruritus;

- respiratory depression;

- sedation;

- urinary retention;

- allergic reaction/rash.

\section{Search methods for identification of studies}

\section{Electronic searches}

We searched the following databases without language restrictions.

- The Cochrane Central Register of Controlled Trials (CENTRAL) via the Cochrane Register of Studies Online on 22 May 2018.

- MEDLINE \& Medline in Process (via Ovid) 1946 to May, week 2, 2018.

- Embase (via Ovid) 1974 to 2018, week 21.

MeSH or equivalent and text word terms were used. Searches were tailored to individual databases. The search strategies for MEDLINE, CENTRAL, and Embase are in Appendix 2, Appendix 3, and Appendix 4 , respectively.

\section{Searching other resources}

We searched the US National Institutes of Health Ongoing Trials Register ClinicalTrials.gov (www.clinicaltrials.gov) and the World Health Organization (WHO) International Clinical Trials Registry Platform (ICTRP) (apps.who.int/trialsearch/) for ongoing or completed trials on 22 May 2018. In addition, we checked reference lists of reviews and retrieved articles for additional studies and performed citation searches on key articles. We contacted experts in the field for unpublished and ongoing trials. We contacted study authors where necessary for additional information.

\section{Data collection and analysis}

\section{Selection of studies}

We performed each stage of study selection in duplicate and checked for agreement between us. We determined eligibility by reading the abstract of each study identified by the search. We eliminated studies that clearly did not satisfy the inclusion criteria, and we obtained full copies of the remaining studies. Two review authors (a combination of two of EM, MF, and RS) read these studies independently and reached agreement by discussion. Where agreement could not be reached, the third review author adjudicated. We did not anonymize the studies in any way before assessment.

We have included a PRISMA flow chart, which shows the status of identified studies (Moher 2009), as recommended in Section 11.2.1 of the Cochrane Handbook for Systematic Reviews of Intervention (Higgins 2011). We included studies in the review irrespective of whether measured outcome data were reported in a 'usable' way.

\section{Data extraction and management}

Two review authors (a combination of two of EM, MF, and RS) independently extracted data using a standardised form and checked for agreement before entry into Review Manager 5 (RevMan 2014). We collated multiple reports of the same study, so that each study, rather than each report, was the unit of interest in the review. We collected information about the included studies (e.g. study methods, study population, baseline pain intensity) in sufficient detail to complete a 'Characteristics of included studies' table.

\section{Assessment of risk of bias in included studies}

Two review authors (a combination of EM, MF, and RS) independently assessed risk of bias for each study, using applicable criteria outlined in Chapter 8 of the Cochrane Handbook for Systematic Reviews of Interventions (Higgins 2011), and adapted from those used by the Cochrane Pregnancy and Childbirth Group, with any disagreements resolved by discussion. We completed a 'Risk of bias' table for each included study using the 'Risk of bias' tool in Review Manager 5 (RevMan 2014).

We assessed the following for each study.

- Random sequence generation (checking for possible selection bias). We assessed the method used to generate the allocation sequence as: low risk of bias (any truly random process, e.g. random number table; computer random number generator); unclear risk of bias (method used to generate sequence not clearly stated). We excluded studies using a non-random process (e.g. odd or even date of birth; hospital or clinic record number).

- Allocation concealment (checking for possible selection bias). The method used to conceal allocation to interventions prior to assignment determines whether intervention allocation could have been foreseen in advance of, or during, recruitment, or changed after assignment. We assessed the methods as: low risk of bias (e.g. telephone or central randomization; consecutively numbered, sealed, opaque envelopes); unclear risk of bias (method not clearly stated). We excluded studies that did not conceal allocation (e.g. open list).

- Blinding of participants and personnel (checking for possible performance bias). We assessed the methods used to blind 
study participants and personnel from knowledge of which intervention a participant received. We assessed methods as: low risk of bias (study states that it was blinded and describes the method used to achieve blinding, such as identical tablets matched in appearance or smell, or a double-dummy technique); unclear risk of bias (study states that it was blinded but does not provide an adequate description of how this was achieved). We excluded studies that were not double-blind.

- Blinding of outcome assessment (checking for possible detection bias). In this review, pain-related outcomes were self assessed, so that the same considerations apply to detection bias as performance bias.

- Incomplete outcome data (checking for possible attrition bias due to the amount, nature, and handling of incomplete outcome data). We assessed the methods used to deal with incomplete data as: low risk (less than $10 \%$ of participants did not complete the study or used BOCF analysis or both); unclear risk of bias (used LOCF analysis); high risk of bias (used 'completer' analysis).

- Selective reporting (checking for reporting bias). We assessed whether primary and secondary outcome measures were prespecified and whether these were consistent with those reported. We assessed reporting of results as having low risk of bias (e.g. the study protocol was available and all of the study's prespecified outcomes of interest in the review were reported in the prespecified way; the study protocol was not available but it is clear that published reports included all expected outcomes, including those that were prespecified); high risk of bias (e.g. not all of the study's prespecified primary outcomes were reported; one or more primary outcomes were reported using measurements, analysis methods, or subsets of data that were not prespecified); or unclear risk of bias (information insufficient to permit judgement of 'low risk' or 'high risk').

- Size of study (checking for possible biases confounded by small size). We assessed studies as being at low risk of bias (200 participants or more per treatment arm); unclear risk of bias (50 to 199 participants per treatment arm); high risk of bias (fewer than 50 participants per treatment arm).

\section{Measures of treatment effect}

We used risk ratio (RR) to establish statistical difference, and number needed to treat for an additional beneficial outcome (NNTB) and pooled percentages as absolute measures of effect.

We used the following terms to describe adverse outcomes in terms of harm or prevention of harm.

- When significantly fewer adverse outcomes occurred with treatment than with control (placebo or active), we used the term 'number needed to treat to prevent one additional harmful event' (NNTp).

- When significantly more adverse outcomes occurred with treatment compared with control (placebo or active), we used the term 'number needed to treat for an additional harmful outcome' (NNTH).

\section{Unit of analysis issues}

We accepted only randomization of the individual participant. When two or more active treatment arms were compared with a placebo arm within the same meta-analysis, we avoided doublecounting of participants in the placebo arm by splitting the total number between the active arms. If we identified multiple-dose studies, we used data for the most commonly used dose only. For cross-over studies, we used data from the first treatment phase.

\section{Dealing with missing data}

The only likely issue with missing data in these studies was from imputation using LOCF when a participant requests rescue medication. It has previously been shown that this does not affect results for up to six hours after taking study medication (Moore 2005). Where large amounts of data were missing, we reported this in our review and assessed such results with caution. Where papers reported results using more than one method of imputation, we analyzed data using the primary method reported and performed sensitivity analysis by entering data from secondary methods. We also attempted to assess differences between intervention groups in reasons for missing data and how these differences might have biased results.

\section{Assessment of heterogeneity}

We assessed statistical heterogeneity by visually examining forest plots and quantified it using the $\mathrm{I}^{2}$ statistic. The $\mathrm{I}^{2}$ statistic is a reliable and robust test to quantify heterogeneity, since it does not depend on the number of trials or on the between-study variance. $1^{2}$ measures the extent of inconsistency among studies' results, and can be interpreted as the proportion of total variation in study estimates that is due to heterogeneity rather than sampling error. $A n I^{2}$ value of greater than $50 \%$ is considered to indicate substantial heterogeneity (Deeks 2011).

\section{Assessment of reporting biases}

To assess the impact of reporting bias we considered the number of additional participants needed in studies with zero effect (relative benefit of one) required to change the NNTB for all statistically significant outcomes to an unacceptably high level (in this case the arbitrary NNTB of 10) (Moore 2008). Where this number was less than 400 (equivalent to four studies with 100 participants per comparison, or 50 participants per group), we considered the results to be susceptible to publication bias and therefore unreliable (low-quality evidence).

We also attempted to mitigate the potential for publication bias by searching clinical trial websites, as noted above, and by contacting the manufacturers of parenteral diclofenac for an internal reference list of completed studies.

\section{Data synthesis}

For efficacy analyses, we used the number of participants in each treatment group who were randomized, received medication, and provided at least one postbaseline assessment. For safety analyses, we used the number of participants randomized to each treatment group who took the study medication.

For the primary outcome (participants achieving at least $50 \%$ pain relief over a four- to six-hour period), if numbers were not reported directly, we converted the mean total pain relief (TOTPAR), or summed pain intensity difference (SPID), VAS TOTPAR, or VAS SPID (see Glossary: Appendix 1) values for the active and placebo groups in each study to \%maxTOTPAR or \%maxSPID by division into the calculated maximum value (Cooper 1991). We then calculated the proportion of participants in each treatment group who achieved at least 50\%maxTOTPAR using verified equations (Moore 1996; 
Moore 1997a; Moore 1997b), and converted these proportions into the number of participants achieving at least 50\%maxTOTPAR by multiplying by the total number of participants in the treatment group. We used this information on the number of participants with at least 50\%maxTOTPAR for active and placebo groups to calculate RR and NNTB.

We accepted the following pain measures for the calculation of TOTPAR or SPID (in order of priority: see Appendix 1).

- 5-point categorical pain relief scales with comparable wording to 'none,' 'slight,' 'moderate,' 'good,' and 'complete.'

- 4-point categorical pain intensity scales with comparable wording to 'none,' 'mild,' 'moderate,' and 'severe.'

- VAS for pain relief.

- VAS for pain intensity.

If none of these measures was available, we planned to use the number of participants reporting 'very good or excellent' on a 5point categorical global scale with the wording 'poor,' 'fair,' 'good,' 'very good,' and 'excellent' for the number of participants achieving at least $50 \%$ pain relief (Collins 2001).

For each treatment group, we extracted the number of participants using rescue medication and the number reporting treatmentemergent AEs.

If there were sufficient data, we calculated RR estimates with 95\% confidence intervals ( $\mathrm{Cls}$ ) using the Mantel-Haenszel method and a fixed-effect model in Review Manager 5 (RevMan 2014). We calculated NNTB and NNTH with 95\% Cls using the pooled number of events and the method of Cook and Sackett (Cook 1995). We assumed a statistically significant difference from control when the $95 \% \mathrm{Cl}$ of the RR did not include the number one.

\section{Quality of evidence}

Two review authors (EM, MF) independently rated the quality of evidence for each outcome. We used the GRADE approach to assess the quality of evidence using GRADEpro GDT software (GRADEpro GDT 2015), and the guidelines provided in Section 12.2 of the Cochrane Handbook for Systematic Reviews of Interventions (Appendix 5) (Higgins 2011). We reported our judgements on the quality of evidence in 'Summary of findings' tables.

We paid particular attention to:

- inconsistency, where point estimates vary widely across studies or Cls of studies show minimal or no overlap (Guyatt 2011);

- potential for publication bias, based on the amount of unpublished data required to make the result clinically irrelevant (Moore 2008).

In addition, there may be circumstances where the overall rating for a particular outcome needs to be adjusted as recommended by GRADE guidelines (Guyatt 2013a). For example, if there were so few data that the results were highly susceptible to the random play of chance, or if studies use LOCF imputation in circumstances where there were substantial differences in AE withdrawals, one would have no confidence in the result, and would need to downgrade the quality of the evidence by three levels, to very low quality. In circumstances where there were no data reported for an outcome, we reported the level of evidence as very low quality (Guyatt 2013b).

\section{'Summary of findings' table}

We included 'Summary of findings' tables as set out in the Cochrane Pain, Palliative and Supportive Care Review Group author guide (PaPaS 2012), and recommended in Chapter 11 of the Cochrane Handbook for Systematic Reviews of Interventions (Higgins 2011), to present the main findings in a transparent and simple tabular format. In particular, we included key information concerning the quality of evidence (using GRADE), the magnitude of effect of the interventions examined, and the sum of available data on the outcomes of at least $50 \%$ of maximum pain relief over four to six hours; median (or mean) time to use of rescue medication; participants using rescue medication within four to six hours; participants with at least one $\mathrm{AE}$; and participants with an SAE.

\section{Subgroup analysis and investigation of heterogeneity}

If there were sufficient data, we planned to analyze different doses separately. We also planned to analyze different formulations of parenteral diclofenac separately. We determined significant differences between different doses or formulations using the $z$ test (Tramèr 1997), if appropriate.

\section{Sensitivity analysis}

For meta-analyses with an $\mathrm{I}^{2}$ score of greater than $50 \%$, we reanalyzed data using a random-effects model.

\section{RES U LTS}

\section{Description of studies}

See Characteristics of included studies; Characteristics of excluded studies; Characteristics of studies awaiting classification; and Characteristics of ongoing studies tables.

\section{Results of the search}

Our literature search yielded 2616 references from CENTRAL, 2053 references from MEDLINE, and 1180 studies from Embase (a total of 3704 after de-duplication). We reviewed the abstracts associated with these references and identified 64 potentially relevant studies, determining that the remaining references clearly did not meet our inclusion criteria. After full-text review, we excluded 54 studies that did not meet our inclusion criteria. In addition, we were unable to find information regarding blinding for Kumar 2016, despite attempting to contact the study authors, and have assigned this study to Studies awaiting classification.

Our search of clinical trial websites yielded 22 ongoing or completed trials from ClinicalTrials.gov and 102 studies from the WHO ICTRP. From these, we found one potentially relevant ongoing study (Figure 1) (NCT03493490). 
Figure 1. Study flow diagram.

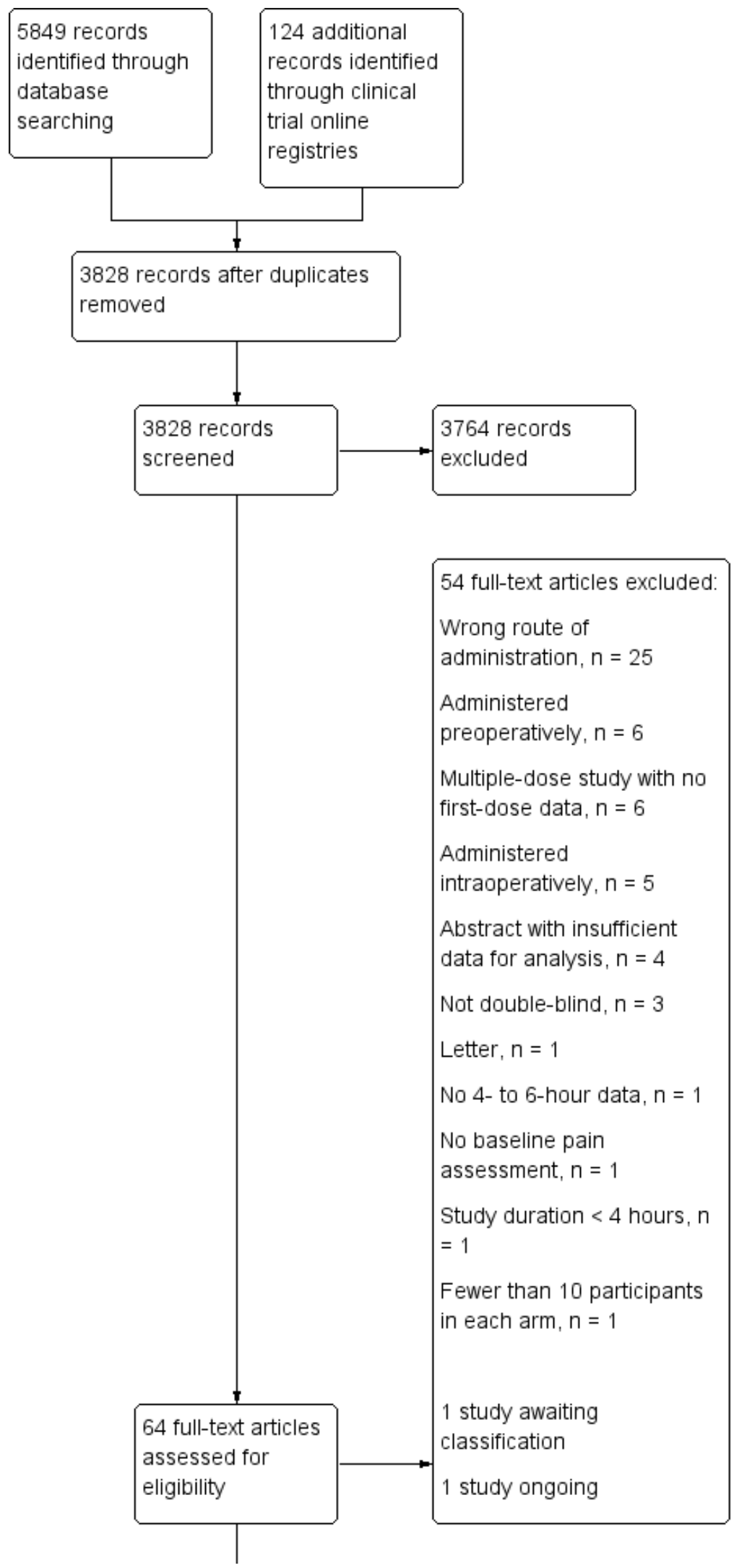


Figure 1. (Continued)

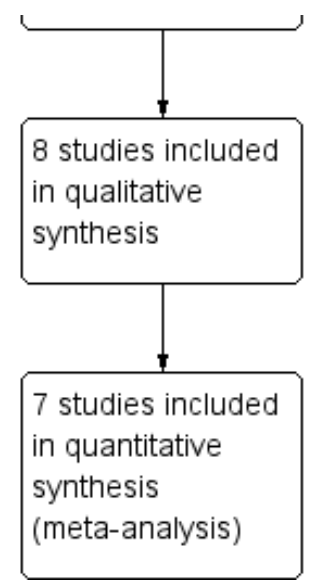

\section{Included studies}

Eight studies fulfilled our inclusion criteria (Christensen 2011; Gan 2012; Garcia 1997; Leeson 2007; Maroo 2013; Seymour 2000; Sneyd 2007; Steffen 1994).

One trial was conducted in Argentina (Garcia 1997), one in Germany (Steffen 1994), one in India (Maroo 2013), three in the UK (Leeson 2007; Seymour 2000; Sneyd 2007), and two in the USA (Christensen 2011; Gan 2012). Total enrollment ranged from 39 to 353 participants, with the number of participants in each study receiving diclofenac ranging from 20 to 175 , placebo 19 to 76, and another NSAID 29 to 82 . Where reported, mean study population ages ranged from 24.5 years, in Leeson 2007, to 54.5 years, in Garcia 1997. The ages of participants generally reflected the type of surgical procedure, for example studies using a dental model enrolled younger participants. Four studies enrolled participants undergoing dental surgery (Christensen 2011; Leeson 2007; Seymour 2000; Sneyd 2007), with participants in Seymour 2000 and Sneyd 2007 administered general anesthesia; two studies enrolled participants undergoing mixed minor/day surgeries (Garcia 1997; Maroo 2013); and single studies assessed participants undergoing abdominal, Gan 2012, and minor orthopedic, Steffen 1994, procedures.

Where reported, all studies were funded in part or entirely by the manufacturers of one of the interventions. Two studies did not report funding (Garcia 1997; Steffen 1994).

Study designs were similar: participants received one of the assigned interventions after reporting moderate to severe pain postoperatively, and outcomes such as pain relief, pain intensity difference, or time to use of rescue medication were assessed. The exception was the study by Steffen 1994, where participants had ready access to an opioid via patient-controlled analgesia after receiving their assigned intervention, and opioid consumption was the primary outcome.

Diclofenac doses varied among and within studies, ranging from $3.75 \mathrm{mg}$ to $75 \mathrm{mg}$. The most commonly administered dose was 75 mg (Christensen 2011; Garcia 1997; Leeson 2007; Maroo 2013; Seymour 2000; Steffen 1994). Three studies assessed more than one dose (Christensen 2011; Gan 2012; Seymour 2000).
The formulation of diclofenac also varied among and within studies. Three studies employed traditional formulations that required further dilution and slow infusion (over 20 to 30 minutes) (Garcia 1997; Sneyd 2007; Steffen 1994). Five studies employed newer formulations that could be administered as an IV bolus without further dilution, in addition to or instead of traditional formulations (Christensen 2011; Gan 2012; Leeson 2007; Maroo 2013; Seymour 2000). Four of the five studies employed a formulation with the solubilizing agent HP $\beta C D$ (Christensen 2011; Gan 2012; Leeson 2007; Seymour 2000), and one study employed a formulation that was only described as propylene glycol-free (Maroo 2013). Two of the studies directly compared the new formulation with a traditional formulation (Leeson 2007; Maroo 2013).

Comparator arms included participants administered placebo (Leeson 2007; Seymour 2000; Sneyd 2007), an alternative parenteral NSAID (Garcia 1997), or both (Christensen 2011; Gan 2012; Steffen 1994). Additionally, one study included two additional arms, administering doses of GR79236X (4 mcg/kg or $10 \mathrm{mcg} / \mathrm{kg}$ ), an experimental adenosine agonist (Sneyd 2007).

\section{Studies awaiting classification}

The manuscript for Kumar 2016 states that participants were blinded, but there is no mention of investigator blinding. This study compared a single postoperative dose of $75 \mathrm{mg}$ of intravenous diclofenac with a single dose of $100 \mathrm{mg}$ of intravenous tramadol in patients undergoing elective surgery. The authors reported that tramadol provided a longer duration of analgesia (undefined) versus diclofenac ( $5.54 \pm 0.78 \mathrm{~h}$ versus $5.45 \pm 0.54 \mathrm{~h}, \mathrm{P}=0.001)$, but that the time to onset of analgesia (undefined) was shorter in the diclofenac group $(3.32 \pm 0.90 \mathrm{~min}, \mathrm{P}=0.001)$ than in the tramadol group ( $4.84 \pm 0.99 \mathrm{~min})$. The mean pain score after 30 minutes was lower in the diclofenac group $(P=0.001)$ but at no other time points. Nausea, vomiting, and drowsiness occurred more frequently in participants receiving tramadol.

\section{Ongoing studies}

One randomized controlled trial, found on ClinicalTrials.gov, is expected to be completed 31 January 2019 (NCT03493490). It aims to enroll 72 participants post-cruciate ligament repair or total knee replacement, and administer intravenous diclofenac, diclofenac plus orphenadrine, or placebo, and follow participants for 48 hours 
postoperatively. Its primary outcome is total opioid use via patientcontrolled analgesia in the first 24 hours after interventions are administered.

\section{Excluded studies}

Fifty-four studies did not meet all of our inclusion criteria (Figure 1). Common reasons included wrong route of administration, pre- or intraoperative times of intervention administration, or multiple-dose studies that did not report data separately for the first dose. Of the last, four publications reported data related to assessment of a novel formulation of diclofenac that employed the same solubilizing agent, HP $\beta C D$, as described in Included studies (Daniels 2013; Daniels 2016; Gan 2016; Gan 2017). These publications merit mention as they describe studies that enrolled large numbers of participants and were similarly designed, enabling pooling of both efficacy and safety data. One of the studies included in the pooled analysis met our inclusion criteria (Gan 2012), and one did not, as it was a multiple-dose study without separate data reported for the first dose (Daniels 2013). Analysis of 608 participants who received at least one dose of HP $\beta C D$ diclofenac (interventions were administered either as a single dose or every 6 hours for up to 5 days) demonstrated a reduction in opioid requirements versus both placebo and ketorolac $(P<0.005$ for all comparisons) (Gan 2017). In the same population, pooled analysis of safety events demonstrated that renal AEs (assessed by examining treatment-emergent AEs and changes in postoperative blood urea nitrogen and serum creatinine levels) were rare in all treatment groups (Daniels 2016); cardiovascular events were also rare and comparable to placebo (Gan 2016).

\section{Risk of bias in included studies}

Our findings are summarized in Figure 2 and Figure 3.

Figure 2. Risk of bias graph: review authors' judgements about each risk of bias item presented as percentages across all included studies.

Random sequence generation (selection bias)

Allocation concealment (selection bias)

Blinding of participants, personnel and outcome assessors Incomplete outcome data (attrition bias): All outcomes Selective reporting (reporting bias)

Sample size

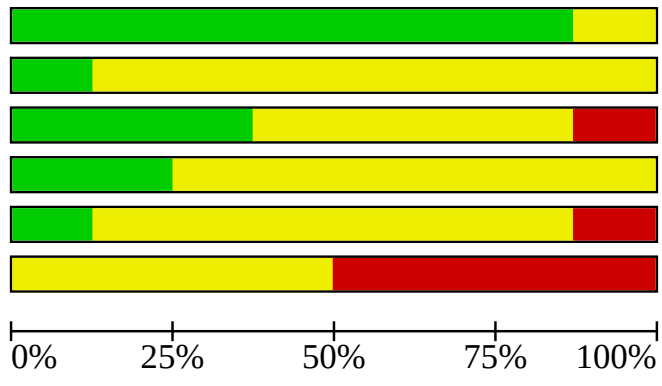

\begin{tabular}{|ll|l}
$\square$ Low risk of bias $\quad \square$ Unclear risk of bias $\quad \square$ High risk of bias \\
\hline
\end{tabular}


Figure 3. Risk of bias summary: review authors' judgements about each risk of bias item for each included study.

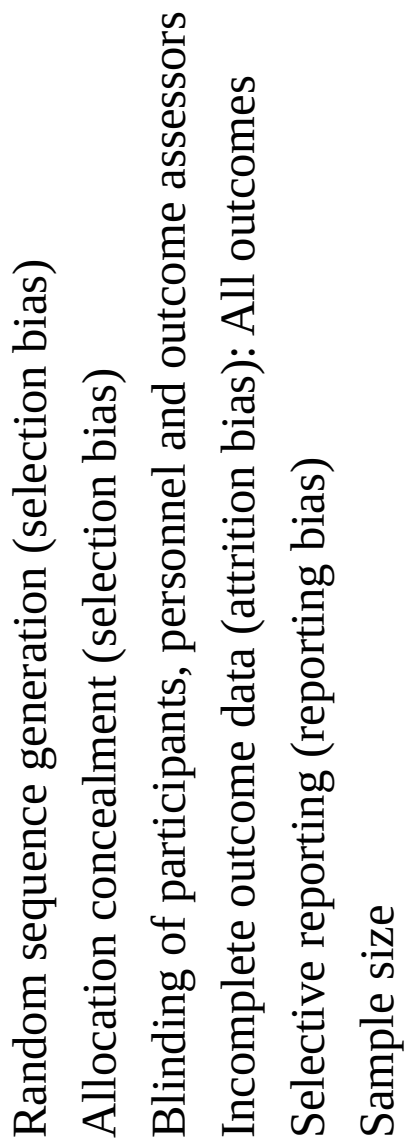

\section{Christensen 2011 \\ Gan 2012 \\ Garcia 1997 \\ Leeson 2007 \\ Maroo 2013 \\ Seymour 2000 \\ Sneyd 2007 \\ Steffen 1994}

\begin{tabular}{|c|c|c|c|c|c|}
\hline+ & $?$ & + & $?$ & $?$ & - \\
\hline+ & $?$ & $?$ & + & $?$ & $?$ \\
\hline$?$ & $?$ & + & $?$ & $?$ & - \\
\hline+ & $?$ & + & $?$ & $?$ & $?$ \\
\hline+ & $?$ & - & + & $?$ & $?$ \\
\hline+ & + & $?$ & $?$ & $?$ & $?$ \\
\hline+ & $?$ & $?$ & $?$ & + & - \\
\hline+ & $?$ & $?$ & $?$ & - & - \\
\hline
\end{tabular}

\section{Allocation}

computer-generated numbers or a table of random numbers.

Random sequence generation

Garcia 1997 did not describe how participants were randomized.

All studies reported that they were randomized, and all but one described adequate methods of randomization, that is via 


\section{Allocation concealment}

Only one study described adequate allocation concealment (Seymour 2000), via a central randomization process. In most of the remaining studies, allocation concealment was not mentioned.

\section{Blinding}

Three studies described adequate methods of blinding both investigators and participants (Christensen 2011; Garcia 1997; Leeson 2007), with Garcia 1997 stating that the interventions were indistinguishable from each other. Christensen 2011 and Garcia 1997 described the methods used to ensure blinding in sufficient detail for us to believe that neither the investigator nor the study participant would have been able to discriminate interventions based on their appearance. We assessed four studies as having an unclear risk of bias, either because they did not describe methods of blinding in any way, or because their descriptions were inadequate for us to determine whether investigators or participants would have been able to distinguish interventions. Lastly, we assessed one study, Maroo 2013, as having a high risk of bias, as the different interventions were administered as either a bolus or short infusion, yet there was no mention of employing a double-dummy technique.

\section{Incomplete outcome data}

We assessed the majority of studies as having an unclear risk of attrition bias, primarily because they did not describe how missing data were imputed. We assessed only two studies as having a low risk of bias (Gan 2012; Maroo 2013). In Gan 2012 , an intentionto-treat analysis was employed, and worst observation carried forward (WOCF) used to impute missing data for the primary endpoint. For Maroo 2013, the authors reported that all participants completed the study and reported data at each time point.

\section{Selective reporting}

Only one study had a low risk of reporting bias (Sneyd 2007). While a protocol was not available for this study, all outcomes listed in its methods section were reported in full in the results section. We assessed one study as having a high risk of bias (Steffen 1994). The data for this study's primary outcome were reported at several time points not mentioned in the methods section. Conversely, secondary outcomes described in the methods section were not reported in the results. We assessed the remaining studies as having unclear risk of bias, mostly due to incomplete reporting of secondary outcomes.

\section{Other potential sources of bias}

The major threat to reliability was the small size of the studies. We assessed four studies as having a high risk of bias, as they had at least one arm that enrolled fewer than 50 participants (Christensen 2011; Garcia 1997; Sneyd 2007; Steffen 1994). We assessed the remaining studies as having an unclear risk due to sample size. The highest number of participants in a single arm was 175, in Maroo 2013.

\section{Effects of interventions}

See: Summary of findings 1 Intravenous diclofenac compared to placebo for acute postoperative pain in adults; Summary of findings 2 Intravenous diclofenac compared to another NSAID for acute postoperative pain in adults
See Summary of findings 1 for outcomes for the main comparison, diclofenac versus placebo, and Summary of findings 2 for the comparison of diclofenac versus another NSAID.

All eight included studies provided usable data for analysis. However, we did not use all data in meta-analysis, either because there was only one study for a given outcome, or there were too few participants or events for a given outcome. We used none of the data from Maroo 2013 in any meta-analysis, as the study compared two different formulations of IV diclofenac without including a placebo group. The only other study to compare two different formulations of diclofenac, Leeson 2007, did not appear to include the same formulations as Maroo 2013, therefore pooling of data between the two studies was not possible.

\section{Proportion of participants achieving at least $50 \%$ postoperative pain relief over a four- to six-hour period}

No study reported numbers of participants achieving this outcome directly. We derived numbers, using the equations described earlier (Data synthesis), from tables or figures. Gan 2012 reported the proportion of participants with at least $30 \%$ pain relief; we used this as a surrogate value.

\section{Diclofenac versus placebo}

Three studies (277 participants) compared diclofenac $75 \mathrm{mg}$, Leeson 2007; Seymour 2000, or 50 mg, Sneyd 2007, with placebo over four hours post-administration of interventions.

- The proportion of participants with at least $50 \%$ pain relief with diclofenac was $65 \%$ (91/141, range $54 \%$ to $77 \%$ ).

- The proportion of participants with at least $50 \%$ pain relief with placebo was $23 \%$ (31/136, range $6 \%$ to $38 \%$ ).

- The relative benefit of treatment compared with placebo was 2.8 (95\% confidence interval $(\mathrm{Cl}) 2.0$ to 4.0$)$; the number needed to treat for an additional beneficial outcome (NNTB) for one additional participant to benefit compared with placebo was 2.4 $(95 \% \mathrm{Cl} 1.9$ to 3.1 ) (Analysis 1.1 ).

Four studies (436 participants) compared diclofenac $75 \mathrm{mg}$, Christensen 2011; Seymour 2000, 50 mg, Sneyd 2007, or 37.5 $\mathrm{mg}$, Gan 2012, with placebo over six hours post-administration of interventions.

- The proportion of participants with at least $50 \%$ pain relief with diclofenac was $60 \%$ (135/225, range $50 \%$ to $70 \%$ ).

- The proportion of participants with at least $50 \%$ pain relief with placebo was $34 \%$ ( $71 / 211$, range $4 \%$ to $55 \%)$.

- The relative benefit of treatment compared with placebo was 1.8 ( $95 \% \mathrm{Cl} 1.4$ to 2.2 ); the NNTB for one additional participant to benefit compared with placebo was $3.8(95 \% \mathrm{Cl} 2.9$ to 5.9$)$ (Analysis 1.2).

We assessed the quality of evidence for this outcome as low. We downgraded quality based on unclear risk of bias for several domains among the included studies and unexplained heterogeneity among studies. In addition, there was a low total number of participants in the analysis over four hours; however, we upgraded quality at this time point due to the large magnitude of effect, that is a risk ratio (RR) of 2.8 . 


\section{Diclofenac versus another NSAID}

No studies provided data for the comparison of intravenous diclofenac with another NSAID over four hours. We therefore assessed the quality of evidence as very low.

Three studies (360 participants) included comparisons of diclofenac 75 mg, Christensen 2011; Garcia 1997, or 37.5 mg, Gan 2012, with another NSAID over six hours.

- The proportion of participants with at least $50 \%$ pain relief with diclofenac was $72 \%$ (132/184, range $59 \%$ to $89 \%)$.

- The proportion of participants with at least $50 \%$ pain relief with another NSAID was $77 \%$ (135/176, range $68 \%$ to $85 \%$ ).

- The relative benefit of treatment compared with another NSAID was $0.9(95 \% \mathrm{Cl} 0.8$ to 1.1$)$; the difference was not statistically significant (Analysis 2.1).

We assessed the quality of evidence for this outcome as low at this time point, based on unclear risk of bias for several domains among the included studies and the low total number of participants analyzed.

\section{Time to use of rescue medication}

This outcome examined the time from taking study medication to use of rescue medication. A longer time to use of rescue medication indicates a longer duration of analgesia from the assigned intervention. Not all studies reported relevant data; of those that did, all reported median times to remedication, rather than means.

\section{Diclofenac versus placebo}

For the comparison of intravenous diclofenac versus placebo, the median time to use of rescue medication was 226 minutes for diclofenac and 80 minutes for placebo ( 5 studies, 542 participants) (Christensen 2011; Gan 2012; Leeson 2007; Seymour 2000; Sneyd 2007).

In almost all of these studies, time to rescue was statistically significantly longer in those participants assigned to diclofenac. Christensen 2011 reported that both IV diclofenac and IV ketorolac achieved statistically significantly longer times to rescue than placebo at all doses $(P<0.05)$. Median time to rescue for those in the diclofenac $75 \mathrm{mg}$ group was 6 hours 2 minutes versus 1 hour 9 minutes in the placebo group. Gan 2012 reported median times to rescue for diclofenac of 2:24 hours $(95 \% \mathrm{Cl} 1: 50$ to $4: 23$ hours, $\mathrm{P}=0.0574$ versus placebo) versus $2: 07$ hours $(95 \% \mathrm{Cl} 1: 15$ to 2:40 hours) in the placebo group and 4:15 hours $(95 \% \mathrm{Cl}$ 3:05 to not estimable, $\mathrm{P}=0.0007$ versus placebo) in the ketorolac group. Leeson 2007 reported that median times to rescue medication for those receiving HP $\beta C D$ diclofenac and polyethylene glycol and benzyl alcohol (PG-BA) diclofenac were 6 hours 26 minutes and 6 hours 32 minutes, respectively, compared with 1 hour 4 minutes for those receiving placebo. Both diclofenac formulations were superior to placebo $(P<0.001)$ and were similar to each other. Seymour 2000 reported that participants receiving diclofenac IV 75 mg waited significantly $(P<0.001)$ longer to use rescue medication than those assigned to placebo: median 62 minutes $(95 \% \mathrm{Cl} 33$ to 219 minutes) versus 50 minutes ( $95 \% \mathrm{Cl} 33$ to 178 minutes). Lastly, Sneyd 2007 reported that median times to rescue morphine were 363 minutes for participants receiving diclofenac $50 \mathrm{mg}$ versus 62 minutes for those receiving placebo $(P=0.002)$.
We judged the quality of evidence as low, based on risk of bias in the included studies and imprecision of findings.

\section{Diclofenac versus another NSAID}

There were insufficient data for pooled analysis for comparisons of diclofenac with another NSAID. Only one study reported data (Gan 2012): the time to use of rescue medication was 144 minutes in those receiving $37.5 \mathrm{mg}$ of IV diclofenac versus 255 minutes in those receiving $30 \mathrm{mg}$ of IV ketorolac.

We therefore judged the quality of evidence as very low.

\section{Number of participants using rescue medication over a four- to six-hour period}

This outcome assessed the need for rescue analgesia in the period immediately after administering the assigned interventions.

\section{Diclofenac versus placebo}

Two studies (235 participants) included comparisons of diclofenac with placebo (Christensen 2011; Seymour 2000).

- The proportion of participants using rescue medication with diclofenac was $48 \%$ (57/119, range $47 \%$ to $49 \%)$.

- The proportion of participants using rescue medication with placebo was $81 \%$ (94/116, range $80 \%$ to $82 \%)$.

- The relative benefit of treatment compared with placebo was $0.59(95 \% \mathrm{Cl} 0.48$ to 0.73$)$; the number needed to treat to prevent one additional harmful event (NNTp) for one additional participant not to need to use rescue medication compared with placebo was $3.0(95 \% \mathrm{Cl} 2.2$ to 4.5$)$ (Analysis 1.3).

We judged the quality of evidence for this outcome as low, due to unclear risk of bias for several domains among the included studies and the low total number of participants analyzed.

\section{Diclofenac versus another NSAID}

Only one study provided usable data for diclofenac versus another NSAID (Christensen 2011).

- The proportion of participants using rescue medication with diclofenac $75 \mathrm{mg}$ was $47 \%$ (24/51).

- The proportion of participants using rescue medication with ketorolac $30 \mathrm{mg}$ was $26 \%$ (12/47).

- The relative risk of diclofenac compared with ketorolac was 1.84 (95\% $\mathrm{Cl} 1.04$ to 3.25$)$; the NNTp for one additional participant not to need to use rescue medication was 4.5 ( $95 \% \mathrm{Cl} 2.5$ to 33) for ketorolac versus diclofenac (Analysis 2.2).

We judged the quality of evidence for this outcome as very low, due to unclear risk of bias for several domains among the included studies and the low total number of participants analyzed. We assessed the low total number of participants analyzed as being a contributing factor to imprecision. In addition, we assessed the findings for this outcome to be at high risk of publication bias. Data from additional unpublished studies demonstrating zero effect with only 120 participants would be sufficient to render the NNTp more than 10 , that is clinically insignificant. 


\section{Withdrawals due to lack of efficacy, adverse events, and for} any cause

Numbers of participants withdrawing were generally low, and reasons for withdrawal were inconsistently reported. We therefore judged the quality of evidence for these outcomes to be very low.

\section{Diclofenac versus placebo}

- The proportion of participants withdrawing due to lack of efficacy was $6 \%(8 / 140)$ with diclofenac versus $5 \%(7 / 128)$ with placebo (Analysis 1.4; participants $=268$; studies $=2$ ).

- The proportion of participants withdrawing due to AEs was $2 \%$ $(4 / 211)$ with diclofenac versus $0 \%(0 / 198)$ with placebo (Analysis 1.5; participants $=409$; studies $=4)$. The four withdrawals all occurred in one study (Gan 2012), and only one was suspected as being treatment-related (peripheral edema).

- The proportion of participants withdrawing for any cause was $11 \%(21 / 191)$ with diclofenac versus $17 \%$ (30/179) with placebo (Analysis 1.6; participants $=370$; studies $=4$ ). The majority of withdrawals occurred in one study (Gan 2012), primarily due to participants' requests.

\section{Diclofenac versus another NSAID}

- The proportion of participants withdrawing due to lack of efficacy was $9 \%$ (8/87) with diclofenac versus $7 \%$ (6/82) with another NSAID (Analysis 2.3; participants = 169; studies $=1)($ Gan 2012).

- The proportion of participants withdrawing due to AEs was $3 \%$ (4/138) with diclofenac versus $2 \%(2 / 129)$ with another NSAID (Analysis 2.4; participants $=267$; studies $=2$ ).

- The proportion of participants withdrawing for any cause was $18 \%(21 / 118)$ with diclofenac versus $15 \%(17 / 111)$ with another NSAID (Analysis 2.5; participants $=229$; studies $=2$ ). The vast majority of withdrawals occurred in one study (Gan 2012), primarily due to participants' requests.

\section{Participants experiencing any adverse event}

Not all studies reported the number of participants experiencing any $\mathrm{AE}$. The time over which AEs were measured varied. In one multiple-dose study (Gan 2012), AEs were measured through the end of the study (five to nine days after baseline observations).

\section{Diclofenac versus placebo}

Two studies (296 participants) included comparisons of diclofenac with placebo (Gan 2012; Seymour 2000).

- The proportion of participants reporting an AE with diclofenac was $71 \%(110 / 155)$

- The proportion of participants reporting an AE with placebo was $71 \%(100 / 141)$.

- The relative benefit of treatment compared with placebo was 0.99 (95\% Cl 0.86 to 1.14); the NNTH was not calculated (Analysis 1.7).

\section{Diclofenac versus another NSAID}

Two studies reported the number of participants experiencing any AE (Gan 2012; Garcia 1997). Seventy-four of 135 participants (55\%) receiving diclofenac experienced an AE versus 75 of $130(58 \%)$ receiving ketorolac (Analysis 2.6).
We assessed the quality of evidence for both comparisons as low, based on unclear risk of bias in several domains for the included studies, and the low total number of participants for each analysis.

\section{Participants experiencing any serious adverse event}

Serious AEs were rare overall, preventing meta-analysis (Analysis 1.8; Analysis 2.7). We assessed the quality of evidence for this outcome as low, based on the very low event rates and unclear risk of bias for several domains in the included studies.

Seven studies reported incidence of SAEs (Christensen 2011; Gan 2012; Garcia 1997; Leeson 2007; Maroo 2013; Sneyd 2007; Steffen 1994). Only one participant administered diclofenac suffered an SAE (Steffen 1994). The participant experienced a reduction in oxygen saturation to less than $90 \%$ at seven hours postdosing. However, in this study participants had free access to opioids via patient-controlled analgesia. Respiratory depression is a recognized side effect of opioid use. One participant receiving placebo experienced an SAE (Christensen 2011), appendicitis, which was deemed unrelated to therapy. One participant administered ketorolac experienced an abdominal hematoma (Gan 2012), which was thought to possibly be treatment-related.

\section{Specific adverse events}

Methods of assessment and the reporting of specific AEs were inconsistent across studies, as was the time over which the information was collected. Our AEs of interest (renal dysfunction, cardiovascular events, bleeding, and thrombophlebitis) occurred infrequently in all groups, therefore data were insufficient for metaanalysis. As with our analysis of SAEs, we assessed the quality of evidence to be low.

\section{Renal dysfunction}

Only one incidence of renal dysfunction was reported (Leeson 2007). This occurred in a participant receiving placebo and was defined as an increase in serum creatinine (data not specified) (Analysis 1.9; Analysis 2.8)

\section{Cardiovascular events}

In the three studies that reported cardiovascular events (Gan 2012; Garcia 1997; Leeson 2007), 2\% (4/188) of participants receiving diclofenac experienced an event versus $5 \%(7 / 128)$ of participants receiving placebo and $4 \%(5 / 130)$ of those receiving another NSAID. In the one study in which cardiovascular events occurred (not defined), none were considered to be treatment-related (Gan 2012). Comparisons between diclofenac and placebo or another NSAID were not statistically different (Analysis 1.10; Analysis 2.9).

\section{Bleeding}

In the two studies that compared diclofenac with placebo (Gan 2012; Leeson 2007), $4 \%$ of participants (6/140) receiving diclofenac experienced clinically significant bleeding versus $5 \%(6 / 128)$ of those receiving placebo (Analysis 1.11).

In the two studies comparing diclofenac with another NSAID (Gan 2012; Garcia 1997), 4\% of participants (5/135) receiving diclofenac experienced clinically significant bleeding versus $4 \%(5 / 130)$ of those receiving another NSAID (Analysis 2.10). 


\section{Thrombophlebitis}

In those studies that assessed thrombophlebitis, the majority employed a six-point scale (grade $0=$ "no reaction" to grade $5=$ "thrombosis with overt infection") and defined events as occurring in participants with a score of more than 1.

In the three studies that compared diclofenac with placebo (Christensen 2011; Gan 2012; Leeson 2007), 3\% of participants (6/191) receiving diclofenac experienced thrombophlebitis versus $6 \%(10 / 179)$ of those receiving placebo (Analysis 1.12).

In the three studies comparing diclofenac with another NSAID (Christensen 2011; Gan 2012; Garcia 1997), 2\% of participants (3/186) receiving diclofenac experienced an event versus 3\% (6/181) of those receiving another NSAID (Analysis 2.11).

\section{Opioid-related events}

We also performed a post hoc analysis of AEs that might be considered to be related to opioid use. There were insufficient data for any pooled analysis when comparing diclofenac with another NSAID. There were sufficient data for meta-analysis for two outcomes, nausea and vomiting, when comparing diclofenac with placebo.

Three studies (401 participants) compared rates of nausea with diclofenac versus placebo (Gan 2012; Leeson 2007; Seymour 2000).

- The proportion of participants reporting nausea with diclofenac was $17 \%$ (36/208, range $2 \%$ to $25 \%)$.

- The proportion of participants reporting nausea with placebo was $25 \%$ (48/193, range $8 \%$ to $38 \%$ ).

- The relative benefit of treatment compared with placebo was 0.68 ( $95 \% \mathrm{Cl} 0.47$ to 0.99$)$; the NNTp for one additional participant not to report nausea compared with placebo was 12.5 (95\% Cl 6.3 to > 100) (Analysis 1.13).

The same three studies (401 participants) compared rates of vomiting with diclofenac versus placebo.

- The proportion of participants experiencing an incidence of vomiting with diclofenac was $6 \%$ (13/208, range $0 \%$ to $12 \%)$.

- The proportion of participants experiencing an incidence of vomiting with placebo was $13 \%$ (25/193, range $6 \%$ to $17 \%)$.

- The relative benefit of treatment compared with placebo was 0.49 (95\% Cl 0.26 to 0.91$)$; the NNTp for one additional participant not to experience vomiting compared with placebo was 14.3 (95\% Cl 7.7 to 100$)$ (Analysis 1.14).

\section{Subgroup analysis, sensitivity analysis, and investigation of heterogeneity}

Where there were sufficient data, we analyzed the effect of different doses separately. Doses assessed within and among studies doses ranged from $3.75 \mathrm{mg}$ to $75 \mathrm{mg}$. The most commonly administered dose was 75 mg (Christensen 2011; Garcia 1997; Leeson 2007; Maroo 2013; Seymour 2000; Steffen 1994). We used the highest dose assessed in each study for our initial analysis. There were sufficient data for a dose-effect analysis for our primary outcome for only one alternative dose, $18.75 \mathrm{mg}$ (Christensen 2011; Gan 2012). We compared participants receiving $18.75 \mathrm{mg}$ with placebo, another NSAID, and with the higher dose of diclofenac for the number of participants with at least $50 \%$ pain relief at six hours.
- For the two included studies, the high-dose analysis (75 mg in Christensen 2011 and 37.5 mg in Gan 2012) demonstrated a relative benefit of treatment compared with placebo of 1.9 $(95 \% \mathrm{Cl} 1.4$ to 2.4 ), whereas for the group receiving $18.75 \mathrm{mg}$ of diclofenac, the relative benefit versus placebo was $1.6(95 \% \mathrm{Cl}$ 1.2 to 2.1 ) (Analysis 1.15).

- In comparison to another NSAID, the high-dose analysis demonstrated a relative benefit of $0.9(95 \% \mathrm{Cl} 0.8$ to 1.1$)$, whereas for the group receiving $18.75 \mathrm{mg}$, the relative benefit was 0.78 (95\% Cl 0.65 to 0.93 ) (Analysis 2.12).

- For the direct comparison of high-dose versus low-dose diclofenac (18.75 mg), the proportion of participants with at least $50 \%$ pain relief was $66 \%(90 / 137)$ in the high-dose arm versus $57 \%(77 / 135)$ in the low-dose arm. The relative benefit of high-dose versus low-dose diclofenac was $1.2(95 \% \mathrm{Cl} 1.0$ to 1.4$)$, that is the difference was not statistically significant (Analysis 3.1).

We also planned to analyze different formulations of parenteral diclofenac separately. There were insufficient data for subgroup meta-analysis. Two studies performed head-to-head analyses of different formulations. Leeson 2007 compared a novel formulation of diclofenac (Dyloject) that was administered as a small-volume IV bolus, with the traditional formulation (Voltarol), which was infused over 30 minutes. For our primary outcome, the proportion of participants with at least $50 \%$ pain relief over four hours was $77 \%(41 / 53)$ for participants receiving the new formulation versus $68 \%(34 / 50)$ for those receiving the traditional formulation. In addition, $6 \%(3 / 53)$ of participants experienced thrombophlebitis (as defined above) in the bolus group versus 12\% (6/50) of those receiving the longer infusion. Similarly, Maroo 2013 compared a reduced-volume propylene-glycol-free formulation (Dynapar AQ), administered as an IV bolus over 5 to 60 seconds, with the traditional formulation (Voveran), diluted to $100 \mathrm{~mL}$ to $500 \mathrm{~mL}$, buffered with sodium bicarbonate, and infused over 30 minutes. For our primary outcome, the proportion of participants with at least 50\% pain relief over four hours was 69\% (121/175) for participants receiving the new formulation versus $63 \%(110 / 175)$ for those receiving the traditional formulation. In addition, only 2 of 175 participants (1\%) experienced thrombophlebitis in the bolus group versus $27 \%(47 / 175)$ in the group receiving the longer infusion.

For meta-analyses with an $\mathrm{I}^{2}$ score of greater than $50 \%$, we reanalyzed the data using a random-effects model. Two analyses that had previously demonstrated superiority of diclofenac over placebo were now no longer statistically significant (Analysis 1.1; Analysis 1.15). For Analysis 1.1, the number of participants with at least $50 \%$ pain relief at six hours, one of the studies, Seymour 2000, had a higher rate of events in the placebo group than the other two studies (Leeson 2007; Sneyd 2007). The reasons for this higher rate in the placebo group are unclear. All three studies employed a dental model, that is third molar extraction. Leeson 2007 and Seymour 2000 both administered $75 \mathrm{mg}$ of diclofenac to the active group, whereas Sneyd 2007 administered $50 \mathrm{mg}$. Residual effects of general anesthesia may account for higher rates in placebo groups, but participants in Sneyd 2007 also received general anesthesia and a higher intraoperative opioid dose than Seymour 2000. Participant withdrawal criteria and imputation of missing data may have contributed to higher placebo rates. In Seymour 2000, participants using rescue analgesia during the first hour were excluded from the study; however, it is unclear how many participants were excluded 
for this reason. For those taking remedication after one hour, LOCF was employed. For Analysis 1.15, which assessed the number of participants with at least $50 \%$ pain relief for the lower diclofenac dose of $18.75 \mathrm{mg}$, we included two studies: Christensen 2011 and Gan 2012. Gan 2012 had a much higher event rate in the placebo group than Christensen 2011. This may be due to the different surgical models (Gan 2012 abdominal, Christensen 2011 dental) or the residual effects of general anesthesia in Gan 2012 (Christensen 2011 employed local anesthesia), or both.

\section{DISCUSSION}

\section{Summary of main results}

We found eight studies for inclusion in this review. Study designs were similar, in that most required participants to report moderate to severe pain postoperatively before being assigned to one of the planned intervention groups. Most were single-dose studies that measured pain relief or pain intensity difference after an intervention was administered. Doses of diclofenac varied among studies, although the most commonly employed dose was 75 $\mathrm{mg}$, that is the dose used in clinical practice. Some studies compared multiple doses. In addition, different formulations of parenteral diclofenac were employed in some studies, with newer formulations being produced with the aim of ease of administration, faster onset of action, and a lower incidence of thrombophlebitis than traditional formulations. Despite the similarity of study designs, considerable heterogeneity existed in many of the pooled analyses. There were no obvious explanations for the differences in event rates among studies. There were insufficient data to draw conclusions regarding differences in efficacy or safety based on dose or formulation. The results of the studies available for parenteral diclofenac suggest that it is superior to placebo and similar to other NSAIDs, with respect to analgesic effect, and that it has a similar safety profile to both. However, the quality of evidence across outcomes was generally low, primarily due to the low number of participants and events and unexplained heterogeneity among studies.

\section{Efficacy}

Analysis of our primary outcome, participants achieving at least $50 \%$ maximum pain relief, demonstrated that diclofenac was superior to placebo and similar to other NSAIDs. Analysis of lowdose versus higher-dose diclofenac did not demonstrate a doseresponse effect, although this was based on data from only two studies. The relative benefit of diclofenac compared with placebo over four hours was $2.8(95 \% \mathrm{Cl} 2.0$ to 4.0$)$. Almost three times as many participants achieved at least $50 \%$ pain relief in the diclofenac group compared with those receiving placebo. The NNTB for one additional participant to benefit compared with placebo was 2.4 (95\% Cl 1.9 to 3.1), which indirectly compares favorably with oral analgesics used in the same setting (Moore 2011b), and similarly to $20 \mathrm{mg}$ of parenteral parecoxib, the only other parenteral NSAID to be analyzed in a Cochrane Review of postoperative pain (Lloyd 2009). Of note, parecoxib is not available in the USA. The relative benefit at six hours was slightly less (RR $1.8,95 \% \mathrm{Cl} 1.4$ to 2.2 ), suggesting that the analgesic effect of diclofenac starts to decline after four hours. Parenteral diclofenac also demonstrated lower (i.e. superior) NNTBs at four and six hours versus those found in a Cochrane Review of parenteral formulations of paracetamol (acetaminophen) for postoperative pain, where NNTBs were 5 and 6 at four and six hours, respectively (McNicol
2016). Direct comparison of diclofenac with other NSAIDs within this review suggested similar efficacy (RR $0.94,95 \% \mathrm{Cl} 0.83$ to 1.06 ), but subgroup analysis where a lower dose of $18.75 \mathrm{mg}$ of diclofenac was compared with parenteral ketorolac demonstrated statistical inferiority (RR $0.78,95 \% \mathrm{Cl} 0.65$ to 0.93 ), suggesting that lower doses may be less effective.

For secondary efficacy outcomes, median time to remedication was longer, and the number of participants requesting rescue analgesia was lower (NNTp 3.0,95\% $\mathrm{Cl} 2.2$ to 4.5 ) in those receiving diclofenac versus those receiving placebo. There were insufficient data to analyze these outcomes in head-to-head comparisons with another NSAID. Lastly, there were insufficient data to perform pooled analyses of the number of participants withdrawing from a trial due to lack of efficacy.

\section{Safety}

Total $A E$ rates were very similar to those with placebo and with other NSAIDs. There was a lack of data for our planned analyses of specific AEs associated with NSAID use, that is renal dysfunction, cardiovascular events, and bleeding, as well as for thrombophlebitis, a recognized issue with parenteral diclofenac use. This no doubt reflects the relative infrequency with which these events occur, particularly in studies of short duration. Limited data from two studies that compared rates of thrombophlebitis with newer formulations of diclofenac versus traditional formulations suggest that rates are lower with newer formulations (Leeson 2007; Maroo 2013). Data from the one study that compared rates of bleeding with diclofenac versus ketorolac did not show a difference, therefore the hypothesis that the balanced COX-1/COX-2 profile of diclofenac results in a reduced rate of bleeding versus the COX-1 specific ketorolac was not confirmed in this review (Gan 2012).

We performed a post hoc analysis of AEs associated with opioid use to assess whether a reduction in requirement for rescue analgesia (typically an opioid) in turn resulted in a reduction in the rate of occurrence of these events. There were statistically significant reductions in the rates of nausea and vomiting when diclofenac was compared to placebo, but insufficient data for any other comparison. This may be due to studies not actively assessing opioid-induced side effects.

Only one participant experienced an SAE, respiratory depression, when administered diclofenac, and this was unlikely to be related to the intervention (Steffen 1994).

Lastly, withdrawals due to AEs were vary rare in all groups, again reflecting the acute nature of such studies.

\section{Overall completeness and applicability of evidence}

The primary limitation of our review was the small number of studies, participants, and events for most analyses. The limited data prevented us from interpreting safety data in particular with any confidence.

Included studies reported data from comparisons of diclofenac with both placebo and with active controls that are routinely used to treat postoperative pain. The studies covered a range of commonly performed surgeries, but no studies were performed in patients undergoing major or cardiovascular surgeries. The lack of studies in major surgeries may explain the lack of data with 
respect to reduction in opioid consumption and opioid-induced AEs, as opioids would be a major component of the postoperative regimen in more invasive procedures. The lack of studies in cardiovascular surgeries is perhaps not surprising given guidelines from regulatory organizations that recommend avoiding NSAIDs in patients undergoing coronary artery bypass surgery (Jenkins 2005).

The mean age of participants across studies indicates that few elderly participants were assessed. The lack of data is unfortunate, given evidence suggesting AE rates related to acute NSAID use are notably higher in this population (Strom 1996).

\section{Quality of the evidence}

When assessing the quality of findings using GRADE, we generally ranked the quality of the evidence as low across all efficacy and safety outcomes, as shown in Summary of findings 1 and Summary of findings 2. 'Low quality' means that our confidence in the effect estimate is limited, and the true effect may be substantially different from the estimate of the effect. Many individual studies had unclear risk of bias for issues such as incomplete outcome data, selective reporting, and small size, and none of the trials was unequivocally at low risk of bias for all criteria. The lack of clarity regarding many of the risks of bias may be due to the reporting standards of journals rather than any fundamental flaws in the methodology of the studies, in which case we would assess the quality of evidence as being moderate. For the outcomes for which we were able to perform pooled analysis, we further downgraded the quality of evidence due to issues with imprecision, unexplained heterogeneity between studies, and low overall numbers of participants and events.

\section{Potential biases in the review process}

We attempted to minimize the potential for publication bias related to unpublished or unidentified studies by assessing clinical trial registries and multiple databases, respectively. In addition, we assessed the impact publication bias may have on our findings.

For analysis of our primary outcome of pain relief, we used the number of participants with $30 \%$ pain relief, rather than at least $50 \%$ pain relief, for one study (Analysis 1.2; Analysis 2.1) (Gan 2012), as these were the only data available for this study. Not surprisingly, more participants achieved at least 30\% pain relief in this study than the proportion of those achieving at least $50 \%$ in the other studies included in these analyses. However, NNTBs for $30 \%$ and $50 \%$ pain relief have been shown to be similar over six hours when effective analgesics are compared with placebo (Moore 1997c; Moore 2005), given that event rates tend to change proportionally in both groups when different cutpoints of pain relief are measured.

We did not assess time to onset of analgesia as an efficacy outcome. One study of a newer diclofenac formulation demonstrated a faster onset of analgesia with this formulation than with the traditional formulation that required slow infusion (Leeson 2007). This may be important to patients.

We are not aware of any other potential biases.

\section{Agreements and disagreements with other studies or reviews}

There are not, to our knowledge, any other systematic reviews of IV diclofenac for postoperative pain. Derry 2015 conducted a systematic review and meta-analysis of single doses of various formulations of oral diclofenac for postoperative pain, assessing similar outcomes to our review. They found similar results for efficacy, including an NNTB of $2.1(95 \% \mathrm{Cl} 1.9$ to 2.5) for diclofenac potassium $50 \mathrm{mg}$ for the proportion of participants with at least $50 \%$ of maximum pain relief over four to six hours postinterventions. Unlike our review, the majority of included studies employed a dental model. It has been suggested that NSAIDs appear to be more effective in dental models than in other postoperative models, although this has not been confirmed (Barden 2004). However, four of the studies used in our analyses of pain relief versus placebo also employed the dental model, suggesting that oral and IV diclofenac may have similar efficacy, although this does not account for situations in which the enteral route is not available. Safety analyses also had similar findings, that is events occurred too infrequently to enable any firm conclusions to be made about either formulation's side effect profile.

\section{AUTHORS' CONCLUSIONS}

\section{Implications for practice}

\section{For adults with moderate to severe postoperative pain}

The amount and quality of evidence for the use of diclofenac for treating postoperative pain is low. The evidence we have indicates that postoperative administration of diclofenac offers good pain relief for the majority of patients, but further research may impact this estimate. Adverse events appear to occur at a similar rate to other non-steroidal anti-inflammatory drugs (NSAIDs), but information is insufficient to assess whether diclofenac has a different rate of bleeding, renal dysfunction, or cardiovascular events when compared with other NSAIDs. We have insufficient information to confirm that newer formulations of diclofenac are more effective and safer than traditional formulations.

\section{For clinicians}

The amount and quality of evidence for the use of diclofenac for treating postoperative pain is low. The evidence we have indicates that postoperative administration of diclofenac offers good pain relief for the majority of patients, but further research may impact this estimate. Adverse events appear to occur at a similar rate to other NSAIDs, but information is insufficient to assess whether diclofenac has a different rate of bleeding, renal dysfunction, or cardiovascular events when compared with other NSAIDs. We have insufficient information to confirm that newer formulations of diclofenac are more effective and safer than traditional formulations.

\section{For policymakers}

The amount and quality of evidence for the use of diclofenac for treating postoperative pain in is low, and policymakers should exercise caution when recommending its use in postoperative guidelines. The evidence we have indicates that postoperative administration of diclofenac offers good pain relief for the majority of patients, but further research may impact this estimate. Adverse events appear to occur at a similar rate to other NSAIDs, but 
information is insufficient to assess whether diclofenac has a lower rate of bleeding, renal dysfunction, or cardiovascular events when compared with other NSAIDs. We have insufficient information to confirm that newer formulations of diclofenac are more effective and safer than traditional formulations.

\section{For funders}

The amount and quality of evidence for the use of diclofenac for treating postoperative pain is low. The evidence we have indicates that postoperative administration of diclofenac offers good pain relief for the majority of patients, but further research may impact this estimate. Adverse events appear to occur at a similar rate to other NSAIDs, but information is insufficient to assess whether diclofenac has a lower rate of bleeding, renal dysfunction, or cardiovascular events when compared with other NSAIDs. We also have insufficient information to confirm that newer, more expensive formulations of diclofenac are more effective and safer than traditional formulations, or that any potential differences in efficacy (pain relief, time to onset of analgesia, requirement for rescue analgesia), safety (rate of thrombophlebitis), or administration costs (no requirement for dilution, quicker administration) translate to a lower overall cost of therapy. Similarly, it is unclear whether the increased cost of parenteral formulations of diclofenac versus oral formulations is offset by increased effectiveness and reduced overall costs.

\section{Implications for research}

\section{General}

While more studies are required to be able to more accurately estimate efficacy and safety of parenteral diclofenac, there is a lack of studies specifically in major and cardiovascular surgeries and in elderly populations.

\section{Design}

The studies included in our review were designed to detect differences in efficacy between interventions. However, further studies that compare different doses of diclofenac may establish whether doses lower than those currently employed are equally effective. Serious adverse events and adverse events associated with NSAIDs were rare or very rare. Epidemiological studies may more accurately determine the adverse profile of diclofenac in this setting.

\section{Outcomes}

Endpoints and the pain scoring scales used to assess them in these studies have been extensively validated. The majority of studies assessed pain relief after administration of each intervention, an outcome shown to be clinically important to patients. While the cost of newer formulations of parenteral diclofenac varies between (and in some cases within) countries, it is typically considerably higher than older formulations or oral formulations. Studies conducting cost-benefit analyses may determine whether this increased cost is offset by increased effectiveness and reduced overall costs.

\section{ACKNOWLEDGEMENTS}

This protocol was based on a series of reviews published in the Cochrane Library that assess single or combined analgesic agents for postoperative pain, and from suggested wording from the Cochrane Pain, Palliative and Supportive Care Review Group.

Cochrane Review Group funding acknowledgement: this project was supported by the National Institute for Health Research (NIHR), via Cochrane Infrastructure funding to the Cochrane Pain, Palliative and Supportive Care Review Group. The views and opinions expressed therein are those of the authors and do not necessarily reflect those of the Systematic Reviews Programme, NIHR, National Health Service (NHS), or the Department of Health. 
R E F E R E N C E S

\section{References to studies included in this review}

Christensen 2011 \{published data only\}

Christensen K, Daniels S, Bandy D, Ernst CC, Hamilton DA, Mermelstein $\mathrm{FH}$, et al. A double-blind placebo-controlled comparison of a novel formulation of intravenous diclofenac and ketorolac for postoperative third molar extraction pain. Anesthesia Progress 2011;58(2):73-81.

\section{Gan 2012 \{published data only\}}

Gan TJ, Daniels SE, Singla N, Hamilton DA, Carr DB. A novel injectable formulation of diclofenac compared with intravenous ketorolac or placebo for acute moderate-to-severe pain after abdominal or pelvic surgery: a multicenter, double-blind, randomized, multiple-dose study. Anesthesia and Analgesia 2012;115(5):1212-20.

\section{Garcia 1997 \{published data only\}}

Garcia DC, Espinosa JD, Marti ML. Analgesic efficacy of both lisine clonixinate and diclofenac for the postsurgical pain during ambulatory surgery [Eficacia analgesica del clonixinato de lisina y del diclofenac en dolor postoperatorio de cirugia ambulatoria]. Prensa Medica Argentina 1997;84(10):1061-5.

\section{Leeson 2007 \{published data only\}}

Leeson RM, Harrison S, Ernst CC, Hamilton DA, Mermelstein FH, Gawarecki DG, et al. Dyloject, a novel injectable diclofenac formulation, offers greater safety and efficacy than Voltarol for postoperative dental pain. Regional Anesthesia and Pain Medicine 2007;32(4):303-10.

\section{Maroo 2013 \{published data only\}}

Maroo SKH, Kakar PN, Varshney AK, Subnis BM, Bogra JA, Mohite SN, et al. Dynapar AQ iv bolus injection for postoperative pain. International Journal of Pharmaceutical Sciences Review and Research 2013;4(12):4729-35.

\section{Seymour 2000 \{published data only\}}

Seymour RA, Moore U, Hawkesford J, Coulthard P, JacksonLeech D, Thomas D, et al. An investigation into the efficacy of intravenous diclofenac in post-operative dental pain. European Journal of Clinical Pharmacology 2000;56(6-7):447-52.

\section{Sneyd 2007 \{published data only\}}

Sneyd JR, Langton JA, Allan LG, Peacock JE, Rowbotham DJ. Multicentre evaluation of the adenosine agonist GR79236X in patients with dental pain after third molar extraction. British Journal of Anaesthesia 2007;98(5):672-6.

\section{Steffen 1994 \{published data only\}}

Steffen P, Wiedemann S, Georgieff M, Hahnel J, Treiber H, Seeling W. Combined intravenous administration of diclofenac and apazone for postoperative analgesia. A randomized study of 112 patients with access to i. v. on-demand analgesia after minor orthopaedic operations [Kombinierte intravenose gabe von diclofenac und azapropazon zur postoperativen analgesie. Eine randomisierte doppelblindstudie an 112 unfallchirurgischen patienten mittels der intravenosen ondemand-analgesie.]. Schmerz (Berlin, Germany) 1994;8:235-42.

\section{References to studies excluded from this review}

Aho 1991 \{published data only\}

Aho MS, Erkola OA, Scheinin H, Lehtinen AM, Korttila KT. Effect of intravenously administered dexmedetomidine on pain after laparoscopic tubal ligation. Anesthesia and Analgesia 1991;73(2):112-8.

Albrecht 1992 \{published data only\}

Albrecht J. The combination of diclofenac and codeine in the treatment of postoperative pain. Die Medizinische Welt 1992;43:515-9.

\section{Al-Khtoum 2006 \{published data only\}}

Al-Khtoum N. Comparative study of local infiltration of bupivacaine and parenteral administration of diclofenac sodium for post tonsillectomy pain in adults. Middle East Journal of Family Medicine 2006;14(3):53.

\section{Anil 2016 \{published data only\}}

Anil A, Kaya FN, Yavascaoglu B, Mercanoglu EE, Turker G, Demirci A. Comparison of postoperative analgesic efficacy of intraoperative single-dose intravenous administration of dexketoprofen trometamol and diclofenac sodium in laparoscopic cholecystectomy. Journal of Clinical Anesthesia 2016;32:127-33.

\section{Arslan 2009 \{published data only\}}

Arslan Y, Coruh T, Yapici N, Aykac Z. The effects of paracetamol, a non-steroidal anti-inflammatory drug (diclofenac sodium) and tramadol in the treatment of postoperative pain after cardiac surgery. Journal of Cardiothoracic and Vascular Anesthesia 2009;1:S13.

\section{Baroni 1983 \{published data only\}}

Baroni L, Grossi E, Trombetta N. Multicenter study on the use of injectable diclofenac in pain states: analysis of the clinical data on 1873 patients [Indagine multicentrica sull'impiego del diclofenac iniettabile negli stati dolorosi: un'analisi dei dati clinici relativi a 1873 pazienti]. La Clinica Terapeutica 1983;106(6):447-56.

\section{Bhoyar 2015 \{published data only\}}

Bhoyar K, Patil V, Shetmahajan M. Opioid sparing effect of diclofenac sodium when used as an intra-operative analgesic during maxillofacial cancer surgeries. Indian Journal of Anaesthesia 2015;59(11):748-52.

\section{Bossi 1984 \{published data only\}}

Bossi L, Galante G, Conoscente F, Avvisati O, Grossi E. Treatment of postoperative pain: double-blind comparison of diclofenac and pentazocine [Trattamento del dolor postoperatario: Confronto in doppio cieco fra diclofenac e pentazocina]. Minerva Anestesiologica 1984;50(7-8):373-8.

Bricker 1987 \{published data only\}

Bricker SR, Savage ME, Hanning CD. Peri-operative blood loss and non-steroidal anti-inflammatory drugs: an investigation 
using diclofenac in patients undergoing transurethral resection of the prostate. European Journal of Anaesthesiology 1987;4(6):429-34.

\section{Campbell 1990 \{published data only\}}

Campbell WI, Kendrick R, Patterson C. Intravenous diclofenac sodium. Does its administration before operation suppress postoperative pain? Anaesthesia 1990;45(9):763-6.

\section{Carlborg 1987 \{published data only\}}

Carlborg L, Lindoff C, Hellman A. Diclofenac versus pethidine in the treatment of pain after hysterectomy. European Journal of Anaesthesiology 1987;4(4):241-7.

\section{Chelly 2013 \{published data only\}}

Chelly JE, Singla SK, Melson TI, Lacouture PG, Paadre S, Carr DB. Safety of a novel parenteral formulation of diclofenac after major orthopedic or abdominal/pelvic surgery in a population including anticoagulated, elderly or renally insufficient patients: an open-label, multiday, repeated dose clinical trial. Pain Medicine (Malden, Mass.) 2013;14(5):749-61.

\section{Chongsomchai 2009 \{published data only\}}

Chongsomchai C, Kemthong W, Thienthong S. A placebocontrolled, double-blind, randomized study of singledose intravenous diclofenac for pain relief after cesarean section. International Journal of Gynaecology and Obstetrics 2009;107(Suppl 2):S475.

\section{Daniels 2013 \{published data only\}}

Daniels S, Melson T, Hamilton DA, Lang E, Carr DB. Analgesic efficacy and safety of a novel injectable formulation of diclofenac compared with intravenous ketorolac and placebo after orthopedic surgery: a multicenter, randomized, double-blinded, multiple-dose trial. Clinical Journal of Pain 2013;29(8):655-63.

\section{Daniels 2016 \{published data only\}}

Daniels SE, Gan TJ, Hamilton DA, Singla N, Lacouture PG, Johnson $\mathrm{O}$, et al. A pooled analysis evaluating renal safety in placebo- and active comparator-controlled Phase III trials of multiple-dose injectable HPßCD-diclofenac in subjects with acute postoperative pain. Pain Medicine 2016;17(12):2378-88

\section{De La Paz 2009 \{published data only\}}

De La Paz-Estrada C, Cespedes-Cuenca Y. Diclofenac vs metamizol in preventive analgesia for gynecological surgery [Diclofenaco vs metamizol en analgesia preventiva para cirugia ginecologica]. Revista Mexicana de Anestesiologia 2009;32(4):209-13.

\section{Elliott 2000 \{published data only\}}

Elliott D, Rasmussen S, Simmons S. Low dose intrathecal morphine and diclofenac sodium for pain relief after caesarean section [abstract]. Anaesthesia and Intensive Care 2000;28(1):105.

\section{Forrest 2002 \{published data only\}}

Forrest JB, Camu F, Greer IA, Kehlet H, Abdalla M, Bonnet F, et al. Ketorolac, diclofenac, and ketoprofen are equally safe for pain relief after major surgery. British Journal of Anaesthesia 2002;88(2):227-33.

Frame 1986 \{published data only\}

Frame JW, Rout PG. A comparison of the analgesic efficacy of flurbiprofen, diclofenac, dihydrocodeine/paracetamol and placebo following oral surgery. British Journal of Clinical Practice 1986;40(11):463-7.

\section{Frezza 1985 \{published data only\}}

Frezza R, Bolognesi P, Bernardi F. Comparison of the action of 3 non-steroidal anti-inflammatory agents in the control of postoperative pain. Effectiveness of NSAID against pain. Attualita Dentale 1985;1(30):40-2.

\section{Gan 2016 \{published data only\}}

Gan TJ, Singla N, Daniels SE, Lacouture PG, Min LH, Reyes CRD, et al. Cardiovascular safety of hydroxypropyl-beta-cyclodextrindiclofenac in the management of acute postsurgical pain: a pooled analysis of 2 randomized, double-blind, placebo- and active comparator-controlled phase III clinical trials. Journal of Clinical Anesthesia 2016;31:249-58.

Gan 2017 \{published data only\}

Gan TJ, Singla N, Daniels SE, Hamilton DA, Lacouture PG, Reyes CRD, et al. Postoperative opioid sparing with injectable hydroxypropyl-beta-cyclodextrin-diclofenac: pooled analysis of data from two Phase III clinical trials. Journal of Pain Research 2017;10:15-29.

\section{Gunes 2011 \{published data only\}}

Gunes Y, Unlugenc H, Yilmaz DM, Ozcengiz D. Management of acute craniotomy pain: the analgesic effect of diclofenac sodium-tramadol or paracetamol-tramadol. Neurosurgery Quarterly 2011;21(4):236-9.

\section{Henrikson 1982 \{published data only\}}

Henrikson PA, Thilander H, Wahlander LA. Absorption and effect of diclofenac-sodium after surgical removal of a lower wisdom tooth. Current Therapeutic Research, Clinical and Experimental 1982;31(1):20-6.

\section{Hernandez 1997 \{published data only\}}

Hernandez LG, Barrientos BG, Lopez DF. Comparison of analgesia provided by diclofenac and dipirone in postoperated patients with abdominal surgery [Comparacion de la analgesia proporcionada por diclofenaco y dipirona en pacientes posoperados de cirugia de abdomen]. Anestesia en Mexico 1997;9(4):137-42.

\section{Hultman 1989 \{published data only\}}

Hultman E, Rupprecht J, Bjorkman R, Niemand D. Diclofenac vs meperidine and placebo for pain relief after knee surgery. Schmerz Pain Douleur 1989;10(2):63-7.

\section{Hynes 1997 \{published data only\}}

Hynes D, McCarroll M, Gerin M, Insuasty JH, Van Holder K. Propacetamol vs diclofenac and placebo for postoperative pain control after total hip arthroplasty [abstract]. European Journal of Anaesthesiology 1997;14(Suppl 15):58. 
Hynes 2006 \{published data only\}

Hynes D, McCarroll M, Hiesse-Provost O. Placebo use to compare the analgesic efficacy of parenteral paracetamol and diclofenac in post-operative orthopaedic pain: authors' reply. Acta Anaesthesiologica Scandinavica 2006;50(9):1168-73.

Iwabuchi 1980 \{published data only\} Iwabuchi T, Soma S. Use of Voltaren for relief of post-extraction pain. Shikai Tenbo 1980;55(2):367-70.

\section{Izquierdo 1995a \{published data only\}}

Izquierdo E, Fabregas N, Valero R, Salvador L, Soley R, Nalda MA. Postoperative analgesia in herniated disk surgery. Comparative study of diclofenac, lysine acetylsalicylate, and ketorolac [Analgesia postoperatoria en la cirugiade hernia discal. Estudio comparativode diclofenaco, acetilsalicilato de lisina y ketorolaco]. Revista Espanolade Anestesiologia y Reanimacion 1995;42(8):316-9.

\section{Kilickaya 2012 \{published data only\}}

Kilickaya R, Unlugenc IH, Gunduz M, Isik G. Comparison of the effects of IV dexketoprofen, lornoksicam and diclophenac sodium on postoperative analgesia and tramadol consumption. Pain Practice 2012;12:141.

\section{Kose 2012 \{published data only\}}

Kose O, Satlam HS, Kumsar S, Budak S, Adsan O. Analgesic therapy after transurethral resection of prostate (TUR-P). Journal of Endourology/Endourological Society 2012;26(Suppl 1):A266

\section{Kvolik 2010 \{published data only\}}

Kvolik S, Djapic D, Kristek J, Rakipovic-Stojanovic A, Ivic $D$, Sakic K, et al. Postoperative wound infiltration with levobupivacaine $0.5 \%$ is superior to the diclofenac $1 \mathrm{mg} /$ $\mathrm{kg}$ three times daily in the breast cancer patients. Regional Anesthesia and Pain Medicine 2010;35(5):E124.

\section{Labrada 2004 \{published data only\}}

Labrada A, Jimenez-Garcia Y. Preventive multimodal analgesia: a comparative study [Analgesia multimodal preventiva: estudio comparativo]. Revista de la Sociedad Espanola del Dolor 2004;11(3):122-8.

\section{Laitinen 1992 \{published data only\}}

Laitinen J, Nuutinen L, Kiiskila EL, Freudenthal Y, Ranta P, Karvonen J. Comparison of intravenous diclofenac, indomethacin and oxycodone as post-operative analgesics in patients undergoing knee surgery. European Journal of Anaesthesiology 1992;9(1):29-34.

\section{Litke 1997 \{published data only\}}

Litke J, Bohatyrewicz A, Mikulski K. Diclofenac for treatment of postoperative pain after hip arthroplasty in older patients. Chirurgia Narzadow Ruchu i Ortopedia Polska 1997;62(5):415-9.

\section{Lopez-Carriches 2005 \{published data only\}}

Lopez-Carriches C, Martinez-Gonzalez JM, Donado-Rodriguez M. Analgesic efficacy of diclofenac versus methylprednisolone in the control of postoperative pain after surgical removal of lower third molars. Medicina Oral, Patologia Oral y Cirugia Bucal 2005;10(5):432-9.

Lovett 1994 \{published data only\}

Lovett PE, Stanton SL, Hennessy D, Cashman JN. Pain relief after major gynaecological surgery. British Journal of Nursing 1994;3(4):159-62.

\section{Manso 1991 \{published data only\}}

Manso FJ, Kaiser C, Calatayud J, Carrillo JS, Guisado B, Barberia E. Effectiveness and tolerance of diclofenac vs. nefopam in treatment of postoperative pain. Revista Europea de Odontoestomatología 1991;3(2):111-4.

\section{Mastronardi 1988 \{published data only\}}

Mastronardi P, D'Onofrio M, Scanni E, Pinto M, Frontespezi S, Ceccarelli MG, et al. Analgesic activity of flupirtine maleate: a controlled double-blind study with diclofenac sodium in orthopaedics. Journal of International Medical Research 1988;16(5):338-48

\section{Mehrotra 1998 \{published data only\}}

Mehrotra A, Kothari D, Upadhyay SC, Shrivastava S. Postoperative analgesia: intramuscular tramadol vs. diclofenac sodium. Journal of Anaesthesiology Clinical Pharmacology 1998;14(1):81-2.

\section{Metternich 1998 \{published data only\}}

Metternich FU, Brusis T, Parandeh-Shab F. Pain therapy after tonsillectomy in adults [Schmerztherapie nach tonsillektomie beim erwachsenen]. HNO 1998;46(1):50-5.

\section{Moffat 1990 \{published data only\}}

Moffat AC, Kenny GN, Prentice JW. Postoperative nefopam and diclofenac. Evaluation of their morphine-sparing effect after upper abdominal surgery. Anaesthesia 1990;45(4):302-5.

Naclerio-Homem 1996 \{published data only\}

Naclerio-Homem MG, Campos AC, Deboni MCZ, Prado MP, Medalha P, Cardoso WP, et al. Comparative evaluation of cetoprofen and diclofenac at the management of pain after tooth extraction. (IADR Abstract 1996). Journal of Dental Research 1996;75(5 Divisional Abstracts):1115 (Abs No 298).

\section{Nelson 1993 \{published data only\}}

Nelson WE, Henderson RC, Almekinders LC, DeMasi RA, Taft TN. An evaluation of pre- and postoperative nonsteroidal antiinflammatory drugs in patients undergoing knee arthroscopy. A prospective, randomized, double-blinded study. American Journal of Sports Medicine 1993;21(4):510-6.

\section{Pellerin 1989 \{published data only\}}

Pellerin I, Sommi F, Castiglioni C. Randomized double-blind study of the analgesic efficacy of nabumetone vs. diclofenac, tenoxicam and placebo for the treatment of postoperative pain [Nabumetone. Studio randomizzato in doppio cieco sull'efficacia analgesica del nabumetone vs. diclofenac, tenoxicam e placebo nel dolore post operatorio]. Basi Razionali della Terapia 1989;19(10):583-6. 
Philip 1985 \{published data only\}

Philip PJ, Lema LE, Carneiro PM. A comparison of diclofenac sodium (Voltaren) and pethidine as post-operative analgesics in major elective surgical procedures. East African Medical Journal 1985;62(9):666-71.

\section{Rautela 1998 \{published data only\}}

Rautela RS, Kumar A, Gupta A, Bhattacharya A. A randomised double blind comparison of ketorolac and diclofenac for post-operative analgesia following major gynaecological surgery. Journal of Anaesthesiology Clinical Pharmacology 1998;14(1):79-81.

Reyes 1988 \{published data only\}

Reyes F. Randomized comparative double-blind study of diclofenac sodium and dipyrone in postoperative pain. Compendium de Investigaciones Clinicas Latinoamericanas 1988;8(1):65-73.

\section{Samimi 2014 \{published data only\}}

Samimi SS, Valadan M, Davari TF. Comparison between diclofenac and paracetamol for treatment of pain after total abdominal hysterectomy. Regional Anesthesia and Pain Medicine 2014;39(5 Suppl 1):E241.

\section{Sandin 1993 \{published data only\}}

Sandin R, Sternlo JE, Stam H, Brodd B, Bjorkman R. Diclofenac for pain relief after arthroscopy: a comparison of early and delayed treatment. Acta Anaesthesiologica Scandinavica 1993;37(8):747-50.

\section{Silvanto 2002 \{published data only\}}

Silvanto M, Lappi M, Rosenberg PH. Comparison of the opioidsparing efficacy of diclofenac and ketoprofen for 3 days after knee arthroplasty. Acta Anaesthesiologica Scandinavica 2002;46(3):322-8.

\section{Thienthong 2012 \{published data only\}}

Thienthong S, Chongsomchai C, Kemthong W. A placebocontrolled, double-blind, randomized study of single-dose intravenous diclofenac for pain relief after a cesarean section. Acta Anaesthesiologica Taiwanica 2012;50(4):150-2.

\section{Zohar 2006 \{published data only\}}

Zohar E, Shapiro A, Eidinov A, Fishman A, Fredman B. Postcesarean analgesia: the efficacy of bupivacaine wound instillation with and without supplemental diclofenac. Journal of Clinical Anesthesia 2006;18(6):415-21.

\section{References to studies awaiting assessment}

\section{Kumar 2016 \{published data only\}}

Kumar PR, Soumya S, Kumar PS, Kumar JS. The effectiveness of intravenous tramadol hydrochloride and diclofenac sodium as postoperative analgesia - a comparative study. International Journal of Pharmaceutical Sciences Review and Research 2016;36(1):260-3.

\section{References to ongoing studies}

NCT03493490 \{published data only\}

NCT03493490. Neodolpasse infusion solution versus diclofenac $75 \mathrm{mg}$ infusion in the treatment of postoperative pain after elective knee surgery. clinicaltrials.gov/ct2/show/NCT03493490 (first received 10 April 2018).

\section{Additional references}

\section{Apfelbaum 2003}

Apfelbaum JL, Chen C, Mehta SS, Gan TJ. Postoperative pain experience: results from a national survey suggest postoperative pain continues to be undermanaged. Anesthesia and Analgesia 2003;97(2):534-40.

\section{APS 2008}

American Pain Society (APS). Principles of Analgesic Use in the Treatment of Acute Pain and Cancer Pain. 6th edition. Glenview, IL: APS, 2008

\section{Barden 2004}

Barden J, Edwards JE, McQuay HJ, Moore RA. Pain and analgesic response after third molar extraction and other postsurgical pain. Pain 2004;107:86-90.

\section{Barden 2009}

Barden J, Derry S, McQuay HJ, Moore RA. Single dose oral ketoprofen and dexketoprofen for acute postoperative pain in adults. Cochrane Database of Systematic Reviews 2009, Issue 4. Art. No: CD007355. [DOI: 10.1002/14651858.CD007355.pub2]

\section{Bauer 2010}

Bauer KA, Gerson W, Wright C, Wang J, McNicol E, Lanier RK, et al. Platelet function following administration of a novel formulation of intravenous diclofenac sodium versus active comparators: a randomized, single dose, crossover study in healthy male volunteers. Journal of Clinical Anesthesia 2010;22(7):510-8.

\section{Cepeda 2005}

Cepeda MS, Carr DB, Miranda N, Diaz A, Silva C, Morales O. Comparison of morphine, ketorolac, and their combination for postoperative pain. Results from a large, randomized, doubleblind trial. Anesthesiology 2005;103(6):1225-32.

\section{Chou 2016}

Chou R, Gordon DB, de Leon-Casasola OA, Rosenberg JM, Bickler S, Brennan T, et al. Management of postoperative pain: a clinical practice guideline from the American Pain Society, the American Society of Regional Anesthesia and Pain Medicine, and the American Society of Anesthesiologists' Committee on Regional Anesthesia, Executive Committee, and Administrative Council. Journal of Pain 2016;17(2):131-57.

\section{Collins 1997}

Collins SL, Moore RA, McQuay HJ. The visual analogue pain intensity scale: what is moderate pain in millimetres? Pain 1997;72(1-2):95-7. [DOI: 10.1016/S0304-3959(97)00005-5] 


\section{Collins 2001}

Collins SL, Edwards J, Moore RA, Smith LA, McQuay HJ. Seeking a simple measure of analgesia for mega-trials: is a single global assessment good enough? Pain 2001;91(1-2):189-94. [DOI: 10.1016/S0304-3959(00)00435-8]

\section{Colucci 2009}

Colucci RD, Wright C, Mermelstein FH, Gawarecki DG, Carr DB. Dyloject, a novel injectable diclofenac solubilised with cyclodextrin: reduced incidence of thrombophlebitis compared to injectable diclofenac solubilised with polyethylene glycol and benzyl alcohol. Acute Pain 2009;11(1):15-21.

\section{Cook 1995}

Cook RJ, Sackett DL. The number needed to treat: a clinically useful measure of treatment effect. BMJ 1995;310(6977):452-4. [DOI: 10.1136/bmj.310.6977.452]

\section{Cooper 1991}

Cooper SA. Single-dose analgesic studies: the upside and downside of assay sensitivity. In: Max MB, Portenoy RK, Laska EM, editors(s). The Design of Analgesic Clinical Trials. Advances in Pain Research and Therapy. Vol. 18. New York: Raven Press, 1991:117-24.

\section{Deeks 2011}

Deeks JJ, Higgins JPT, Altman DG. Chapter 9: Analysing data and undertaking meta-analyses. In: Higgins JP, Green S, editor(s). Cochrane Handbook for Systematic Reviews of Interventions Version 5.1.0 (updated March 2011). The Cochrane Collaboration, 2011. Available from handbook.cochrane.org.

\section{Derry 2009}

Derry C, Derry S, Moore RA, McQuay HJ. Single dose oral ibuprofen for acute postoperative pain in adults. Cochrane Database of Systematic Reviews 2009, Issue 3. Art. No: CD001548. [DOI: 10.1002/14651858.CD001548.pub2]

\section{Derry 2010}

Derry S, Moore RA, McQuay HJ. Single dose oral codeine, as a single agent, for acute postoperative pain in adults. Cochrane Database of Systematic Reviews 2010, Issue 4. Art. No: CD008099. [DOI: 10.1002/14651858.CD008099.pub2]

\section{Derry 2013a}

Derry CJ, Derry S, Moore RA. Single dose oral ibuprofen plus paracetamol (acetaminophen) for acute postoperative pain. Cochrane Database of Systematic Reviews 2013, Issue 6. Art. No: CD010210. [DOI: 10.1002/14651858.CD010210.pub2]

\section{Derry 2013b}

Derry S, Karlin SM, Moore RA. Single dose oral ibuprofen plus codeine for acute postoperative pain in adults. Cochrane Database of Systematic Reviews 2013, Issue 3. Art. No: CD010107. [DOI: 10.1002/14651858.CD010107.pub2]

\section{Derry 2015}

Derry S, Wiffen PJ, Moore RA. Single dose oral diclofenac for acute postoperative pain in adults. Cochrane Database of Systematic Reviews 2015, Issue 7. Art. No: CD004768. [DOI: 10.1002/14651858.CD004768]

\section{Derry 2016}

Derry S, Cooper TE, Phillips T. Single fixed-dose oral dexketoprofen plus tramadol for acute postoperative pain in adults. Cochrane Database of Systematic Reviews 2016, Issue 6. Art. No: CD012232. [DOI: 10.1002/14651858.CD012232]

\section{Feldman 1997}

Feldman HI, Kinman JL, Berlin JA, Hennessy S, Kimmel SE, Farrar J, et al. Parenteral ketorolac: the risk for acute renal failure. Annals of Internal Medicine 1997;126(3):193-9.

\section{FitzGerald 2001}

FitzGerald GA, Patrono C. The coxibs, selective inhibitors of cyclooxygenase-2. New England Journal of Medicine 2001;345(6):433-42. [DOI: 10.1056/NEJM200108093450607]

\section{FitzGerald 2004}

FitzGerald GA. Coxibs and cardiovascular disease. New England Journal of Medicine 2004;351(17):1709-11.

\section{Gan 2010}

Gan TJ. Diclofenac: an update on its mechanism of action and safety profile. Current Medical Research and Opinion 2010;26(7):1715-31.

\section{GRADEpro GDT 2015 [Computer program]}

GRADEpro Guideline Development Tool [Software]. McMaster University (developed by Evidence Prime, Inc). Available from www.gradepro.org, 2015.

\section{Guyatt 2011}

Guyatt GH, Oxman AD, Kunz R, Woodcock J, Brozek J, Helfand M, et al. GRADE guidelines: 7 . Rating the quality of evidence-inconsistency. Journal of Clinical Epidemiology 2011;64(12):1294-302. [DOI: 10.1016/j.jclinepi.2011.03.017]

\section{Guyatt 2013a}

Guyatt G, Oxman AD, Sultan S, Brozek J, Glasziou P, AlonsoCoello $P$, et al. GRADE guidelines: 11 . Making an overall rating of confidence in effect estimates for a single outcome and for all outcomes. Journal of Clinical Epidemiology 2013;66(2):151-7. [DOI: 10.1016/j.jclinepi.2012.01.006]

\section{Guyatt 2013b}

Guyatt GH, Oxman AD, Santesso N, Helfand M, Vist G, Kunz R, et al. GRADE guidelines: 12. Preparing summary of findings tables-binary outcomes. Journal of Clinical Epidemiology 2013;66(2):158-72. [DOI: 10.1016/j.jclinepi.2012.01.012]

\section{Hawkey 2002}

Hawkey CJ. Cyclooxygenase inhibition: between the devil and the deep blue sea. Gut 2002;50 Suppl 3:iii25-30.

\section{Higgins 2011}

Higgins JP, Green S, editor(s). Cochrane Handbook for Systematic Reviews of Interventions Version 5.1.0 (updated March 2011). The Cochrane Collaboration, 2011. Available from handbook.cochrane.org. 


\section{Hoy 2016}

Hoy SM. Diclofenac sodium bolus injection (Dyloject): a review in acute pain management. Drugs 2016;76(12):1213-20.

\section{Jenkins 2005}

Jenkins JK, Seligman PJ. Memorandum: analysis and recommendations for agency action regarding nonsteroidal anti-inflammatory drugs and cardiovascular risk. www.fda.gov/downloads/drugs/drugsafety/ postmarketdrugsafetyinformationforpatientsandproviders/ ucm106201.pdf (accessed 7 October 2017).

\section{Lloyd 2009}

Lloyd R, Derry S, Moore RA, McQuay HJ. Intravenous or intramuscular parecoxib for acute postoperative pain in adults. Cochrane Database of Systematic Reviews 2009, Issue 2. Art. No: CD004771. [DOI: 10.1002/14651858.CD004771]

\section{Macintyre 2010}

Macintyre PE, Schug SA, Scott DA, Visser EJ, Walker SM, APM: SE Working Group of the Australian and New Zealand College of Anaesthetists and Faculty of Pain Medicine. Acute Pain Management: Scientific Evidence. 3rd edition. Melbourne: ANZCA \& FPM, 2010.

\section{McCormack 2008}

McCormack PL, Scott LJ. Diclofenac sodium injection (Dyloject): in postoperative pain. Drugs 2008;68(1):123-30.

\section{McNicol 2016}

McNicol ED, Ferguson MC, Haroutounian S, Carr DB, Schumann R. Single dose intravenous paracetamol or intravenous propacetamol for postoperative pain. Cochrane Database of Systematic Reviews 2016, Issue 5. Art. No: CD007126. [DOI: 10.1002/14651858.CD007126]

\section{McQuay 2005}

McQuay HJ, Moore RA. Placebo. Postgraduate Medical Journal 2005;81(953):155-60. [DOI: 10.1136/pgmj.2004.024737]

\section{McQuay 2012}

McQuay HJ, Derry S, Eccleston C, Wiffen PJ, Moore RA. Evidence for analgesic effect in acute pain-50 years on. Pain 2012;153(7):1364-7. [DOI: 10.1016/j.pain.2012.01.024]

\section{Moher 2009}

Moher D, Liberati A, Tetzlaff J, Altman DG, the PRISMA Group. Preferred reporting items for systematic reviews and meta-analyses: the PRISMA statement. PLoS Medicine 2009;6(7):e1000097.

\section{Moore 1996}

Moore A, McQuay H, Gavaghan D. Deriving dichotomous outcome measures from continuous data in randomised controlled trials of analgesics. Pain 1996;66(2-3):229-37. [DOI: 10.1016/0304-3959(96)03032-1]

\section{Moore 1997a}

Moore A, McQuay H, Gavaghan D. Deriving dichotomous outcome measures from continuous data in randomised controlled trials of analgesics: verification from independent data. Pain 1997;69(1-2):127-30. [DOI: 10.1016/

S0304-3959(96)03251-4]

\section{Moore 1997b}

Moore A, Moore O, McQuay H, Gavaghan D. Deriving dichotomous outcome measures from continuous data in randomised controlled trials of analgesics: use of pain intensity and visual analogue scales. Pain 1997;69(3):311-5. [DOI: 10.1016/S0304-3959(96)03306-4]

\section{Moore 1997c}

Moore RA, McQuay HJ. Single-patient data meta-analysis of 3453 postoperative patients: oral tramadol versus placebo, codeine and combination analgesics. Pain 1997;69:287-94.

\section{Moore 2003}

Moore RA, Edwards J, Barden J, McQuay HJ. Bandolier's Little Book of Pain. Oxford: Oxford University Press, 2003. [ISBN: 0-19-263247-7]

\section{Moore 2005}

Moore RA, Edwards JE, McQuay HJ. Acute pain: individual patient meta-analysis shows the impact of different ways of analysing and presenting results. Pain 2005;116(3):322-31. [DOI: 10.1016/j.pain.2005.05.001]

\section{Moore 2006}

Moore A, McQuay H. Bandolier's Little Book of Making Sense of the Medical Evidence. Oxford: Oxford University Press, 2006. [ISBN: 0-19-856604-2]

\section{Moore 2008}

Moore RA, Barden J, Derry S, McQuay HJ. Managing potential publication bias. In: McQuay HJ, Kalso E, Moore RA, editors(s). Systematic Reviews in Pain Research: Methodology Refined. Seattle: IASP Press, 2008:15-24. [978-0-931092-69-5]

\section{Moore 2011a}

Moore RA, Straube S, Paine J, Derry S, McQuay HJ. Minimum efficacy criteria for comparisons between treatments using individual patient meta-analysis of acute pain trials: examples of etoricoxib, paracetamol, ibuprofen, and ibuprofen/ paracetamol combinations after third molar extraction. Pain 2011;152(5):982-9. [DOI: 10.1016/j.pain.2010.11.030]

\section{Moore 2011b}

Moore RA, Derry S, McQuay HJ, Wiffen PJ. Single dose oral analgesics for acute postoperative pain in adults. Cochrane Database of Systematic Reviews 2011, Issue 9. Art. No: CD008659. [DOI: 10.1002/14651858.CD008659.pub2]

\section{Moore 2015a}

Moore RA, Derry S, Aldington D, Wiffen PJ. Single dose oral analgesics for acute postoperative pain in adults an overview of Cochrane reviews. Cochrane Database of Systematic Reviews 2015, Issue 9. Art. No: CD008659. [DOI: 10.1002/14651858.CD008659.pub3]

\section{Moore 2015b}

Moore RA, Derry S, Aldington D, Wiffen PJ. Adverse events associated with single dose oral analgesics for acute 
postoperative pain in adults - an overview of Cochrane reviews. Cochrane Database of Systematic Reviews 2015, Issue 10. Art. No: CD011407. [DOI: 10.1002/14651858.CD011407.pub2]

\section{PaPaS 2012}

Cochrane Pain, Palliative and Supportive Care Group (PaPaS) author and referee guidance. papas.cochrane.org/papasdocuments (accessed 19 October 2014).

\section{RevMan 2014 [Computer program]}

The Nordic Cochrane Centre, The Cochrane Collaboration Review Manager. Version 5.3. Copenhagen: The Nordic Cochrane Centre, The Cochrane Collaboration, 2014.

\section{Scott 2012}

Scott LJ. Intravenous ibuprofen: in adults for pain and fever. Drugs 2012;72(8):1099-109.

\section{Strom 1996}

Strom BL, Berlin JA, Kinman JL, Spitz PW, Hennessy S, Feldman $\mathrm{H}$, et al. Parenteral ketorolac and risk of gastrointestinal and operative site bleeding: a postmarketing surveillance study. JAMA 1996;275(5):376-82.

\section{CHARACTERISTICS OF STUDIES}

Characteristics of included studies [ordered by study ID]

\section{Todd 1988}

Todd PA, Sorkin EM. Diclofenac sodium: a reappraisal of its pharmacodynamic and pharmacokinetic properties, and therapeutic efficacy. Drugs 1988;35(3):244-85.

\section{Toms 2008}

Toms L, McQuay HJ, Derry S, Moore RA. Single dose oral paracetamol (acetaminophen) for postoperative pain in adults. Cochrane Database of Systematic Reviews 2008, Issue 4. Art. No: CD004602. [DOI: 10.1002/14651858.CD004602.pub2]

\section{Toms 2009}

Toms L, Derry S, Moore RA, McQuay HJ. Single dose oral paracetamol (acetaminophen) with codeine for postoperative pain in adults. Cochrane Database of Systematic Reviews 2009, Issue 1. Art. No: CD001547. [DOI: 10.1002/14651858.CD001547.pub2]

\section{Tramèr 1997}

Tramèr MR, Reynolds DJM, Moore RA, McQuay HJ. Impact of covert duplicate results on meta-analysis: a case study. BMJ 1997;315(7109):635-40. [DOI: 10.1136/bmj.315.7109.635]

Christensen 2011

\section{Study characteristics}

Methods

Randomized, double-blind, placebo and active controlled, parallel, single dose, multicenter. Efficacy monitored over $24 \mathrm{~h}$ postintervention; safety monitored over 9 days postintervention. Intervention administered at first report of moderate to severe postoperative pain.

Participants

Type of surgery: third molar extraction (1 or more extractions, 1 of which was a fully or partially impacted mandibular third molar requiring bone removal)

\section{Diclofenac $3.75 \mathrm{mg}, 9.4 \mathrm{mg}, 18.75 \mathrm{mg}, 37.5 \mathrm{mg}$, and $75 \mathrm{mg}$ groups}

Entered/completing: 51/51 for each group

Age (mean, SD): not reported

Sex (male, \%): not reported

Placebo group

Entered/completing: $51 / 51$

Age (mean, SD): not reported

Sex (male, \%): not reported

\section{Ketorolac group}

Entered/completing: 47/47

Age (mean, SD): not reported

Sex (male, \%): not reported 
Christensen 2011 (Continued)

Interventions
Diclofenac: 3.75 mg, 9.4 mg, 18.75 mg, 37.5 mg, or 75 mg single IV bolus injection over 15 seconds

Placebo: unspecified solution administered in same manner

Ketorolac: $30 \mathrm{mg}$ administered in same manner
Primary (as specified in study): TOTPAR over $0 \mathrm{~h}$ to $6 \mathrm{~h}$ in the ITT population

Secondary:

- Time-specific pain relief (VAS and categorical)

- Peak pain relief (VAS and categorical)

- SPID over 0 to 2, 0 to 4, 0 to 6,0 to 8,0 to 10,0 to 12 , and 0 to 24 hours (VAS and categorical)

- Time-specific PID (VAS and categorical)

- Peak PID (VAS and categorical)

- Summed pain relief intensity differences (SPRID) over 0 to 2, 0 to 4, 0 to 6,0 to 8,0 to 10,0 to 12 , and 0 to 24 hours (VAS and categorical)

- Time to administration of rescue medication

- Proportion of patients requiring rescue medication

- Time to meaningful pain relief

- Time to perceptible pain relief

- Patient global evaluation

- Safety

Source of funding Javelin Pharmaceuticals, Inc., Cambridge, MA (manufacturers of IV diclofenac, now Hospira, Inc., Lake Forest, IL following acquisition in 2010)

Were treatment groups comparable at baseline?
Yes: demographic (age, sex, ethnic origin, height, weight) and clinical (degree of molar impaction, surgical time and trauma, baseline pain) variables

Notes

\section{Risk of bias}

\begin{tabular}{lll}
\hline Bias & Authors' judgement & Support for judgement \\
\hline $\begin{array}{l}\text { Random sequence genera- } \\
\text { tion (selection bias) }\end{array}$ & Low risk & "computer-generated randomization schedule" \\
\hline $\begin{array}{l}\text { Allocation concealment } \\
\text { (selection bias) }\end{array}$ & Unclear risk & Not mentioned \\
\hline $\begin{array}{l}\text { Blinding of participants, } \\
\text { personnel and outcome } \\
\text { assessors }\end{array}$ & Low risk & $\begin{array}{l}\text { "A third party doser who had no contact with patients except when dosing ad- } \\
\text { ministered study treatment prepared the syringe with appropriate study treat- } \\
\text { ment using a blind label within 1 hour of dosing" }\end{array}$ \\
\hline $\begin{array}{l}\text { Incomplete outcome data } \\
\text { (attrition bias) } \\
\text { All outcomes }\end{array}$ & Unclear risk & $\begin{array}{l}\text { Intention-to-treat analysis performed on all participants for both efficacy and } \\
\text { safety. Methods of data imputation not described. }\end{array}$ \\
\hline $\begin{array}{l}\text { Selective reporting (re- } \\
\text { porting bias) }\end{array}$ & Unclear risk & $\begin{array}{l}\text { All outcomes specified in methods reported in results. Data and SDs not re- } \\
\text { ported for all dose levels for every outcome. }\end{array}$ \\
\hline $\begin{array}{l}\text { Sample size } \\
\text { nigh }\end{array}$ & High risk & $\begin{array}{l}\text { 51 participants each in diclofenac group and placebo group, and 47 partici- } \\
\text { pants in ketorolac group }\end{array}$ \\
\hline
\end{tabular}


Gan 2012

\section{Study characteristics}

Methods

Multicenter, multiple-dose, multiple-day, randomized, double-blind, active- and placebo-controlled, parallel-group phase 3 study. Efficacy assessed through Day 5 or discharge. Safety assessed 30 days postbaseline. Intervention administered when participant reported moderate to severe postoperative pain within 6 hours of completing surgery.

Participants

Type of surgery: abdominal or pelvic (hysterectomy, general abdominal, inguinal hernia, myomectomy, partial colectomy, general pelvic, salpingo-oophorectomy, ventral hernia, other)

Mean baseline VAS 67 to 70/100 and comparable among groups; paracetamol/opioids/other NSAIDs/ PCA not permitted; short-acting barbiturates or benzodiazepines were allowed with sufficient washout prior to assessment; rescue medication was available (IV morphine 5 to $7.5 \mathrm{mg}$ ).

\section{Diclofenac group}

Entered/completing: 87/68

Age (mean, SD): $43.3 \pm 10.83$

Sex (male, \%): 19 (21.8\%)

\section{Placebo group}

Entered/completing: 76/57

Age (mean, SD): $42.8 \pm 9.66$

Sex (male, \%): 15 (19.7\%)

\section{Ketorolac group}

Entered/completing: 82/67

Age (mean, SD): $42.9 \pm 11.42$

Sex (male, \%): 15 (18.3\%)

Interventions

Diclofenac: $37.5 \mathrm{mg} / 1 \mathrm{~mL}$ IV bolus administered when participant reported moderate to severe postoperative pain within 6 hours of completing surgery. Doses repeated every $6 \mathrm{~h}$ until end of study or participant withdrawal.

Placebo: as with diclofenac. Nature of placebo not specified.

Ketorolac: $30 \mathrm{mg} / 1 \mathrm{~mL}$ as with diclofenac

Outcomes

Primary (as specified in study): SPID 0 to $48 \mathrm{~h}$ post-first dose of study drug

Secondary:

- SPID over 0 to $24 \mathrm{~h}$

- TOTPAR for the 0 - to 24 - and 0 - to 48 -hour intervals ( 0 to 72,0 to 96 , and 0 to 120 hours as well, if data permitted)

- Proportion of patients with clinically meaningful $(\geq 30 \%)$ reduction in pain intensity (vs baseline, using 0-to-100-millimeter VAS)

- PID at each scheduled assessment

- Time from administration of study drug to administration of rescue medication

- Frequency and amount of rescue medication

- Patient-reported global evaluation of the study drug at 24 and 48 hours on a 5-point categorical scale ("excellent," "very good," "good," "fair," and "poor") 
Gan 2012 (Continued)

Safety: physical exam, labs, vitals, ECG, thrombophlebitis, AEs

Source of funding

Javelin Pharmaceuticals, Inc., Cambridge, MA (manufacturers of IV diclofenac, now Hospira, Inc., Lake Forest, IL following acquisition in 2010)

Were treatment groups comparable at baseline?
Yes: demographic (age, sex, ethnicity, height, weight) and surgical (time to first doses of intervention, surgical procedure, baseline pain intensity) variables

Notes

Rescue medication (bolus IV morphine $5 \mathrm{mg}$, titrated up to $7.5 \mathrm{mg}$ after $30 \mathrm{~min}$ if analgesia was inadequate) was available upon patient request, up to once every 3 hours any time after administration of the initial dose of study drug, but participants were encouraged to wait at least 1 hour after study medication injection.

Data from $37.5 \mathrm{mg}$ diclofenac dose (highest in the study) chosen for all outcomes.

\section{Risk of bias}

\begin{tabular}{|c|c|c|}
\hline Bias & Authors' judgement & Support for judgement \\
\hline $\begin{array}{l}\text { Random sequence genera- } \\
\text { tion (selection bias) }\end{array}$ & Low risk & Computer-generated random code \\
\hline $\begin{array}{l}\text { Allocation concealment } \\
\text { (selection bias) }\end{array}$ & Unclear risk & Not mentioned \\
\hline $\begin{array}{l}\text { Blinding of participants, } \\
\text { personnel and outcome } \\
\text { assessors }\end{array}$ & Unclear risk & $\begin{array}{l}\text { "Clinical staff and patients were blinded to study drug assignment". No further } \\
\text { details }\end{array}$ \\
\hline $\begin{array}{l}\text { Incomplete outcome data } \\
\text { (attrition bias) } \\
\text { All outcomes }\end{array}$ & Low risk & $\begin{array}{l}\text { Intention-to-treat population. For pain intensity and pain relief, if rescue med- } \\
\text { ication was administered within } 3 \mathrm{~h} \text { of the next scheduled assessment, WOCF } \\
\text { from the preceding } 6 \text { hours. If the assessments needed to do this were unavail- } \\
\text { able, assessments were imputed using BOCF. For withdrawals due to AEs or } \\
\text { lack of efficacy, BOCF. }\end{array}$ \\
\hline $\begin{array}{l}\text { Selective reporting (re- } \\
\text { porting bias) }\end{array}$ & Unclear risk & $\begin{array}{l}\text { Protocol available on ClinicalTrials.gov. All prespecified outcomes reported in } \\
\text { full except PID for each stated time point and grade of thrombophlebitis. }\end{array}$ \\
\hline \multirow[t]{3}{*}{ Sample size } & Unclear risk & Diclofenac N = 87 \\
\hline & & Placebo $\mathrm{N}=76$ \\
\hline & & Ketorolac $\mathrm{N}=82$ \\
\hline
\end{tabular}

\section{Garcia 1997}

\section{Study characteristics}

\begin{tabular}{|c|c|}
\hline \multirow[t]{2}{*}{ Methods } & $\begin{array}{l}\text { Double-blind, randomized, active controlled, parallel group, single dose in participants with mild to se- } \\
\text { vere postoperative pain }\end{array}$ \\
\hline & $\begin{array}{l}\text { Interventions administered once participants were able to report pain postoperatively (Aldrete anes- } \\
\text { thesia recovery scale score of } 9 \text { or } 10) \text {. }\end{array}$ \\
\hline
\end{tabular}

$\begin{array}{ll}\text { Participants } & \begin{array}{l}\text { Type of surgery: minor ambulatory (saphenectomies, ligament surgeries, variceal resection of varices, } \\ \text { arthroscopies) }\end{array}\end{array}$
arthroscopies)

\section{Diclofenac group}


Garcia 1997 (Continued)

Entered/completing: 48/47?

Age (mean, SD): $54.5 \pm 14.0$

Sex (male, \%): not reported

Lysine clonixinate group

Entered/completing: 48/47?

Age (mean, SD): $50.7 \pm 16.8$

Sex (male, \%): not reported

Interventions

Diclofenac: $75 \mathrm{mg}$ single dose in $150 \mathrm{~mL}$ normal saline over 15 minutes after first postoperative pain report

Lysine clonixinate: $200 \mathrm{mg}$ as with diclofenac

\begin{tabular}{ll}
\hline Outcomes & Primary (as specified in study): VAS and categorical pain intensity at 1, 3, and 6 hours postinterventions \\
& Secondary: \\
& Participant's overall evaluation of pain control (total, partial, or zero) and tolerance (good, fair, or poor) \\
& AEs \\
\hline Source of funding & Not reported \\
\hline $\begin{array}{l}\text { Were treatment groups } \\
\text { comparable at baseline? }\end{array}$ & $\begin{array}{l}\text { Yes: demographics (age, weight, height) and clinical (duration of surgery and anesthesia, vitals signs, } \\
\text { baseline pain) }\end{array}$ \\
\hline Notes & $\begin{array}{l}\text { 3 participants in lysine clonixinate group reported only mild pain at baseline. } \\
\text { No mention of use of rescue medication }\end{array}$ \\
\hline
\end{tabular}

\section{Risk of bias}

\begin{tabular}{lll}
\hline Bias & Authors' judgement & Support for judgement \\
\hline $\begin{array}{l}\text { Random sequence genera- } \\
\text { tion (selection bias) }\end{array}$ & Unclear risk & Not described \\
\hline $\begin{array}{l}\text { Allocation concealment } \\
\text { (selection bias) }\end{array}$ & Unclear risk & Not mentioned \\
\hline $\begin{array}{l}\text { Blinding of participants, } \\
\text { personnel and outcome } \\
\text { assessors }\end{array}$ & Low risk & $\begin{array}{l}\text { Ampoules described as being indistinguishable from each other and both par- } \\
\text { ticipant and researcher were blinded to interventions. }\end{array}$ \\
\hline $\begin{array}{l}\text { Incomplete outcome data } \\
\begin{array}{l}\text { (attrition bias) } \\
\text { All outcomes }\end{array}\end{array}$ & Unclear risk & $\begin{array}{l}\text { No mention of ITT analysis or how missing data were imputed. It appears that } \\
1 \text { participant in each group did not supply data at 3 h and } 6 \mathrm{~h} \text { postintervention. }\end{array}$ \\
\hline $\begin{array}{l}\text { Selective reporting (re- } \\
\text { porting bias) }\end{array}$ & Unclear risk & $\begin{array}{l}\text { Participant's overall evaluation of tolerance assessed but not reported. All oth- } \\
\text { er outcomes reported in full. }\end{array}$ \\
\hline $\begin{array}{l}\text { Sample size } \\
\text { nigh risk }\end{array}$ & \begin{tabular}{l} 
48 participants in each arm \\
\hline
\end{tabular}
\end{tabular}


Leeson 2007

\section{Study characteristics}

Methods

Double-blind, double dummy, randomized controlled, single dose, single center. Efficacy assessed up to $12 \mathrm{~h}$ postdose. Interventions administered after first report of moderate to severe pain.

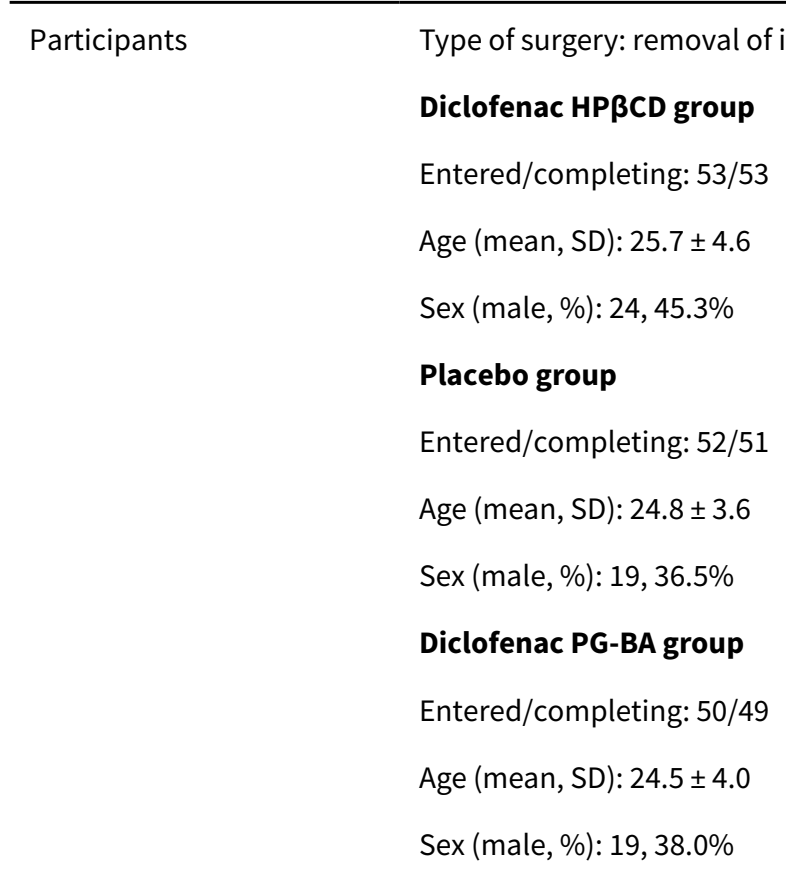

Interventions

Diclofenac HP $\beta C D$ : $75 \mathrm{mg} / 2 \mathrm{~mL}$ bolus (Dyloject) single dose after first report of moderate to severe pain ( $\geq 50 \mathrm{~mm}$ on a 0 -to-100-millimeter VAS)

Placebo: an immediate bolus or 30-minute infusion (nature of placebo solution not described)

Diclofenac PG-BA: diclofenac sodium $75 \mathrm{mg} / 3 \mathrm{~mL}$ (Voltarol) as a 30-minute infusion as with diclofenac HP $\beta C D$

Outcomes Primary (as specified in study): superiority of HPBCD diclofenac sodium to placebo and non-inferiority of HP $\beta C D$ diclofenac sodium to PG-BA diclofenac sodium according to TOTPAR over $4 \mathrm{~h}$ on a VAS scale

Secondary:

- Categorical TOTPAR over $4 \mathrm{~h}$; VAS and categorical TOTPAR up to $8 \mathrm{~h}$

- Other standard measures of pain intensity and relief

- Patient global evaluation

- Time to request for first rescue medication

Safety: vital signs and physical examination, including thrombophlebitis (6-point scale, $0=$ no reaction to $5=$ palpable swelling or thrombosis beyond the length of the cannula, with infection), laboratory analyses

Source of funding Javelin Pharmaceuticals, Inc., Cambridge, MA (manufacturers of IV diclofenac, now Hospira, Inc., Lake Forest, IL following acquisition in 2010)

Were treatment groups comparable at baseline?

Yes: demographic (age, sex, ethnic origin) and clinical (VAS pain intensity at baseline, time to dosing) variables

Notes

Study compared 2 different formulations of IV diclofenac in addition to placebo. 


\section{Risk of bias}

\begin{tabular}{|c|c|c|}
\hline Bias & Authors' judgement & Support for judgement \\
\hline $\begin{array}{l}\text { Random sequence genera- } \\
\text { tion (selection bias) }\end{array}$ & Low risk & Permuted blocks based on a block size of 3 \\
\hline $\begin{array}{l}\text { Allocation concealment } \\
\text { (selection bias) }\end{array}$ & Unclear risk & Not mentioned \\
\hline $\begin{array}{l}\text { Blinding of participants, } \\
\text { personnel and outcome } \\
\text { assessors }\end{array}$ & Low risk & $\begin{array}{l}\text { Double-dummy technique, with each participant receiving a 30-minute IV in- } \\
\text { fusion of a clear, colorless solution of either active drug or placebo through a } \\
\text { cannula placed in } 1 \text { arm. As soon as this infusion began, participants also re- } \\
\text { ceived an IV bolus of a clear, colorless solution containing either active drug or } \\
\text { placebo through a cannula in the other arm. }\end{array}$ \\
\hline $\begin{array}{l}\text { Incomplete outcome data } \\
\text { (attrition bias) } \\
\text { All outcomes }\end{array}$ & Unclear risk & $\begin{array}{l}\text { Only } 2 \text { dropouts for reasons likely unrelated to interventions. Methods of im- } \\
\text { puting missing data not described. }\end{array}$ \\
\hline $\begin{array}{l}\text { Selective reporting (re- } \\
\text { porting bias) }\end{array}$ & Unclear risk & $\begin{array}{l}\text { Secondary outcomes not fully described in methods section. Categorical TOT- } \\
\text { PAR over } 4 \text { h described in methods but not reported in results. }\end{array}$ \\
\hline Sample size & Unclear risk & $\begin{array}{l}\text { Diclofenac } \mathrm{HP} \beta C D, \mathrm{~N}=53 \\
\text { Placebo, } \mathrm{N}=52 \\
\text { Diclofenac PG-BA, } \mathrm{N}=50\end{array}$ \\
\hline
\end{tabular}

Maroo 2013

\section{Study characteristics}

Methods Randomized, multicenter, double-blind, single-dose phase III study. Study period of $12 \mathrm{~h}$. Interventions administered postoperatively when participant reported moderate to severe pain ( $\geq 4 / 10$ on a 0 -to-10 VAS).

\section{Participants}

Type of surgery: elective day surgery expected to cause moderate to severe pain (no other details)

Necessary medications were allowed as long as they did not interfere with the study medication (no further details provided).

18 to 60 years included.

\section{Diclofenac bolus group}

Entered/completing: 175/175

Age (mean, SD): $40.00 \pm 12.88$

Sex (male, \%): 114, 65\%

\section{Diclofenac infusion group}

Entered/completing: 175/175 
Maroo 2013 (Continued)

Age (mean, SD): $39.96 \pm 13.39$

Sex (male, \%): 111, 63\%

Interventions Diclofenac bolus: $75 \mathrm{mg} / 1 \mathrm{~mL}$ (Dynapar AQ) administered as a single IV bolus over 5 to 60 seconds

Diclofenac infusion: $75 \mathrm{mg} / 3 \mathrm{~mL}$ (Voveran) single dose, diluted with 100 to $500 \mathrm{~mL}$ of either $0.9 \%$ saline or $5 \%$ glucose, buffered with $0.5 \mathrm{~mL}$ of $8.4 \%$ sodium bicarbonate (or a corresponding volume of a different concentration), infused over $30 \mathrm{~min}$

\section{Outcomes}

Primary (as specified in study): time to onset of analgesia (not defined) and postoperative pain intensity (assessed by VAS at 0, $15 \mathrm{~min}, 30 \mathrm{~min}, 45 \mathrm{~min}, 1,2$, 4, 8, and $12 \mathrm{~h}$ )

Secondary:

- Percentage pain relief (15 min after intervention administered)

- Degree of pain relief (5-point categorical scale: $15 \mathrm{~min}, 1$, 4, 8, and $12 \mathrm{~h}$ )

- Global assessment by patient and investigator (end of study)

- Requirement for rescue medication

Safety: pain intensity and grade of thrombophlebitis at injection site; systemic AEs (up to $12 \mathrm{~h}$ )

Safety and efficacy endpoints were evaluated over 12-hour study period.

\begin{tabular}{ll}
\hline Source of funding & Troikaa Pharmaceuticals Ltd., India (Dynapar manufacturer) \\
\hline $\begin{array}{l}\text { Were treatment groups } \\
\text { comparable at baseline? }\end{array}$ & Yes: demographic (age, sex, weight) and clinical (duration of surgery, baseline pain intensity) variables \\
\hline Notes & $\begin{array}{l}\text { Registered on Clinical Trials Registry - India (CTRI) before first participant enrollment (CTRI registration } \\
\text { number: CTRI/2010/091/000096). Registry states the study was double-blind (participants and outcome } \\
\text { assessor), whereas in the publication it is stated as "assessor blind." }\end{array}$
\end{tabular}

\section{Risk of bias}

\begin{tabular}{|c|c|c|}
\hline Bias & Authors' judgement & Support for judgement \\
\hline $\begin{array}{l}\text { Random sequence genera- } \\
\text { tion (selection bias) }\end{array}$ & Low risk & Computer-generated simple randomization \\
\hline $\begin{array}{l}\text { Allocation concealment } \\
\text { (selection bias) }\end{array}$ & Unclear risk & $\begin{array}{l}\text { "The enrolled patients were identified only by randomization number, not by } \\
\text { name or initials"; "An open list of random numbers" }\end{array}$ \\
\hline $\begin{array}{l}\text { Blinding of participants, } \\
\text { personnel and outcome } \\
\text { assessors }\end{array}$ & High risk & $\begin{array}{l}\text { Described as participant and outcome assessor blinded in protocol, but meth- } \\
\text { ods to ensure blinding not detailed. Participants received either bolus injec- } \\
\text { tion or 30-minute infusion; no mention of double-dummy technique. }\end{array}$ \\
\hline $\begin{array}{l}\text { Incomplete outcome data } \\
\text { (attrition bias) } \\
\text { All outcomes }\end{array}$ & Low risk & $\begin{array}{l}\text { "No patients were dropped out or discontinued due to any reasons. The data } \\
\text { obtained from all } 350 \text { patients were subjected to statistical analysis" }\end{array}$ \\
\hline $\begin{array}{l}\text { Selective reporting (re- } \\
\text { porting bias) }\end{array}$ & Unclear risk & $\begin{array}{l}\text { Protocol available on clinical trial website. Criteria for time to onset of anal- } \\
\text { gesia not defined. All other outcomes described in protocol reported in full. } \\
\text { Number of participants requiring rescue medication reported, but not men- } \\
\text { tioned as an outcome in protocol. }\end{array}$ \\
\hline Sample size & Unclear risk & 175 participants in both arms \\
\hline
\end{tabular}


Seymour 2000

\section{Study characteristics}

\begin{tabular}{|c|c|}
\hline Methods & $\begin{array}{l}\text { Randomized, double-blind, dose-ranging and placebo-controlled, multicenter study. Study duration of } \\
12 \mathrm{~h} \text { postinterventions. Interventions administered if participant reported } \geq 30 / 100 \text {-millimeter VAS pain } \\
\text { within } 1 \mathrm{~h} \text { postoperatively. }\end{array}$ \\
\hline \multirow[t]{9}{*}{ Participants } & Type of surgery: dental; removal of third molars \\
\hline & Diclofenac 75 mg group \\
\hline & Entered/completing: 68/? \\
\hline & Age (mean, SD): 25 (95\% Cl 24 to 26$)$ \\
\hline & Sex (male, \%): $26,38 \%$ \\
\hline & Placebo group \\
\hline & Entered/completing: 65/? \\
\hline & Age (mean, SD): 25 (95\% Cl 24 to 26$)$ \\
\hline & Sex (male, \%): 23, 35\% \\
\hline \multirow[t]{2}{*}{ Interventions } & Diclofenac: $75 \mathrm{mg} / 3 \mathrm{~mL}$ IV bolus single dose at first report of a VAS pain intensity score of $\geq 30 / 100 \mathrm{~mm}$ \\
\hline & Placebo: Saline, as with diclofenac \\
\hline \multirow[t]{7}{*}{ Outcomes } & $\begin{array}{l}\text { Primary (as specified in study): VAS pain intensity at multiple time points }(0,10,20,30 \text {, and } 45 \text { min and } \\
\text { at } 1,1.5,2,3,4,5 \text {, and } 6 \mathrm{~h} \text { ) postdosing }\end{array}$ \\
\hline & Secondary: \\
\hline & - Pain intensity categorical ( $0=$ none, $3=$ severe) at same time points as VAS pain intensity \\
\hline & - Pain relief categorical ( $0=$ none, $3=$ complete $)$ at same time points as VAS pain intensity \\
\hline & - Time to first rescue medication (participants taking rescue within $1 \mathrm{~h}$ were excluded from the study) \\
\hline & - Number of participants requiring rescue medication \\
\hline & - Global assessment $(0=$ poor, $4=$ excellent $)$ at $4 \mathrm{~h}, 12 \mathrm{~h}$, and $24 \mathrm{~h}$ postdosing \\
\hline
\end{tabular}

Source of funding

MDS Harris and South African Druggist (manufacturer) supported (undefined) the study.

Were treatment groups comparable at baseline?

Yes: demographic (sex, age, weight) and clinical (mean operating time, baseline pain score) variables

\begin{tabular}{|c|c|}
\hline Notes & $\begin{array}{l}\text { Diclofenac preparation was (at the time of the study) a new formulation that could be administered via } \\
\text { bolus IV injection. }\end{array}$ \\
\hline & medication was a combination of codeine phosphate $30 \mathrm{mg}$ and paracetamol $500 \mathrm{mg}$. \\
\hline
\end{tabular}

\section{Risk of bias}

\begin{tabular}{lll}
\hline Bias & Authors' judgement & Support for judgement \\
\hline $\begin{array}{l}\text { Random sequence genera- } \\
\text { tion (selection bias) }\end{array}$ & Low risk & $\begin{array}{l}\text { "Patients were randomised to treatment in blocks of four treatments using a } \\
\text { central randomization list created by Penn Pharmaceuticals" }\end{array}$ \\
\hline $\begin{array}{l}\text { Allocation concealment } \\
\text { (selection bias) }\end{array}$ & Low risk & $\begin{array}{l}\text { "Patients were randomised to treatment in blocks of four treatments using a } \\
\text { central randomization list created by Penn Pharmaceuticals" }\end{array}$ \\
\hline
\end{tabular}


Seymour 2000 (Continued)

Blinding of participants, Unclear risk Not described personnel and outcome assessors

\begin{tabular}{lll}
\hline $\begin{array}{l}\text { Incomplete outcome data } \\
\text { (attrition bias) } \\
\text { All outcomes }\end{array}$ & Unclear risk & $\begin{array}{l}\text { Participants taking remedication during the first hour were excluded from the } \\
\text { study. Unclear how many participants were excluded for this reason. For those } \\
\text { taking remedication after } 1 \mathrm{~h}, \text { LOCF was employed. }\end{array}$ \\
\hline $\begin{array}{l}\text { Selective reporting (re- } \\
\text { porting bias) }\end{array}$ & Unclear risk & $\begin{array}{l}\text { All efficacy outcomes reported in full in results section. Assessment of AEs not } \\
\text { mentioned in methods, but reported in results. }\end{array}$ \\
\hline Sample size & Unclear risk & Total of 269 participants, with range of 63 to 73 in each group \\
\hline
\end{tabular}

\section{Sneyd 2007}

\section{Study characteristics}

\begin{tabular}{ll}
\hline Methods & $\begin{array}{l}\text { Multicenter, randomized, double-blind, placebo controlled, parallel group, single dose. Assessments } \\
\text { up to } 8 \mathrm{~h} \text { postinterventions. Interventions administered once participants reported moderate pain. }\end{array}$ \\
\hline Participants & Diclofenac group \\
& Entered/completing: $20 / 20$ \\
& Age (mean, SD): $26.7 \pm 4.1$ \\
& Sex (male, \%): 10, $48 \%$ \\
& Placebo group \\
& Entered/completing: $19 / 19$ (3 withdrew but were included in analysis) \\
& Age (mean, SD): $26.9 \pm 3.6$ \\
& Sex (male, \%): $6,32 \%$
\end{tabular}

Interventions

Diclofenac: $50 \mathrm{mg}$ single dose over 15 minutes in $1 \mathrm{~mL} / \mathrm{kg}$ solution

Placebo: saline $1 \mathrm{~mL} / \mathrm{kg}$ single dose over 15 minutes

Primary (as specified in study):
Proportion of participants achieving meaningful pain relief (mild or no pain on the VRS) at or before $8 \mathrm{~h}$
Secondary:
- Weighted mean of change of VAS from baseline
- Percentage of time with good pain control ("mild" or "no pain") over the first $8 \mathrm{~h}$ after dosing
- Time to rescue or additional analgesic use
- Time to minimum pain score on the VAS before additional analgesic use during the first $8 \mathrm{~h}$ after dosing
- Time to onset of "perceptible pain relief"
- Time to onset of "meaningful pain relief"
- AES


Sneyd 2007 (Continued)

Were treatment groups comparable at baseline?
Yes: age, weight, number of teeth extracted, surgery time

Study included an additional 2 arms: GR79236X $4 \mathrm{mcg} / \mathrm{kg}$ and $10 \mathrm{mcg} / \mathrm{kg}$, an experimental adenosine agonist (data not presented here).

\section{Risk of bias}

\begin{tabular}{|c|c|c|}
\hline Bias & Authors' judgement & Support for judgement \\
\hline $\begin{array}{l}\text { Random sequence genera- } \\
\text { tion (selection bias) }\end{array}$ & Low risk & Computer-generated randomization schedule \\
\hline $\begin{array}{l}\text { Allocation concealment } \\
\text { (selection bias) }\end{array}$ & Unclear risk & Not mentioned \\
\hline $\begin{array}{l}\text { Blinding of participants, } \\
\text { personnel and outcome } \\
\text { assessors }\end{array}$ & Unclear risk & $\begin{array}{l}\text { "Drug administration was double-blinded with all study infusions prepared in } \\
\text { the pharmacy". No mention that interventions appeared identical }\end{array}$ \\
\hline $\begin{array}{l}\text { Incomplete outcome data } \\
\text { (attrition bias) } \\
\text { All outcomes }\end{array}$ & Unclear risk & $\begin{array}{l}\text { "All patients randomized to the study drug and who received the dose were } \\
\text { included in the efficacy and safety analysis. Patients who withdrew from the } \\
\text { study prematurely had their missing data imputed using the 'last observa- } \\
\text { tion carried forward' principle". Appears that all participants in the diclofenac } \\
\text { group completed study. } 3 \text { participants withdrew from placebo arm. }\end{array}$ \\
\hline $\begin{array}{l}\text { Selective reporting (re- } \\
\text { porting bias) }\end{array}$ & Low risk & All outcomes mentioned in methods reported in full in results. \\
\hline \multirow[t]{2}{*}{ Sample size } & High risk & Diclofenac group $N=20$ \\
\hline & & Placebo group $\mathrm{N}=19$ \\
\hline
\end{tabular}

\section{Steffen 1994}

\section{Study characteristics}

Methods Active- and placebo-controlled, single-dose, single-center study. Outcomes measured over $24 \mathrm{~h}$ postoperatively. Interventions administered immediately after surgery.

Participants Type of surgery: orthopedic (knee joint arthrotomies or other minor orthopedic operations)

\section{Diclofenac group}

Entered/completing: $31 / 29$

Age (mean, SD): $36 \pm 16.3$

Sex (male, \%): 20, 65\%

\section{Placebo group}

Entered/completing: 32/25

Age (mean, SD): $38 \pm 14.8$

Sex (male, \%): 15, 47\% 
Steffen 1994 (Continued)

\section{Azapropazone group}

Entered/completing: 29/27

Age (mean, SD): $38 \pm 12.8$

Sex (male, \%): 15, 52\%

Interventions Diclofenac: $75 \mathrm{mg}$ in $50 \mathrm{~mL}$ of $0.9 \%$ sodium chloride, single dose administered over 20 minutes in the
recovery room

Placebo: $50 \mathrm{~mL}$ 0.9\% sodium chloride as with diclofenac

Azapropazone: $600 \mathrm{mg}$ as with diclofenac

All participants received piritramide via PCA for $24 \mathrm{~h}$, titrated to target pain score of 3 on a 0-to-10 NRS. If the participant was not yet able to use the PCA, the study doctor activated the pump for the participant.

Outcomes Primary (as specified in study): median total consumption of piritramide via PCA after $6 \mathrm{~h}$ and at the end of the study $(24 \mathrm{~h})$ and median piritramide utilization increase between 6 and $24 \mathrm{~h}$ postop

Secondary:

- NRS pain intensity hourly through $6 \mathrm{~h}$, and at $24 \mathrm{~h}$

- Vital signs (HR, BP), oxygen saturation, serum creatinine

\begin{tabular}{ll}
\hline Source of funding & Not reported \\
\hline $\begin{array}{l}\text { Were treatment groups } \\
\text { comparable at baseline? }\end{array}$ & $\begin{array}{l}\text { Yes: demographic (sex, ASA group, age, height, weight) and clinical (anesthesia time, surgery time, } \\
\text { baseline pain score) variables }\end{array}$ \\
\hline Notes & $\begin{array}{l}\text { Fourth group received the combination of both diclofenac and azapropazone; we did not include this in } \\
\text { our review. }\end{array}$ \\
& $\begin{array}{l}\text { No sample size calculation } \\
\text { Study employed opioid consumption as its primary outcome, i.e. participants were able to self admin- } \\
\text { ister opioid and remain in the study. Consequently, we could not include pain scores in review meta- } \\
\text { analysis. }\end{array}$
\end{tabular}

\section{Risk of bias}

\begin{tabular}{|c|c|c|}
\hline Bias & Authors' judgement & Support for judgement \\
\hline $\begin{array}{l}\text { Random sequence genera- } \\
\text { tion (selection bias) }\end{array}$ & Low risk & Random number tables \\
\hline $\begin{array}{l}\text { Allocation concealment } \\
\text { (selection bias) }\end{array}$ & Unclear risk & Not mentioned \\
\hline $\begin{array}{l}\text { Blinding of participants, } \\
\text { personnel and outcome } \\
\text { assessors }\end{array}$ & Unclear risk & $\begin{array}{l}\text { All interventions were administered in } 50 \mathrm{~mL} 0.9 \% \text { sodium chloride, but blind- } \\
\text { ing otherwise not described. }\end{array}$ \\
\hline $\begin{array}{l}\text { Incomplete outcome data } \\
\text { (attrition bias) } \\
\text { All outcomes }\end{array}$ & Unclear risk & $\begin{array}{l}\text { Withdrawals all appear to be unrelated to interventions. Appears that all re- } \\
\text { maining participants contributed data at } 6 \text { h, but unclear if this occurred at } \\
\text { other time points. 24-hour outcome assessed in } 100 \text { participants (from } 112 \text { in } \\
\text { four study groups) only due to technical pump difficulties and "other reasons." }\end{array}$ \\
\hline
\end{tabular}


Steffen 1994 (Continued)

Selective reporting (reporting bias)

High risk

Piritramide consumption reported at several time points, but only described as being assessed at $6 \mathrm{~h}$ and $24 \mathrm{~h}$ in methods. Vital signs assessed, but data not reported. Adverse events not reported in detail.

Sample size High risk

31, 32, and 29 participants in diclofenac, placebo, and azapropazone groups, respectively

AE: adverse event; ASA: American Society of Anesthesiologists; BOCF: baseline observation carried forward; $\mathrm{BP}$ : blood pressure; Cl: confidence interval; ECG: electrocardiogram; HPBCD: hydroxypropyl- $\beta$-cyclodextrin; HR: heart rate; ITT: intention-to-treat; IV: intravenous; LOCF: last observation carried forward; NRS: numerical rating scale; NSAID: non-steroidal anti-inflammatory drug; PCA: patient-controlled analgesia; PG-BA: polyethylene glycol and benzyl alcohol; PID: pain intensity difference; SD: standard deviation; SPID: summed pain intensity difference; TOTPAR: total pain relief; VAS: visual analogue scale; VRS: verbal rating scale; WOCF: worst observation carried forward.

Characteristics of excluded studies [ordered by study ID]

\begin{tabular}{|c|c|}
\hline Study & Reason for exclusion \\
\hline Aho 1991 & Study duration $<4 \mathrm{~h}$ \\
\hline Al-Khtoum 2006 & Administered preoperatively \\
\hline Albrecht 1992 & Wrong route of administration \\
\hline Anil 2016 & Administered intraoperatively \\
\hline Arslan 2009 & Abstract with insufficient data for analysis \\
\hline Baroni 1983 & Wrong route of administration \\
\hline Bhoyar 2015 & Administered intraoperatively \\
\hline Bossi 1984 & Wrong route of administration \\
\hline Bricker 1987 & Administered preoperatively \\
\hline Campbell 1990 & Administered preoperatively \\
\hline Carlborg 1987 & Wrong route of administration \\
\hline Chelly 2013 & Not double-blind \\
\hline Chongsomchai 2009 & Abstract with insufficient data for analysis \\
\hline Daniels 2013 & Multiple-dose study with no first-dose data \\
\hline Daniels 2016 & Multiple-dose analysis of 2 studies with no first-dose data \\
\hline De La Paz 2009 & Administered preoperatively \\
\hline Elliott 2000 & Wrong route of administration \\
\hline Forrest 2002 & Multiple-dose study with no first-dose data \\
\hline Frame 1986 & Not double-blind \\
\hline
\end{tabular}




\begin{tabular}{|c|c|}
\hline Study & Reason for exclusion \\
\hline Frezza 1985 & Fewer than 10 participants in each arm \\
\hline Gan 2016 & Multiple-dose analysis of 2 studies with no first-dose data \\
\hline Gan 2017 & Multiple-dose analysis of 2 studies with no first-dose data \\
\hline Gunes 2011 & Administered intraoperatively \\
\hline Henrikson 1982 & Wrong route of administration \\
\hline Hernandez 1997 & Wrong route of administration \\
\hline Hultman 1989 & Wrong route of administration \\
\hline Hynes 1997 & Wrong route of administration \\
\hline Hynes 2006 & Letter \\
\hline Iwabuchi 1980 & Wrong route of administration \\
\hline Izquierdo 1995a & Not double-blind \\
\hline Kilickaya 2012 & Administered intraoperatively \\
\hline Kose 2012 & Abstract with insufficient data for analysis \\
\hline Kvolik 2010 & Abstract with insufficient data for analysis \\
\hline Labrada 2004 & Administered preoperatively \\
\hline Laitinen 1992 & No baseline pain assessment \\
\hline Litke 1997 & Wrong route of administration \\
\hline Lopez-Carriches 2005 & Wrong route of administration \\
\hline Lovett 1994 & Wrong route of administration \\
\hline Manso 1991 & Wrong route of administration \\
\hline Mastronardi 1988 & Wrong route of administration \\
\hline Mehrotra 1998 & Wrong route of administration \\
\hline Metternich 1998 & Wrong route of administration \\
\hline Moffat 1990 & Wrong route of administration \\
\hline Naclerio-Homem 1996 & Administered preoperatively \\
\hline Nelson 1993 & Wrong route of administration \\
\hline Pellerin 1989 & Wrong route of administration \\
\hline Philip 1985 & Wrong route of administration \\
\hline
\end{tabular}




\begin{tabular}{ll}
\hline Study & Reason for exclusion \\
\hline Rautela 1998 & Wrong route of administration \\
\hline Reyes 1988 & Wrong route of administration \\
\hline Samimi 2014 & Wrong route of administration \\
\hline Sandin 1993 & Wrong route of administration \\
\hline Silvanto 2002 & Multiple-dose study with no first-dose data \\
\hline Thienthong 2012 & No 4- to 6-hour data \\
\hline Zohar 2006 & Administered intraoperatively \\
\hline
\end{tabular}

Characteristics of studies awaiting classification [ordered by study ID]

Kumar 2016

\section{Methods}

Active controlled, parallel group, single dose, single center. Assessments up to $6 \mathrm{~h}$ postinterventions. Interventions administered once participants reported moderate pain.

\section{Type of surgery: elective (no further details)}

\section{Diclofenac group}

Entered/completing: 30/30

Age (mean, SD): $36.7 \pm 12.9$

Sex (male, \%): 15, 50\%

\section{Tramadol group}

Entered/completing: 30/30

Age (mean, SD): $41.5 \pm 15.1$

Sex (male, \%): 14, 47\%

Interventions

Diclofenac: $75 \mathrm{mg}$ in $100 \mathrm{~mL}$ of $0.9 \%$ sodium chloride, single dose administered over 30 minutes in the recovery room

Tramadol: $100 \mathrm{mg}$ in $100 \mathrm{~mL}$ 0.9\% sodium chloride, as with diclofenac

\begin{tabular}{ll}
\hline Outcomes & Time to onset of analgesia (not defined) \\
& Duration of analgesia (not defined) \\
& Vital signs \\
& Adverse events \\
\hline Notes & $\begin{array}{l}\text { States that participants were blinded, but no mention of investigator blinding. Authors did not re- } \\
\text { ply to request for clarification. }\end{array}$ \\
\hline
\end{tabular}


Characteristics of ongoing studies [ordered by study ID]

NCT03493490

Study name

Methods

Methods

Neodolpasse infusion solution versus diclofenac $75 \mathrm{mg}$ infusion in the treatment of postoperative pain after elective knee surgery

Placebo- and active-controlled, triple-blind, parallel-group, single-center exploratory phase 4 study. Outcomes assessed over the first $48 \mathrm{~h}$ postsurgery. Participant randomization takes place postsurgery as soon as the participant is able to adequately co-operate. Ability to co-operate is defined as successful VAS assessment. The first infusion of the intervention is started immediately after randomization.

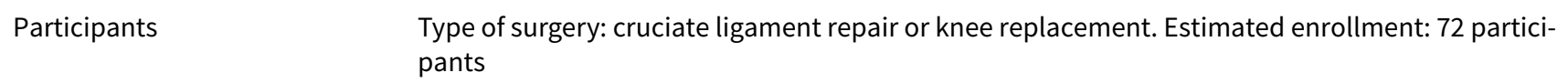

Interventions Diclofenac: $75 \mathrm{mg} / 250 \mathrm{~mL} \mathrm{IV} \mathrm{administered} \mathrm{over} 30$ minutes as soon as participant is able to complete a VAS assessment postsurgery. Dose repeated $8 \mathrm{~h}$ later.

Placebo: $250 \mathrm{~mL}$ 0.9\% sodium chloride, as with diclofenac

\section{Diclofenac/orphenadrine:}

Diclofenac $75 \mathrm{mg}+$ orphenadrine $30 \mathrm{mg} / 250 \mathrm{~mL}$, as with diclofenac

Outcomes Primary:

Total dose of patient-controlled analgesia hydromorphone required over the first 24 hours postsurgery. Measured in numbers of boli as well as milligrams.

Secondary:

Pain relief during the infusion periods and until $48 \mathrm{~h}$ after the intervention using a VAS

\begin{tabular}{ll}
\hline Starting date & 1 March 2018 \\
\hline Contact information & Oliver Kimberger, MD; study@kimberger.at \\
\hline Notes & $\begin{array}{l}\text { No mention of minimum pain intensity requirement for inclusion. Unclear if data assessed over 4- } \\
\text { to 6-hour period postintervention. }\end{array}$ \\
\hline
\end{tabular}

IV: intravenous; VAS: visual analogue scale.

\section{DATA AND ANALYSES}

Comparison 1. Diclofenac versus placebo

\begin{tabular}{lllll}
\hline Outcome or subgroup title & No. of studies & $\begin{array}{l}\text { No. of partici- } \\
\text { pants }\end{array}$ & Statistical method & Effect size \\
\hline $\begin{array}{l}1.1 \text { Number of participants with at least } \\
50 \% \text { pain relief at } 4 \text { hours }\end{array}$ & 3 & 277 & $\begin{array}{l}\text { Risk Ratio (M-H, Fixed, } \\
95 \% \mathrm{Cl})\end{array}$ & $2.82[2.01,3.97]$ \\
\hline $\begin{array}{l}1.2 \text { Number of participants with at least } \\
50 \% \text { pain relief at } 6 \text { hours }\end{array}$ & 4 & 436 & $\begin{array}{l}\text { Risk Ratio (M-H, Fixed, } \\
95 \% \mathrm{Cl})\end{array}$ & $1.76[1.42,2.17]$ \\
\hline
\end{tabular}




\begin{tabular}{|c|c|c|c|c|}
\hline Outcome or subgroup title & No. of studies & $\begin{array}{l}\text { No. of partici- } \\
\text { pants }\end{array}$ & Statistical method & Effect size \\
\hline $\begin{array}{l}\text { 1.3 Number of participants using rescue } \\
\text { medication over } 4 \text { to } 6 \text { hours postinterven- } \\
\text { tions }\end{array}$ & 2 & 235 & $\begin{array}{l}\text { Risk Ratio (M-H, Fixed, } \\
95 \% \mathrm{Cl})\end{array}$ & $0.59[0.48,0.73]$ \\
\hline $\begin{array}{l}\text { 1.4 Number of participants withdrawing } \\
\text { due to lack of efficacy }\end{array}$ & 2 & 268 & $\begin{array}{l}\text { Risk Ratio (M-H, Fixed, } \\
95 \% \mathrm{Cl})\end{array}$ & $1.00[0.38,2.62]$ \\
\hline $\begin{array}{l}1.5 \text { Number of participants withdrawing } \\
\text { due to adverse events }\end{array}$ & 4 & 409 & $\begin{array}{l}\text { Risk Ratio (M-H, Fixed, } \\
95 \% \mathrm{Cl})\end{array}$ & $\begin{array}{l}7.88[0.43 \\
143.94]\end{array}$ \\
\hline $\begin{array}{l}1.6 \text { Number of participants withdrawing for } \\
\text { any cause }\end{array}$ & 4 & 370 & $\begin{array}{l}\text { Risk Ratio (M-H, Fixed, } \\
95 \% \mathrm{Cl})\end{array}$ & $0.64[0.39,1.06]$ \\
\hline $\begin{array}{l}1.7 \text { Number of participants reporting any } \\
\text { adverse event }\end{array}$ & 2 & 296 & $\begin{array}{l}\text { Risk Ratio (M-H, Fixed, } \\
95 \% \mathrm{Cl})\end{array}$ & $0.99[0.86,1.14]$ \\
\hline $\begin{array}{l}1.8 \text { Number of participants experiencing a } \\
\text { serious adverse event }\end{array}$ & 5 & 472 & $\begin{array}{l}\text { Risk Ratio (M-H, Fixed, } \\
95 \% \mathrm{Cl})\end{array}$ & $1.02[0.15,7.02]$ \\
\hline $\begin{array}{l}1.9 \text { Number of participants experiencing } \\
\text { renal dysfunction }\end{array}$ & 3 & 331 & $\begin{array}{l}\text { Risk Ratio (M-H, Fixed, } \\
95 \% \mathrm{Cl})\end{array}$ & $0.33[0.01,7.85]$ \\
\hline $\begin{array}{l}\text { 1.10 Number of participants experiencing a } \\
\text { cardiovascular event }\end{array}$ & 2 & 268 & $\begin{array}{l}\text { Risk Ratio (M-H, Fixed, } \\
95 \% \mathrm{Cl})\end{array}$ & $0.50[0.15,1.64]$ \\
\hline $\begin{array}{l}1.11 \text { Number of participants experiencing } \\
\text { bleeding }\end{array}$ & 2 & 268 & $\begin{array}{l}\text { Risk Ratio (M-H, Fixed, } \\
95 \% \mathrm{Cl})\end{array}$ & $0.89[0.30,2.68]$ \\
\hline $\begin{array}{l}1.12 \text { Number of participants experiencing } \\
\text { thrombophlebitis }\end{array}$ & 3 & 370 & $\begin{array}{l}\text { Risk Ratio (M-H, Fixed, } \\
95 \% \mathrm{Cl})\end{array}$ & $0.54[0.20,1.44]$ \\
\hline $\begin{array}{l}1.13 \text { Number of participants reporting nau- } \\
\text { sea }\end{array}$ & 3 & 401 & $\begin{array}{l}\text { Risk Ratio (M-H, Fixed, } \\
95 \% \mathrm{Cl})\end{array}$ & $0.68[0.47,0.99]$ \\
\hline $\begin{array}{l}\text { 1.14 Number of participants experiencing } \\
\text { vomiting }\end{array}$ & 3 & 401 & $\begin{array}{l}\text { Risk Ratio (M-H, Fixed, } \\
95 \% \mathrm{Cl})\end{array}$ & $0.49[0.26,0.91]$ \\
\hline $\begin{array}{l}1.15 \text { Number of participants with at least } \\
50 \% \text { pain relief at } 6 \text { hours: } 18.75 \mathrm{mg}\end{array}$ & 2 & 262 & $\begin{array}{l}\text { Risk Ratio (M-H, Fixed, } \\
95 \% \mathrm{Cl})\end{array}$ & $1.61[1.24,2.10]$ \\
\hline
\end{tabular}


Analysis 1.1. Comparison 1: Diclofenac versus placebo, Outcome 1: Number of participants with at least $50 \%$ pain relief at 4 hours

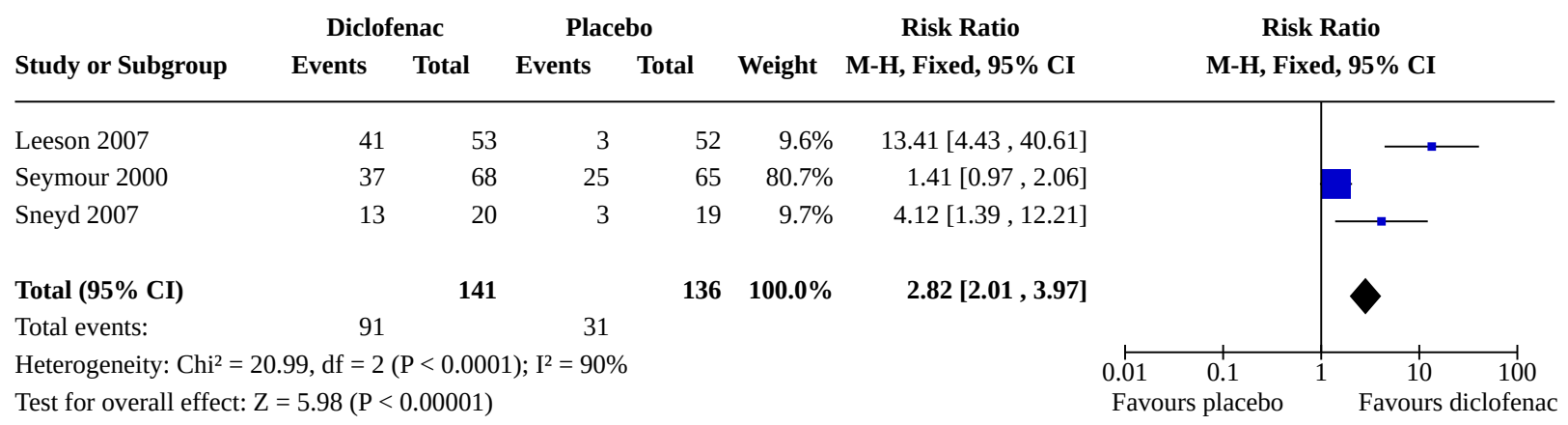

Test for subgroup differences: Not applicable

Analysis 1.2. Comparison 1: Diclofenac versus placebo, Outcome 2: Number of participants with at least $50 \%$ pain relief at 6 hours

$\begin{array}{llll}\text { Diclofenac } & \text { Placebo } & \text { Risk Ratio } & \text { Risk Ratio }\end{array}$

Study or Subgroup $\quad$ Events $\quad$ Total $\quad$ Events $\quad$ Total $\quad$ Weight $\quad$ M-H, Fixed, 95\% CI $\quad$ M-H, Fixed, 95\% CI

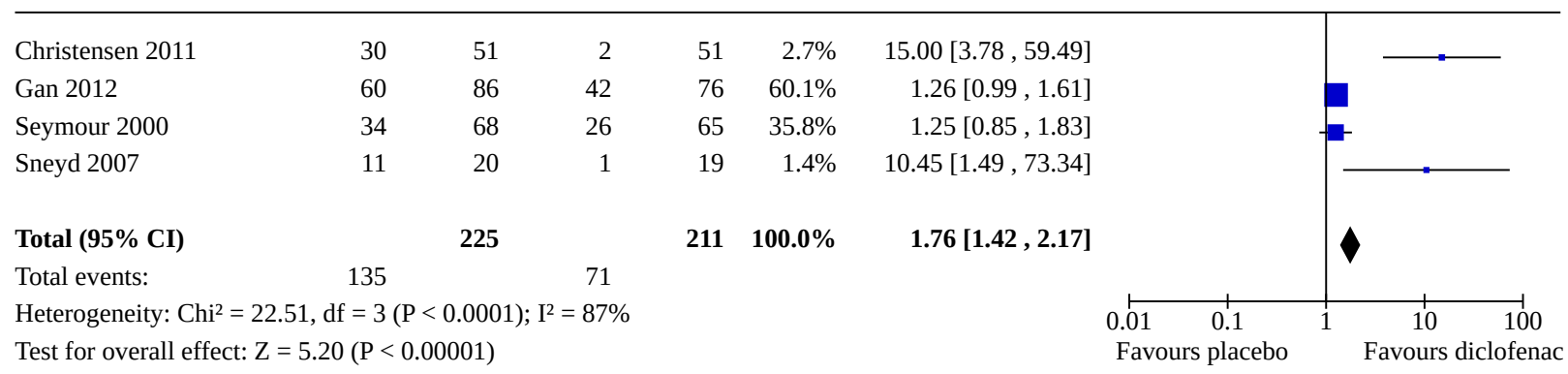

Test for subgroup differences: Not applicable

Analysis 1.3. Comparison 1: Diclofenac versus placebo, Outcome 3: Number of participants using rescue medication over 4 to 6 hours postinterventions

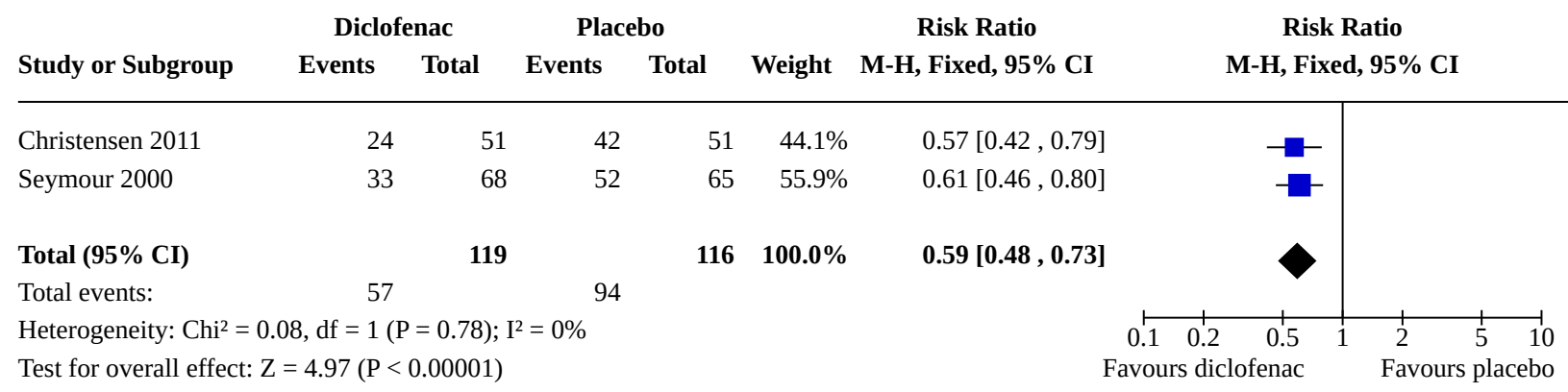


Analysis 1.4. Comparison 1: Diclofenac versus placebo, Outcome 4: Number of participants withdrawing due to lack of efficacy

\begin{tabular}{|c|c|c|c|c|c|c|c|}
\hline \multirow[b]{2}{*}{ Study or Subgroup } & \multicolumn{2}{|c|}{ Diclofenac } & \multicolumn{2}{|c|}{ Placebo } & \multirow[b]{2}{*}{ Weight } & \multirow{2}{*}{$\begin{array}{c}\text { Risk Ratio } \\
\text { M-H, Fixed, 95\% CI }\end{array}$} & \multirow{2}{*}{$\begin{array}{c}\text { Risk Ratio } \\
\text { M-H, Fixed, 95\% CI }\end{array}$} \\
\hline & Events & Total & Events & Total & & & \\
\hline Gan 2012 & 8 & 87 & 7 & 76 & $100.0 \%$ & $1.00[0.38,2.62]$ & \\
\hline Leeson 2007 & 0 & 53 & 0 & 52 & & Not estimable & \\
\hline Total $(95 \%$ CI $)$ & & 140 & & 128 & $100.0 \%$ & $1.00[0.38,2.62]$ & \\
\hline Total events: & 8 & & 7 & & & & \\
\hline \multirow{2}{*}{\multicolumn{3}{|c|}{$\begin{array}{l}\text { Heterogeneity: Not applicable } \\
\text { Test for overall effect: } \mathrm{Z}=0.00(\mathrm{P}=1.00)\end{array}$}} & & & & & $0 . \stackrel{b}{1}^{\prime} \quad 0.1$ \\
\hline & & & & & & & Favours diclofenac \\
\hline
\end{tabular}

\section{Analysis 1.5. Comparison 1: Diclofenac versus placebo, Outcome} 5: Number of participants withdrawing due to adverse events

\begin{tabular}{|c|c|c|c|c|}
\hline & Dic & nac & & \\
\hline ubgroup & Events & Tota & Event & To \\
\hline
\end{tabular}

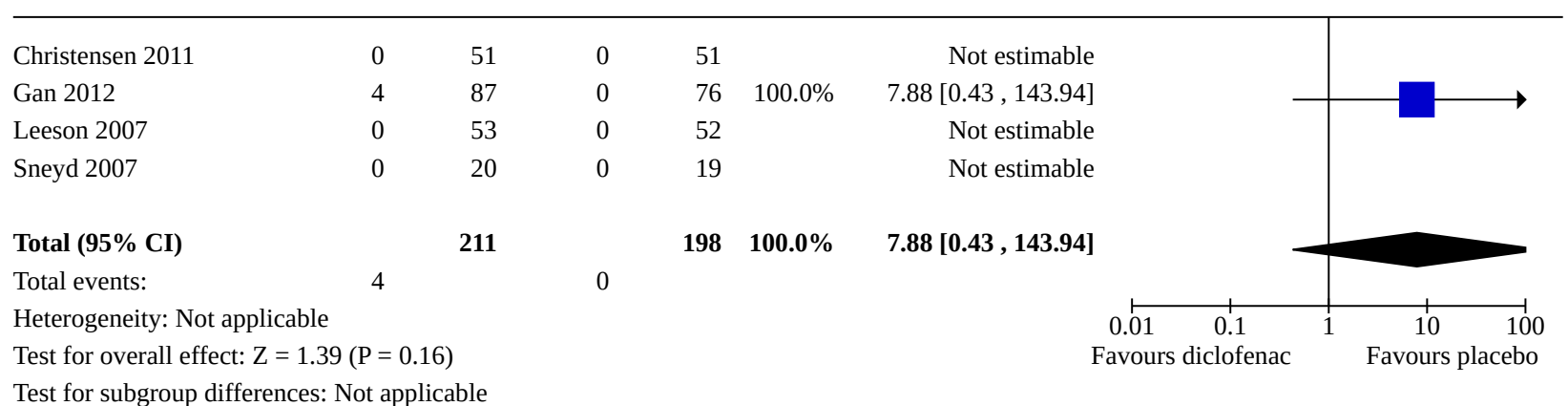

Test for subgroup differences: Not applicable

Analysis 1.6. Comparison 1: Diclofenac versus placebo, Outcome 6: Number of participants withdrawing for any cause

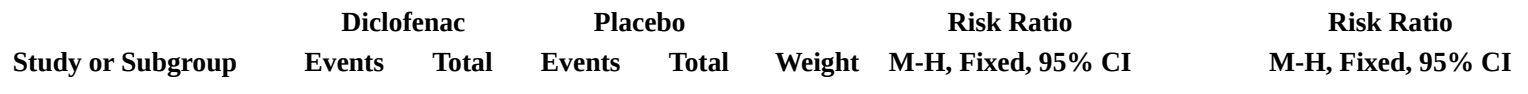

\begin{tabular}{lrrrrrr}
\hline Gan 2012 & 19 & 87 & 19 & 76 & $62.9 \%$ & $0.87[0.50,1.52]$ \\
Leeson 2007 & 0 & 53 & 1 & 52 & $4.7 \%$ & $0.33[0.01,7.85]$ \\
Sneyd 2007 & 0 & 20 & 3 & 19 & $11.1 \%$ & $0.14[0.01,2.47]$ \\
Steffen 1994 & 2 & 31 & 7 & 32 & $21.3 \%$ & $0.29[0.07,1.31]$ \\
& & & & & & \\
Total (95\% CI) & 21 & & 30 & & &
\end{tabular}

Heterogeneity: $\mathrm{Chi}^{2}=3.49, \mathrm{df}=3(\mathrm{P}=0.32) ; \mathrm{I}^{2}=14 \%$

Test for overall effect: $\mathrm{Z}=1.75(\mathrm{P}=0.08)$

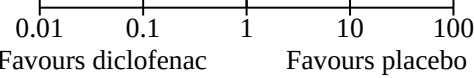

Test for subgroup differences: Not applicable 
Analysis 1.7. Comparison 1: Diclofenac versus placebo, Outcome 7: Number of participants reporting any adverse event

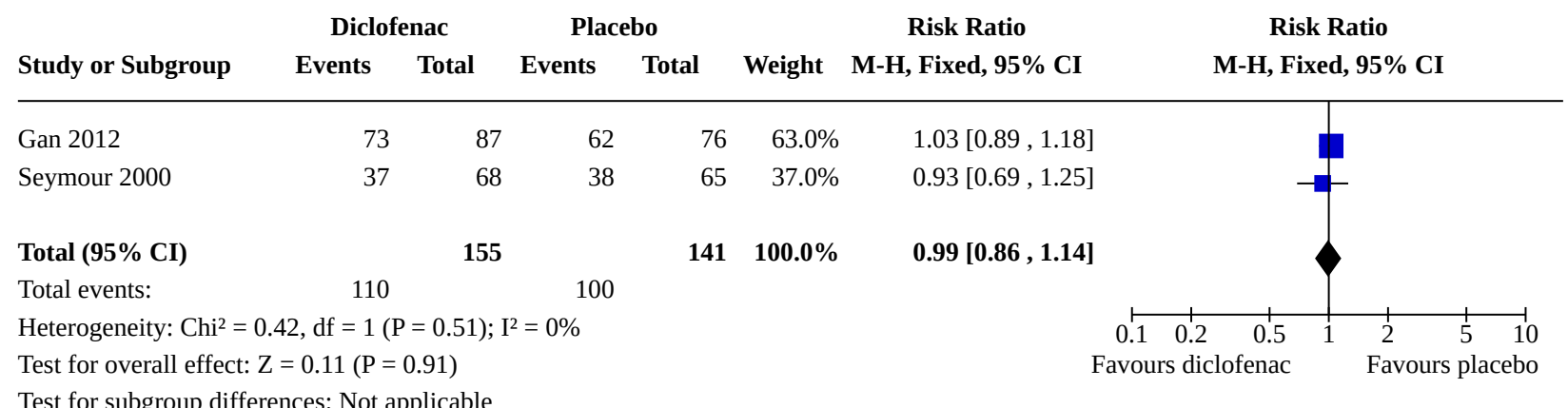

Analysis 1.8. Comparison 1: Diclofenac versus placebo, Outcome 8: Number of participants experiencing a serious adverse event

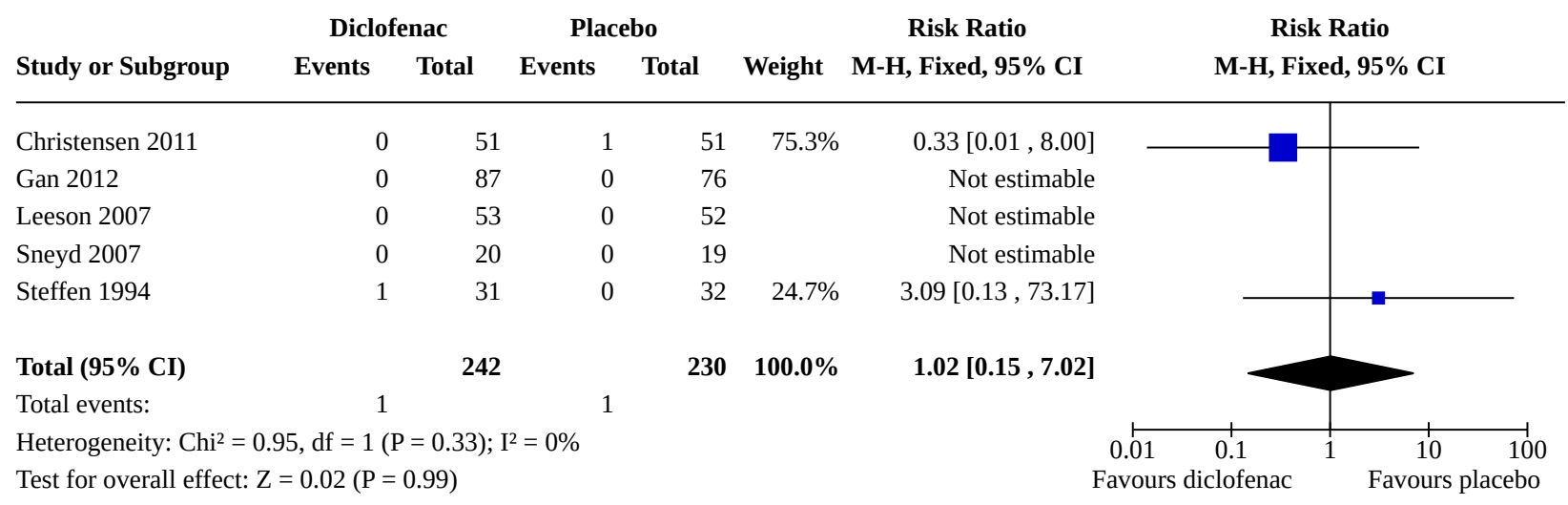

Test for subgroup differences: Not applicable

Analysis 1.9. Comparison 1: Diclofenac versus placebo, Outcome 9: Number of participants experiencing renal dysfunction
Diclofenac
Placebo
Risk Ratio
Risk Ratio

Study or Subgroup

Events Total Events Total

Weight M-H, Fixed, 95\% CI

M-H, Fixed, 95\% CI

\begin{tabular}{|c|c|c|c|c|c|c|}
\hline Gan 2012 & 0 & 87 & 0 & 76 & & Not estimable \\
\hline Leeson 2007 & 0 & 53 & 1 & 52 & $100.0 \%$ & $0.33[0.01,7.85]$ \\
\hline Steffen 1994 & 0 & 31 & 0 & 32 & & Not estimable \\
\hline Total (95\% CI) & & 171 & & 160 & $100.0 \%$ & $0.33[0.01,7.85]$ \\
\hline Total events: & 0 & & 1 & & & \\
\hline
\end{tabular}

Heterogeneity: Not applicable

Test for overall effect: $\mathrm{Z}=0.69(\mathrm{P}=0.49)$

Test for subgroup differences: Not applicable 
Analysis 1.10. Comparison 1: Diclofenac versus placebo, Outcome 10: Number of participants experiencing a cardiovascular event

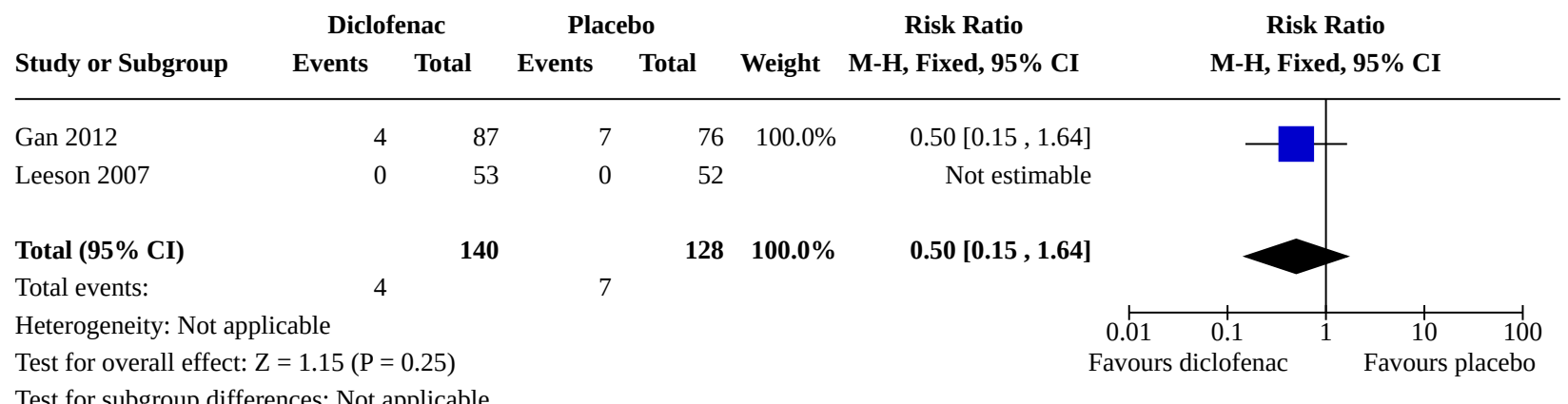

\section{Analysis 1.11. Comparison 1: Diclofenac versus placebo, Outcome 11: Number of participants experiencing bleeding}

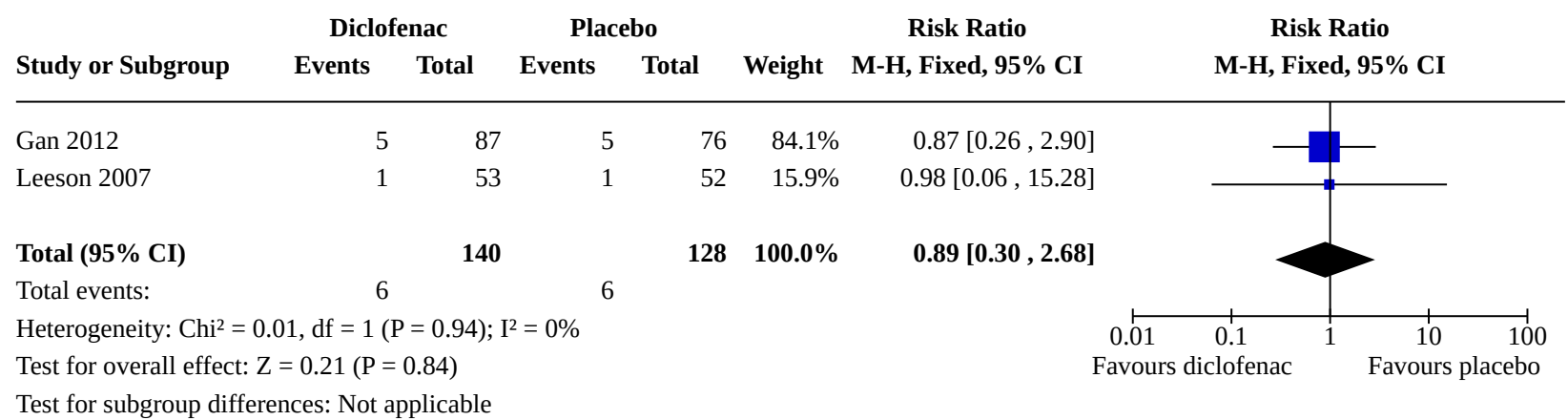

\section{Analysis 1.12. Comparison 1: Diclofenac versus placebo, Outcome 12: Number of participants experiencing thrombophlebitis}

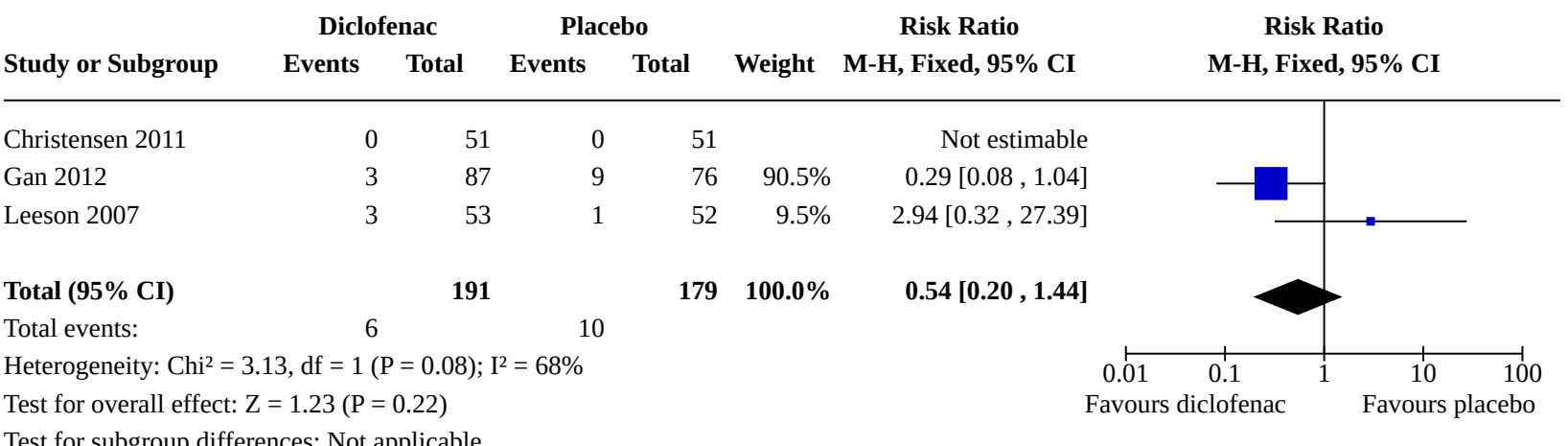


Analysis 1.13. Comparison 1: Diclofenac versus placebo, Outcome 13: Number of participants reporting nausea

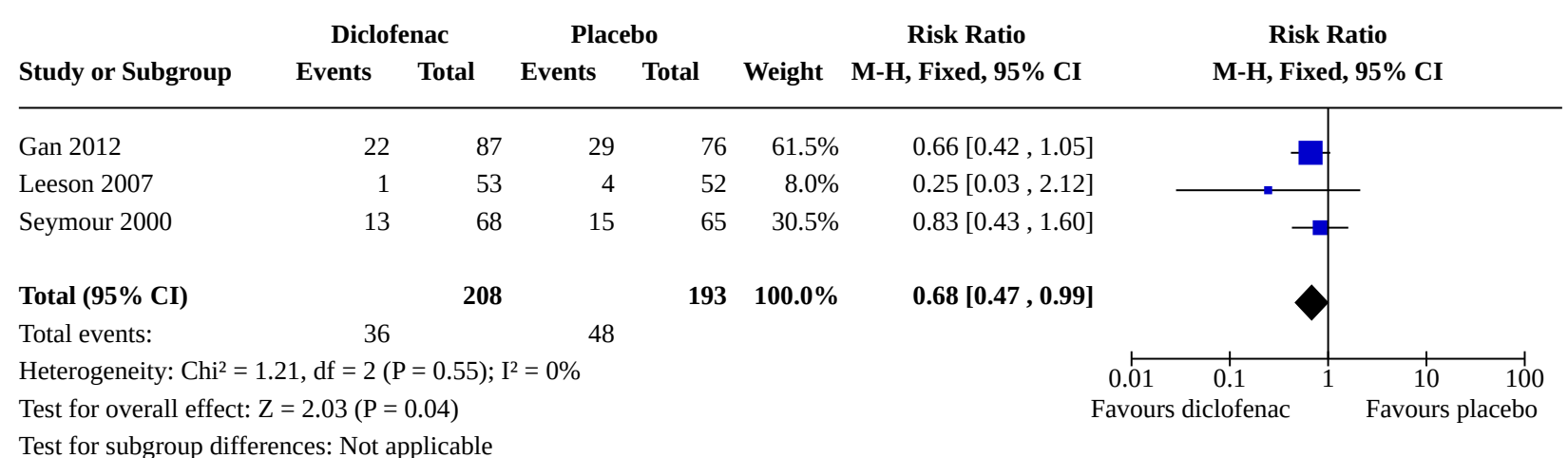

Analysis 1.14. Comparison 1: Diclofenac versus placebo, Outcome 14: Number of participants experiencing vomiting

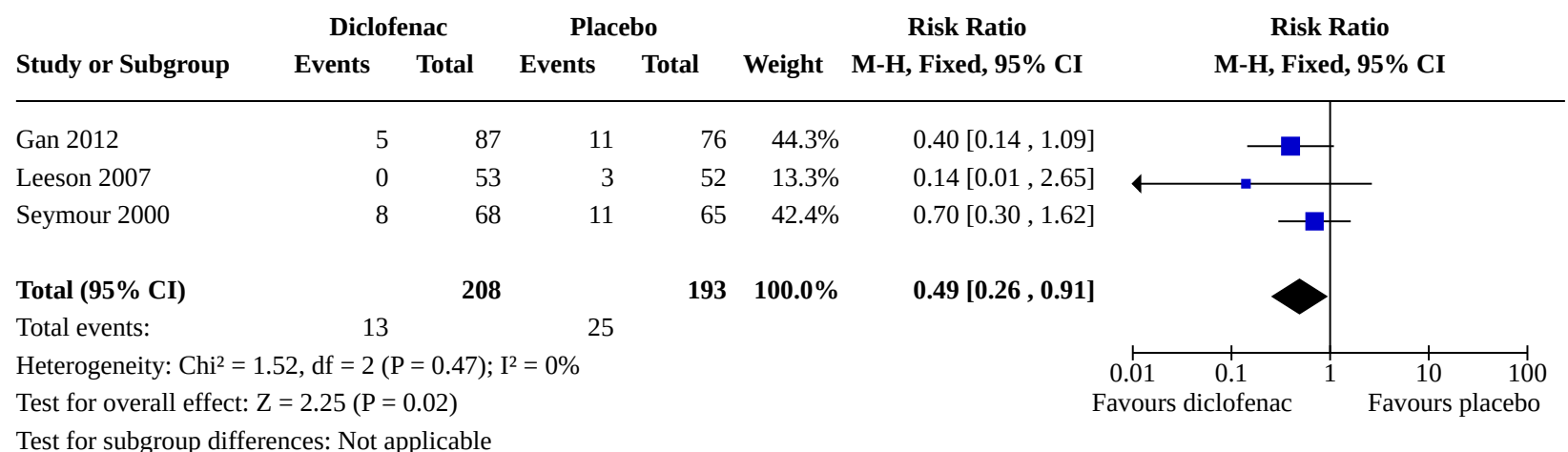

Analysis 1.15. Comparison 1: Diclofenac versus placebo, Outcome 15: Number of participants with at least $50 \%$ pain relief at 6 hours: $18.75 \mathrm{mg}$

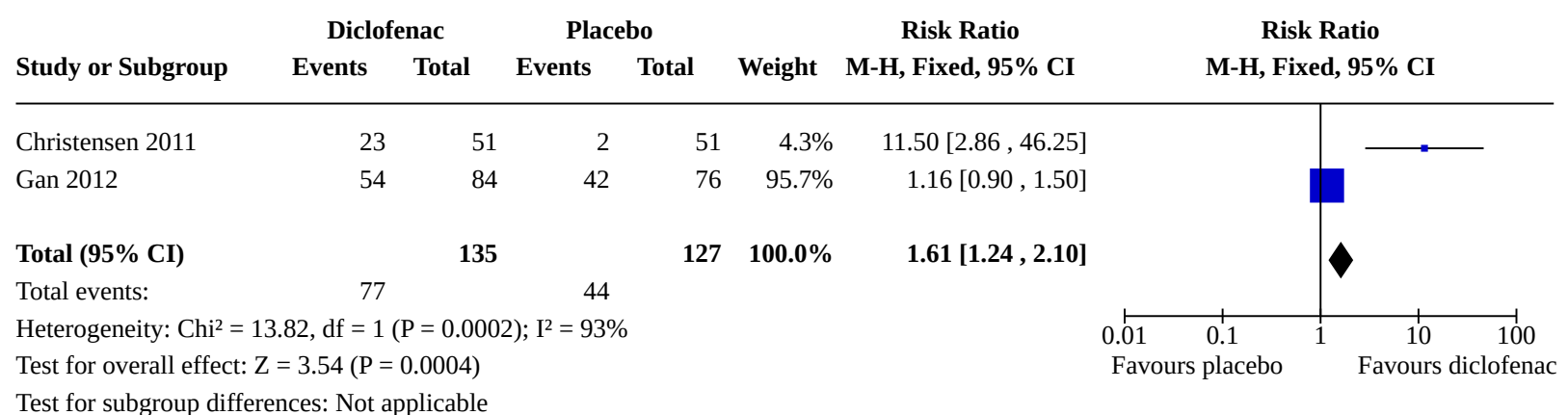

\section{Comparison 2. Diclofenac versus another NSAID}

\begin{tabular}{lllll}
\hline Outcome or subgroup title & No. of studies & $\begin{array}{l}\text { No. of partici- } \\
\text { pants }\end{array}$ & Statistical method & Effect size \\
\hline $\begin{array}{l}\text { 2.1 Number of participants with at least } \\
50 \% \text { pain relief at } 6 \text { hours }\end{array}$ & 3 & 360 & $\begin{array}{l}\text { Risk Ratio (M-H, Fixed, } \\
95 \% \mathrm{Cl})\end{array}$ & $0.94[0.83,1.06]$ \\
\hline \hline
\end{tabular}

Single-dose intravenous diclofenac for acute postoperative pain in adults (Review) 


\begin{tabular}{|c|c|c|c|c|}
\hline Outcome or subgroup title & No. of studies & $\begin{array}{l}\text { No. of partici- } \\
\text { pants }\end{array}$ & Statistical method & Effect size \\
\hline $\begin{array}{l}\text { 2.2 Number of participants using rescue } \\
\text { medication over } 4 \text { to } 6 \text { hours postinterven- } \\
\text { tions }\end{array}$ & 1 & & $\begin{array}{l}\text { Risk Ratio (M-H, Fixed, } \\
95 \% \mathrm{Cl})\end{array}$ & $\begin{array}{l}\text { Totals not select- } \\
\text { ed }\end{array}$ \\
\hline $\begin{array}{l}2.3 \text { Number of participants withdrawing } \\
\text { due to lack of efficacy }\end{array}$ & 1 & & $\begin{array}{l}\text { Risk Ratio (M-H, Fixed, } \\
95 \% \mathrm{Cl})\end{array}$ & $\begin{array}{l}\text { Totals not select- } \\
\text { ed }\end{array}$ \\
\hline $\begin{array}{l}\text { 2.4 Number of participants withdrawing } \\
\text { due to adverse events }\end{array}$ & 2 & 267 & $\begin{array}{l}\text { Risk Ratio (M-H, Fixed, } \\
95 \% \mathrm{Cl})\end{array}$ & $1.89[0.35,10.02]$ \\
\hline $\begin{array}{l}2.5 \text { Number of participants withdrawing for } \\
\text { any cause }\end{array}$ & 2 & 229 & $\begin{array}{l}\text { Risk Ratio (M-H, Fixed, } \\
95 \% \mathrm{Cl})\end{array}$ & $1.16[0.65,2.07]$ \\
\hline $\begin{array}{l}\text { 2.6 Number of participants reporting any } \\
\text { adverse event }\end{array}$ & 2 & 265 & $\begin{array}{l}\text { Risk Ratio (M-H, Fixed, } \\
95 \% \mathrm{Cl})\end{array}$ & $0.93[0.82,1.06]$ \\
\hline $\begin{array}{l}\text { 2.7 Number of participants experiencing a } \\
\text { serious adverse event }\end{array}$ & 4 & 423 & $\begin{array}{l}\text { Risk Ratio (M-H, Fixed, } \\
95 \% \mathrm{Cl})\end{array}$ & $0.94[0.13,6.58]$ \\
\hline $\begin{array}{l}\text { 2.8 Number of participants experiencing } \\
\text { renal dysfunction }\end{array}$ & 3 & 325 & $\begin{array}{l}\text { Risk Ratio (M-H, Fixed, } \\
95 \% \mathrm{Cl})\end{array}$ & Not estimable \\
\hline $\begin{array}{l}2.9 \text { Number of participants experiencing a } \\
\text { cardiovascular event }\end{array}$ & 2 & 265 & $\begin{array}{l}\text { Risk Ratio (M-H, Fixed, } \\
95 \% \mathrm{Cl})\end{array}$ & $0.75[0.21,2.71]$ \\
\hline $\begin{array}{l}\text { 2.10 Number of participants experiencing } \\
\text { bleeding }\end{array}$ & 2 & 265 & $\begin{array}{l}\text { Risk Ratio (M-H, Fixed, } \\
95 \% \mathrm{Cl})\end{array}$ & $0.94[0.28,3.14]$ \\
\hline $\begin{array}{l}\text { 2.11 Number of participants experiencing } \\
\text { thrombophlebitis }\end{array}$ & 3 & 367 & $\begin{array}{l}\text { Risk Ratio (M-H, Fixed, } \\
95 \% \mathrm{Cl})\end{array}$ & $0.47[0.12,1.82]$ \\
\hline $\begin{array}{l}2.12 \text { Number of participants with at least } \\
50 \% \text { pain relief at } 6 \text { hours: } 18.75 \mathrm{mg}\end{array}$ & 2 & 264 & $\begin{array}{l}\text { Risk Ratio (M-H, Fixed, } \\
95 \% \mathrm{Cl})\end{array}$ & $0.78[0.65,0.93]$ \\
\hline
\end{tabular}

\section{Analysis 2.1. Comparison 2: Diclofenac versus another NSAID, Outcome 1: Number of participants with at least $50 \%$ pain relief at 6 hours}

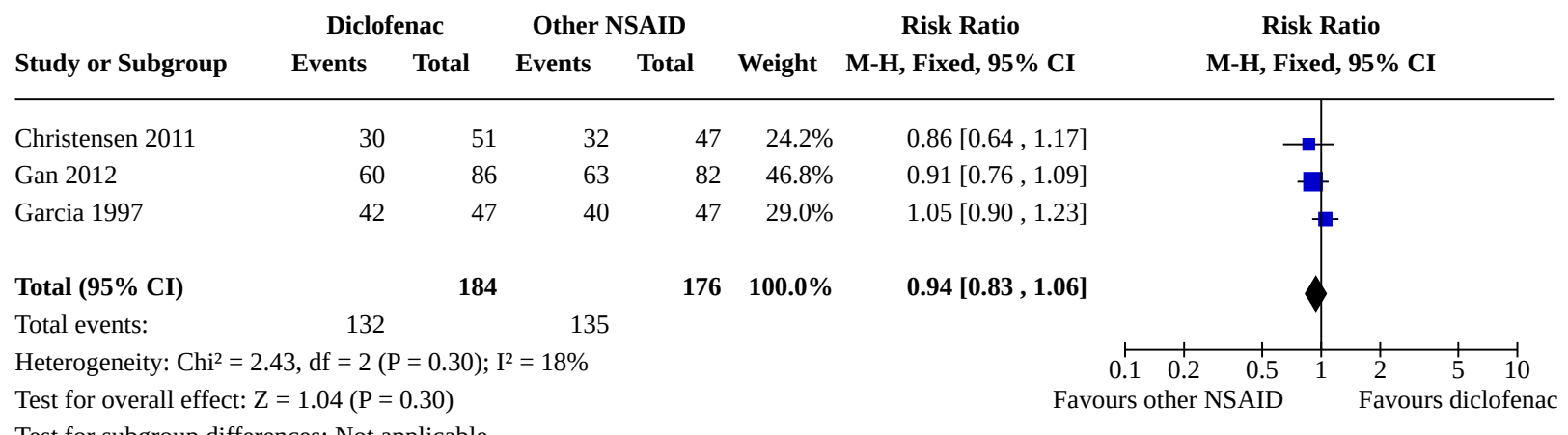


Analysis 2.2. Comparison 2: Diclofenac versus another NSAID, Outcome 2: Number of participants using rescue medication over 4 to 6 hours postinterventions

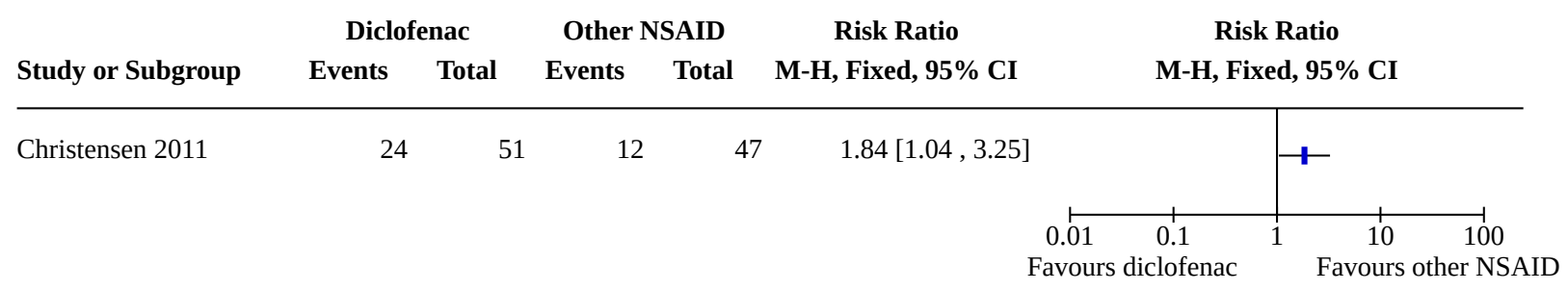

Analysis 2.3. Comparison 2: Diclofenac versus another NSAID, Outcome 3: Number of participants withdrawing due to lack of efficacy

\begin{tabular}{lcccccc} 
& \multicolumn{2}{c}{ Diclofenac } & \multicolumn{2}{c}{ Other NSAID } & Risk Ratio & Risk Ratio \\
Study or Subgroup & Events & Total & Events & Total & M-H, Fixed, 95\% CI & M-H, Fixed, 95\% CI
\end{tabular}

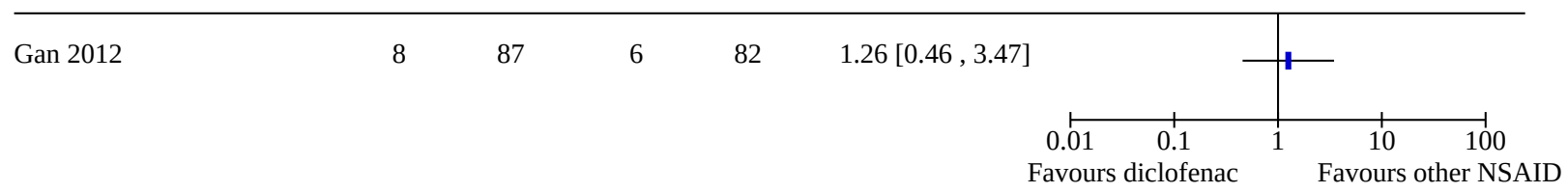

Analysis 2.4. Comparison 2: Diclofenac versus another NSAID, Outcome 4: Number of participants withdrawing due to adverse events

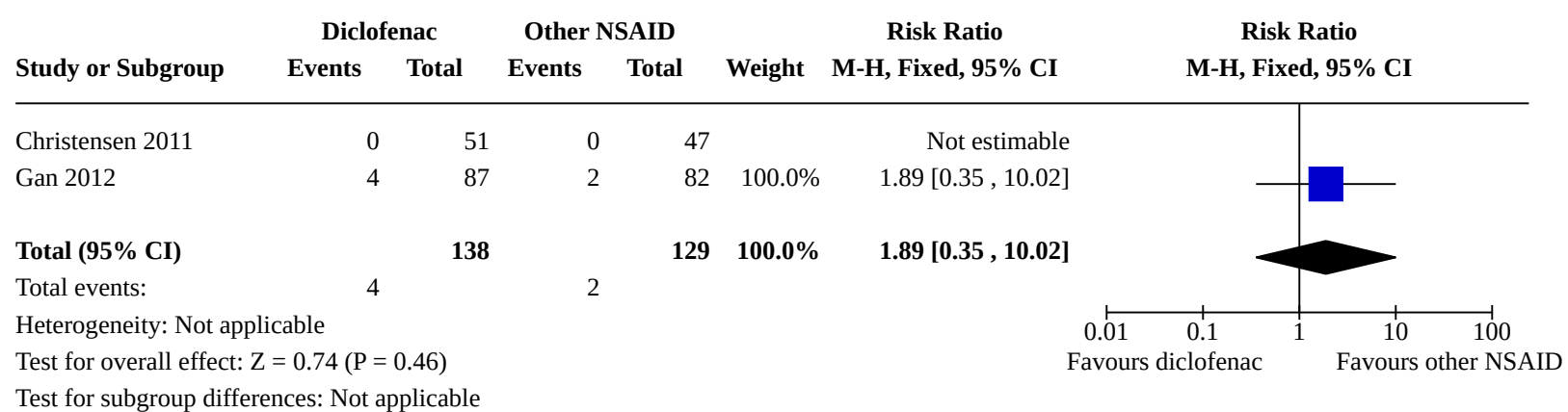

Analysis 2.5. Comparison 2: Diclofenac versus another NSAID, Outcome 5: Number of participants withdrawing for any cause

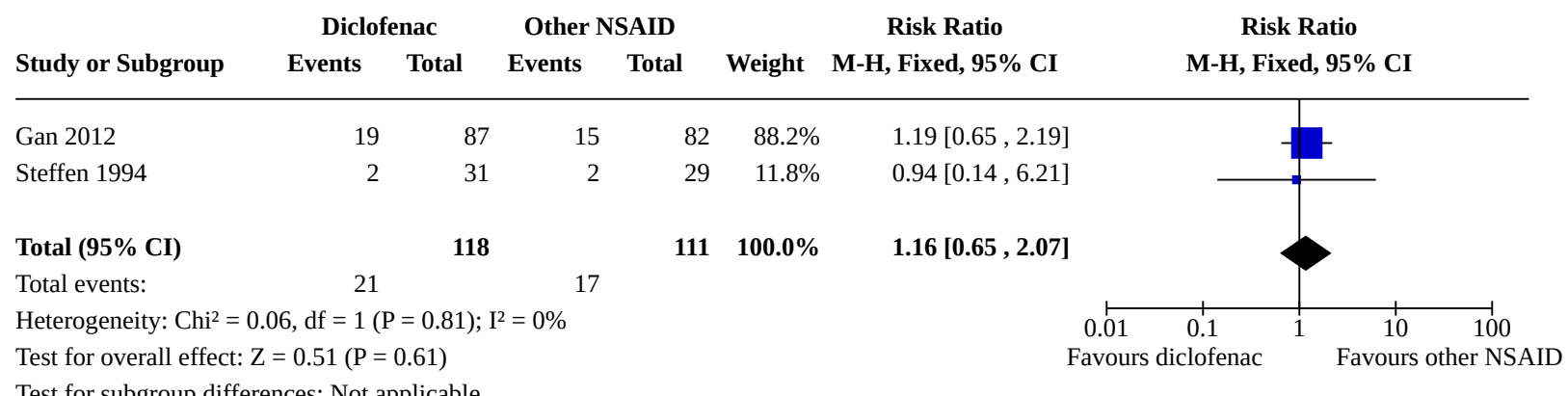


Analysis 2.6. Comparison 2: Diclofenac versus another NSAID, Outcome 6: Number of participants reporting any adverse event

\begin{tabular}{lccccccc} 
& \multicolumn{2}{c}{ Diclofenac } & \multicolumn{2}{c}{ Other NSAID } & \multicolumn{2}{c}{ Risk Ratio } & \multicolumn{2}{c}{ Risk Ratio } \\
Study or Subgroup & Events & Total & Events & Total & Weight & M-H, Fixed, 95\% CI & M-H, Fixed, 95\% CI
\end{tabular}

\begin{tabular}{lrrrrrr}
\hline Gan 2012 & 73 & 87 & 72 & 82 & $96.1 \%$ & $0.96[0.85,1.08]$ \\
Garcia 1997 & 1 & 48 & 3 & 48 & $3.9 \%$ & $0.33[0.04,3.09]$ \\
& & & & & & \\
Total (95\% CI) & 74 & & 75 & & &
\end{tabular}

Heterogeneity: $\mathrm{Chi}^{2}=0.99, \mathrm{df}=1(\mathrm{P}=0.32) ; \mathrm{I}^{2}=0 \%$

Test for overall effect: $\mathrm{Z}=1.07(\mathrm{P}=0.28)$

Test for subgroup differences: Not applicable

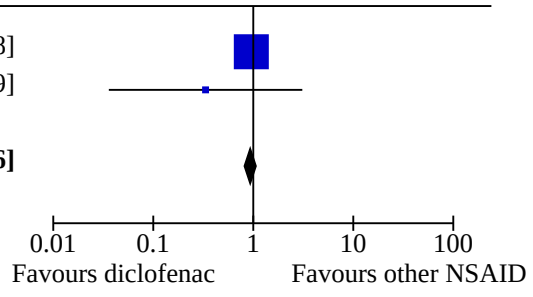

Analysis 2.7. Comparison 2: Diclofenac versus another NSAID, Outcome 7: Number of participants experiencing a serious adverse event

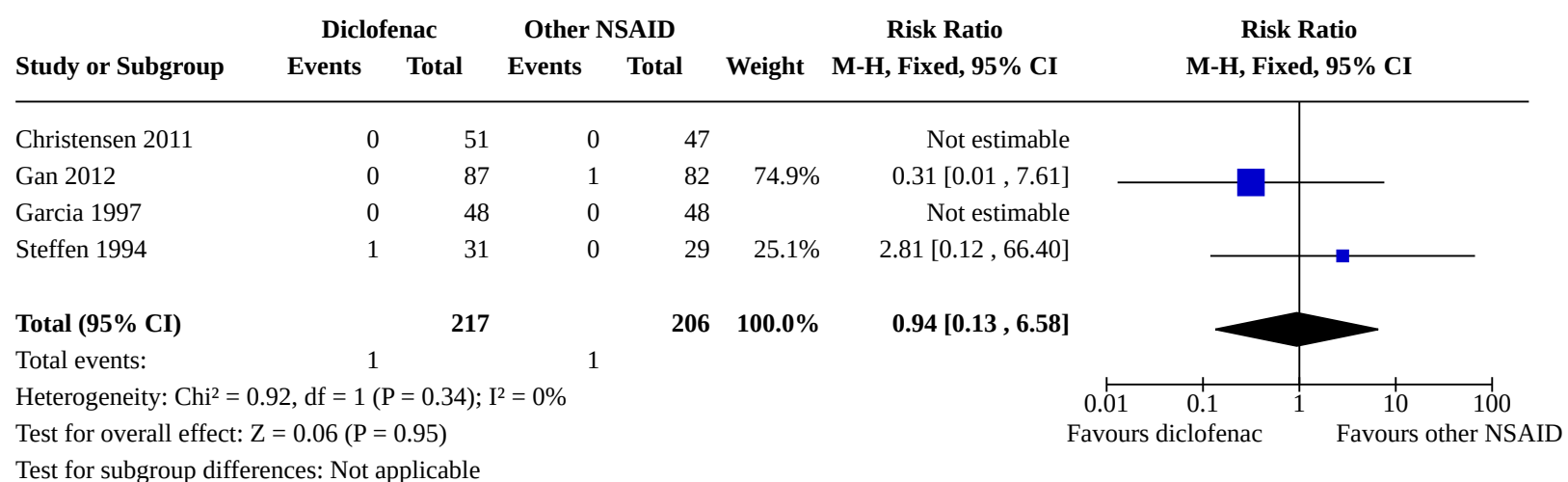

Analysis 2.8. Comparison 2: Diclofenac versus another NSAID, Outcome 8: Number of participants experiencing renal dysfunction

\begin{tabular}{|c|c|c|c|c|c|c|c|}
\hline & Dicl & nac & Other & SAID & & Risk Ratio & Risk Ratio \\
\hline Study or Subgroup & Events & Total & Events & Total & Weight & M-H, Fixed, 95\% CI & M-H. Fixed, 95\% CI \\
\hline
\end{tabular}

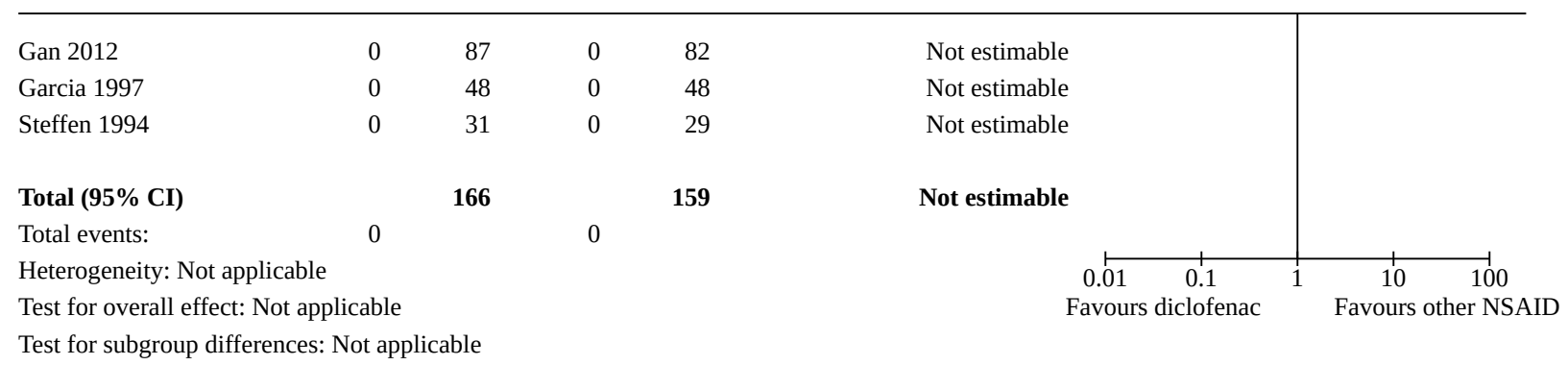


Analysis 2.9. Comparison 2: Diclofenac versus another NSAID, Outcome 9: Number of participants experiencing a cardiovascular event

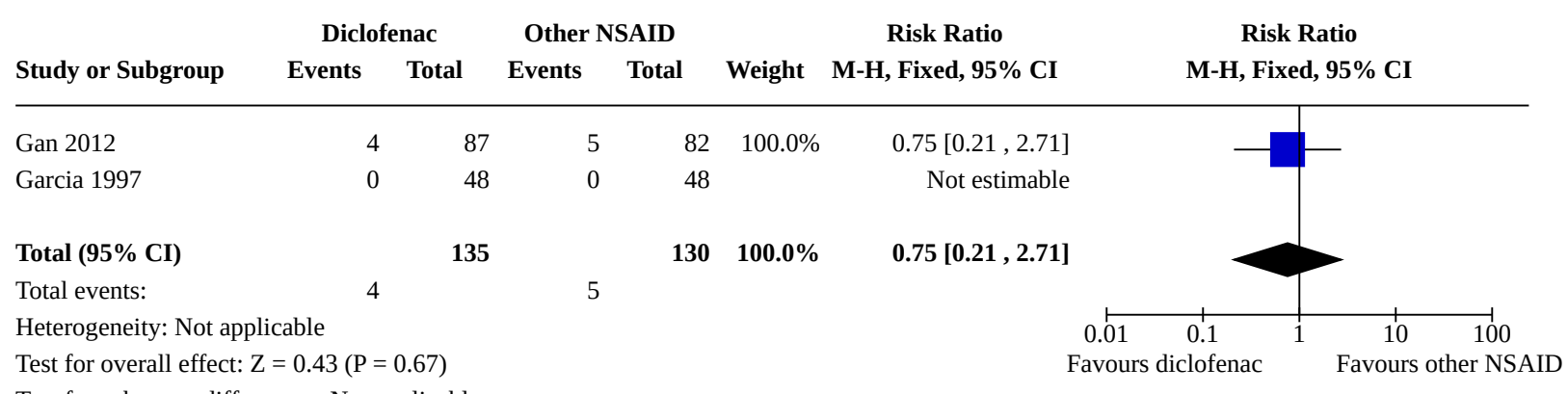

\section{Analysis 2.10. Comparison 2: Diclofenac versus another NSAID, Outcome 10: Number of participants experiencing bleeding}

\begin{tabular}{|c|c|c|c|c|c|c|c|}
\hline \multirow[b]{2}{*}{ Study or Subgroup } & \multicolumn{2}{|c|}{ Diclofenac } & \multicolumn{2}{|c|}{ Other NSAID } & \multirow[b]{2}{*}{ Weight } & \multirow{2}{*}{$\begin{array}{c}\text { Risk Ratio } \\
\text { M-H, Fixed, 95\% CI }\end{array}$} & \multirow{2}{*}{$\begin{array}{c}\text { Risk Ratio } \\
\text { M-H, Fixed, 95\% CI }\end{array}$} \\
\hline & Events & Total & Events & Total & & & \\
\hline Gan 2012 & 5 & 87 & 5 & 82 & $100.0 \%$ & $0.94[0.28,3.14]$ & \\
\hline Garcia 1997 & 0 & 48 & 0 & 48 & & Not estimable & \\
\hline Total (95\% CI) & & 135 & & 130 & $100.0 \%$ & $0.94[0.28,3.14]$ & \\
\hline Total events: & 5 & & 5 & & & & \\
\hline \multirow{2}{*}{\multicolumn{3}{|c|}{$\begin{array}{l}\text { Heterogeneity: Not applicable } \\
\text { Test for overall effect: } \mathrm{Z}=0.10(\mathrm{P}=0.92)\end{array}$}} & & & & & 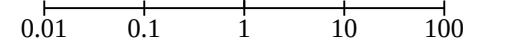 \\
\hline & & & & & & & Favours other NSAID \\
\hline
\end{tabular}

Analysis 2.11. Comparison 2: Diclofenac versus another NSAID, Outcome 11: Number of participants experiencing thrombophlebitis

\begin{tabular}{|c|c|c|c|c|c|c|c|}
\hline & Favours & lofenac & Other & SAID & & Risk Ratio & Risk Ratio \\
\hline Study or Subgroup & Events & Total & Events & Total & Weight & M-H, Fixed, 95\% CI & M-H, Fixed, 95\% CI \\
\hline
\end{tabular}

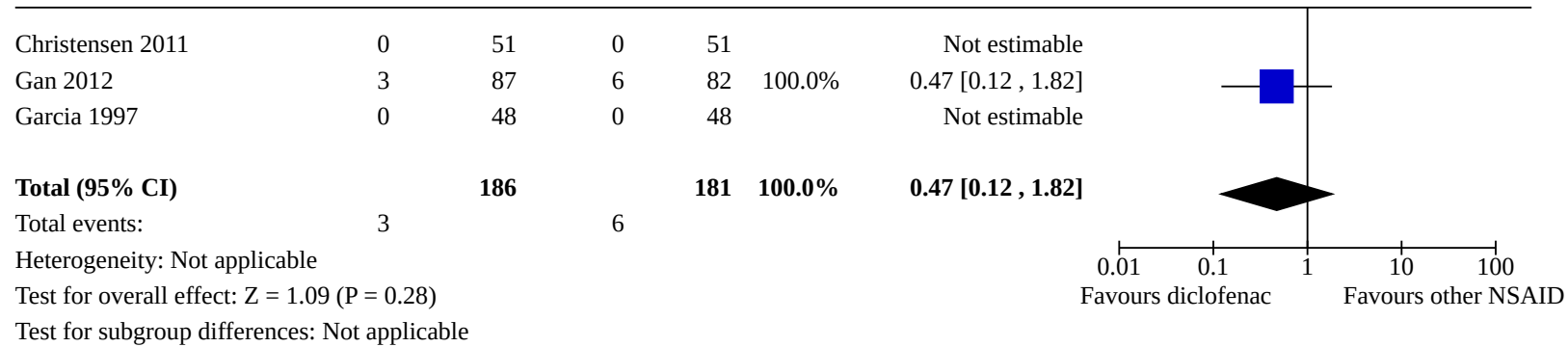


Analysis 2.12. Comparison 2: Diclofenac versus another NSAID, Outcome 12: Number of participants with at least $50 \%$ pain relief at 6 hours: $18.75 \mathrm{mg}$

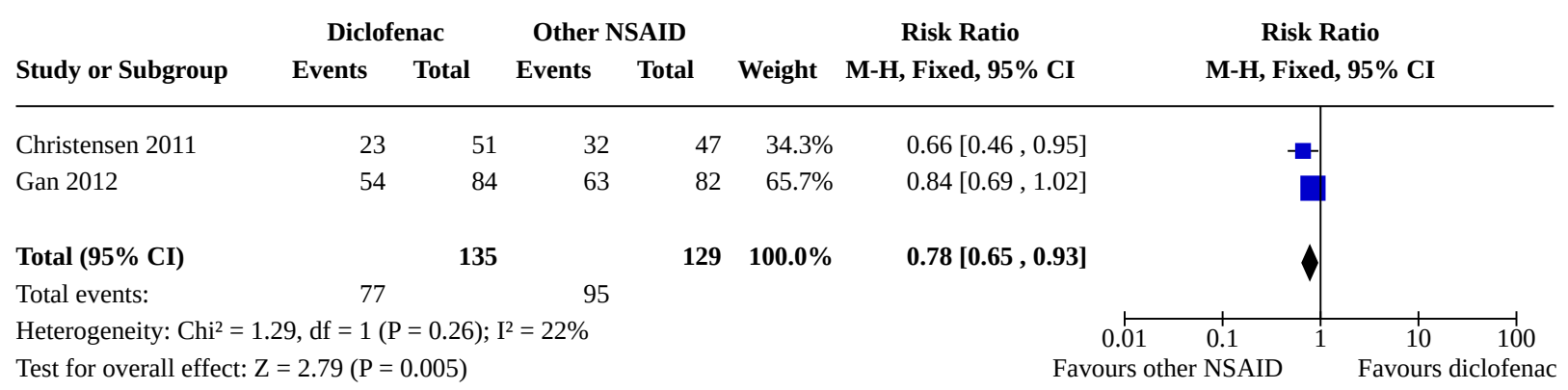

\section{Comparison 3. Diclofenac high dose versus low dose}

\begin{tabular}{lllll}
\hline Outcome or subgroup title & No. of studies & $\begin{array}{l}\text { No. of partici- } \\
\text { pants }\end{array}$ & Statistical method & Effect size \\
\hline $\begin{array}{l}\text { 3.1 Number of participants with at least } \\
\text { 50\% pain relief at } 6 \text { hours }\end{array}$ & 2 & 272 & $\begin{array}{l}\text { Risk Ratio (M-H, Fixed, } \\
95 \% \mathrm{Cl})\end{array}$ & $1.15[0.95,1.39]$ \\
\hline
\end{tabular}

Analysis 3.1. Comparison 3: Diclofenac high dose versus low dose, Outcome 1: Number of participants with at least $50 \%$ pain relief at 6 hours

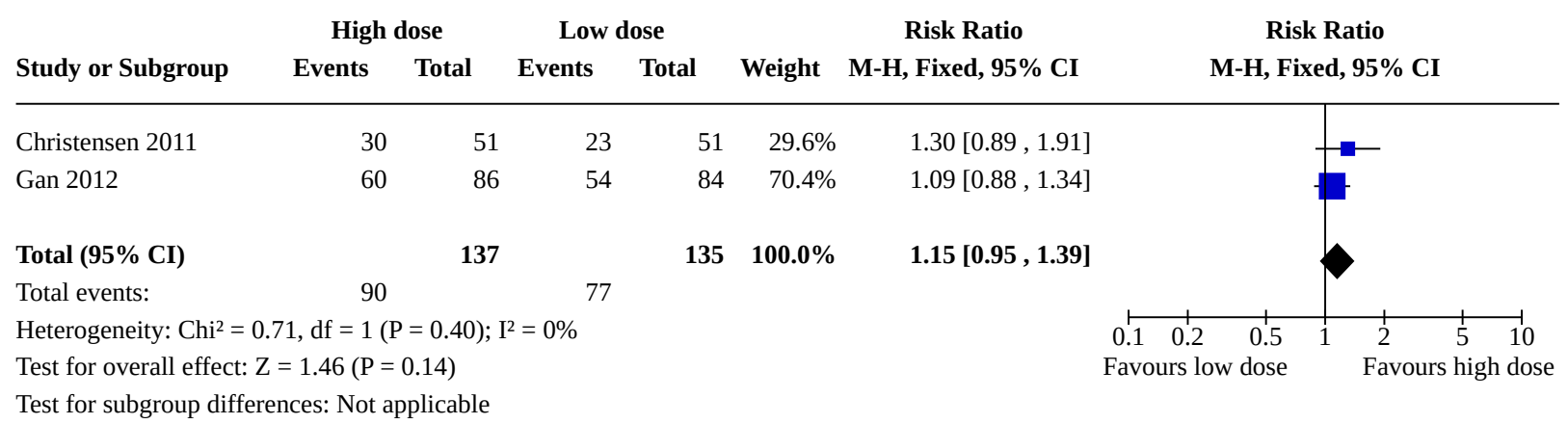

\section{AP PE N D I CES}

\section{Appendix 1. Glossary}

Categorical rating scale: the most common are the four-category scale for pain intensity (none, mild, moderate, and severe) and the fivecategory scale for pain relief (none, slight, moderate, good or lots, and complete). For analysis, numbers are given to the verbal categories (for pain intensity, none $=0$, mild $=1$, moderate $=2$, and severe $=3$; for relief, none $=0$, slight $=1$, moderate $=2$, good or lots $=3$, and complete =4). Data from different participants are then combined to produce means (rarely medians) and measures of dispersion (usually standard errors of means). The validity of converting categories into numerical scores is checked by comparison with concurrent visual analogue scale measurements. Good correlation is found, especially between pain relief scales using cross-modality matching techniques. Results are usually reported as continuous data, mean or median pain relief or intensity. Few studies present results as discrete data, giving the number of participants who report a certain level of pain intensity or relief at any given assessment point. The main advantages of the categorical scales are that they are quick and simple. The small number of descriptors may force the scorer to choose a particular category when none describes the pain satisfactorily. 
Visual analogue scale (VAS): for pain intensity, lines with left end labelled 'no pain' and right end labelled 'worst pain imaginable,' and for pain relief lines with left end labelled 'no relief of pain' and right end labelled 'complete relief of pain,' seem to overcome the limitation of forcing participant descriptors into particular categories. Participants mark the line at the point that corresponds to their pain or pain relief. The scores are obtained by measuring the distance between the 'no relief of pain' end and the participant's mark, usually in millimeters. The main advantages of VAS are that they are simple and quick to score, avoid imprecise descriptive terms, and provide many points from which to choose. More concentration and co-ordination are needed, which can be difficult postoperatively or with neurological disorders.

Total pain relief (TOTPAR): TOTPAR is calculated as the sum of pain relief scores over a period of time. If a participant had complete pain relief (as measured on a 5-point categorical scale) immediately after taking an analgesic, and maintained that level of pain relief for six hours, they would have a six-hour TOTPAR of the maximum of $24(6 \times 4)$. Differences between pain relief values at the start and end of a measurement period are dealt with by the trapezoidal rule. This is a simple method that approximately calculates the definite integral of the area under the pain relief curve by calculating the sum of the areas of several trapezoids that together closely approximate to the area under the curve.

Summed pain intensity difference (SPID): SPID is calculated as the sum of the differences between the pain scores and baseline pain score over a period of time. Differences between pain intensity values at the start and end of a measurement period are dealt with by the trapezoidal rule.

VAS TOTPAR and VAS SPID are visual analogue versions of TOTPAR and SPID.

See 'Measuring pain' in Bandolier's Little Book of Pain (Moore 2003).

\section{Appendix 2. MEDLINE search strategy}

1. (diclofenac or dichlofenal or diclonate or feloran or novapirina or orthofen or orthophen or voltaren or voltarol or ortofen or dyloject).tw.

2. Diclofenac/

3. 1 or 2

4. exp Pain, Postoperative/

5. pain.tw.

6.4 or 5

7. randomized controlled trial.pt.

8. controlled clinical trial.pt.

9. randomized.ab.

10. placebo.ab.

11. drug therapy.fs.

12. randomly.ab.

13. trial.ab.

14. groups.ab.

15.7 or 8 or 9 or 10 or 11 or 12 or 13 or 14

16. exp animals/ not humans.sh.

17. 15 not 16

18. 3 and 6 and 17

\section{Appendix 3. CENTRAL search strategy}

\#1 ((diclofenac or dichlofenal or diclonate or feloran or novapirina or orthofen or orthophen or voltaren or voltarol or ortofen or dyloject)):TI,AB,KY

\#2 MESH DESCRIPTOR Diclofenac 
\#3 \#1 OR \#2

\#4 MESH DESCRIPTOR Pain, Postoperative EXPLODE ALL TREES

\#5 pain:TI,AB,KY

\#6 \#4 OR \#5

\#7 \#3 AND \#6

\section{Appendix 4. Embase search strategy}

1 (diclofenac or dichlofenal or diclonate or feloran or novapirina or orthofen or orthophen or voltaren or voltarol or ortofen or dyloject).tw.

2 Diclofenac/

31 or 2

4 exp Pain, Postoperative/

5 pain.tw.

64 or 5

7 random $\$ . t w$.

8 factorial\$.tw.

9 crossover\$.tw.

10 cross over\$.tw.

11 cross-over\$.tw.

12 placebo\$.tw.

13 (doubl\$ adj blind\$).tw.

14 (singl\$ adj blind\$).tw.

15 assign\$.tw.

16 allocat\$.tw.

17 volunteer\$.tw.

18 Crossover Procedure/

19 double-blind procedure.tw.

20 Randomized Controlled Trial/

21 Single Blind Procedure/

22 or/ $7-21$

23 (animal/ or nonhuman/) not human/

2422 not 23

253 and 6 and 24

26 limit 25 to embase

\section{Appendix 5. GRADE: criteria for assigning grade of evidence}

The GRADE approach uses five considerations (study limitations, consistency of effect, imprecision, indirectness, and publication bias) to assess the quality of the body of evidence for each outcome. The GRADE system uses the following criteria for assigning grade of evidence. 
- High: we are very confident that the true effect lies close to that of the estimate of the effect.

- Moderate: we are moderately confident in the effect estimate; the true effect is likely to be close to the estimate of effect, but there is a possibility that it is substantially different.

- Low: our confidence in the effect estimate is limited; the true effect may be substantially different from the estimate of the effect.

- Very low: we have very little confidence in the effect estimate; the true effect is likely to be substantially different from the estimate of effect.

The GRADE system uses the following criteria for assigning a quality level to a body of evidence (Chapter 12, Higgins 2011).

- High: randomised trials; or double-upgraded observational studies.

- Moderate: downgraded randomized trials; or upgraded observational studies.

- Low: double-downgraded randomized trials; or observational studies.

- Very low: triple-downgraded randomized trials; or downgraded observational studies; or case series/case reports.

Factors that may decrease the quality level of a body of evidence are:

- limitations in the design and implementation of available studies suggesting high likelihood of bias;

- indirectness of evidence (indirect population, intervention, control, outcomes);

- unexplained heterogeneity or inconsistency of results (including problems with subgroup analyses);

- imprecision of results (wide confidence intervals);

- high probability of publication bias.

Factors that may increase the quality level of a body of evidence are:

- large magnitude of effect;

- all plausible confounding would reduce a demonstrated effect or suggest a spurious effect when results show no effect;

- dose-response gradient.

We decreased the grade rating by one (-1) or two (- 2) (up to a maximum of - 3 to 'very low') if we identified:

- serious (-1) or very serious (- 2) limitation to study quality;

- important inconsistency (-1);

- some (-1) or major (-2) uncertainty about directness;

- imprecise or sparse data (-1);

- high probability of reporting bias (-1).

WHAT'S NEW

\begin{tabular}{lll}
\hline Date & Event & Description \\
\hline 24 August 2020 & Review declared as stable & See Published notes. \\
\hline
\end{tabular}

\section{H I S T O R Y}

Protocol first published: Issue 1, 2017

Review first published: Issue 8, 2018

\begin{tabular}{lll}
\hline Date & Event & Description \\
\hline 11 January 2019 & Amended & Contact details updated. \\
\hline
\end{tabular}

\section{CONTRIBUTIONS OF AUTHORS}

The contributions of the three authors are as follows. 


\begin{tabular}{ll}
\hline Draft the protocol & EM, MF, RS \\
\hline Develop and run the search strategy & EM \\
& $\begin{array}{l}\text { Cochrane Pain, Palliative and Supportive Care In- } \\
\text { formation Specialist provided support. }\end{array}$ \\
\hline Obtain copies of studies & EM, MF \\
\hline Select which studies to include & EM, MF, RS \\
\hline Extract data from studies & EM, MF, RS \\
\hline Enter data into Review Manager 5 & EM \\
\hline Perform the analysis & EM, MF \\
\hline Interpret the analysis & EM, MF, RS \\
\hline Draft the final review & EM, MF, RS \\
\hline Update the review & EM, MF, RS \\
\hline
\end{tabular}

\section{DECLARATIONS OF INTEREST}

Ewan D McNicol (EM): none known. EM is a pharmacist with a Master's degree in Pain Research, Education and Policy, and manages patients with acute pain.

McKenzie Ferguson (MF): none known.

Roman Schumann (RS): none known. RS is an anesthesiologist whose practice includes acute perioperative pain management.

\section{SOURCES OF SUPPORT}

\section{Internal sources}

- Saltonstall Fund for Pain Research, USA

- Oxford Pain Relief Trust, UK

\section{External sources}

- No sources of support supplied

\section{DIFFERENCES BETWEEN PROTOCOL AND REVIEW}

We performed a post hoc analysis of rates of adverse events that are commonly attributed to opioids, to ascertain whether diclofenac reduced rates versus placebo and versus other active treatments.

\section{NOTES}

\section{Assessed for updating in 2020}

In July 2020 we did not identify any potentially relevant studies likely to change the conclusions. Therefore, this review has now been stabilised following discussion with the authors and editors. The review will be re-assessed for updating in two years. If appropriate, we will update the review before this date if new evidence likely to change the conclusions is published, or if standards change substantially which necessitate major revisions. 


\section{N D X T ERMS}

\section{Medical Subject Headings (MeSH)}

Acute Pain [ ${ }^{\star}$ drug therapy]; Analgesics, Opioid [adverse effects]; Anti-Inflammatory Agents, Non-Steroidal [ ${ }^{\star}$ administration \& dosage] [adverse effects]; Diclofenac [*administration \& dosage] [adverse effects]; Injections, Intravenous; Pain, Postoperative [ ${ }^{*}$ drug therapy]; Placebos [administration \& dosage]; Randomized Controlled Trials as Topic

\section{MeSH check words}

Adult; Humans 